
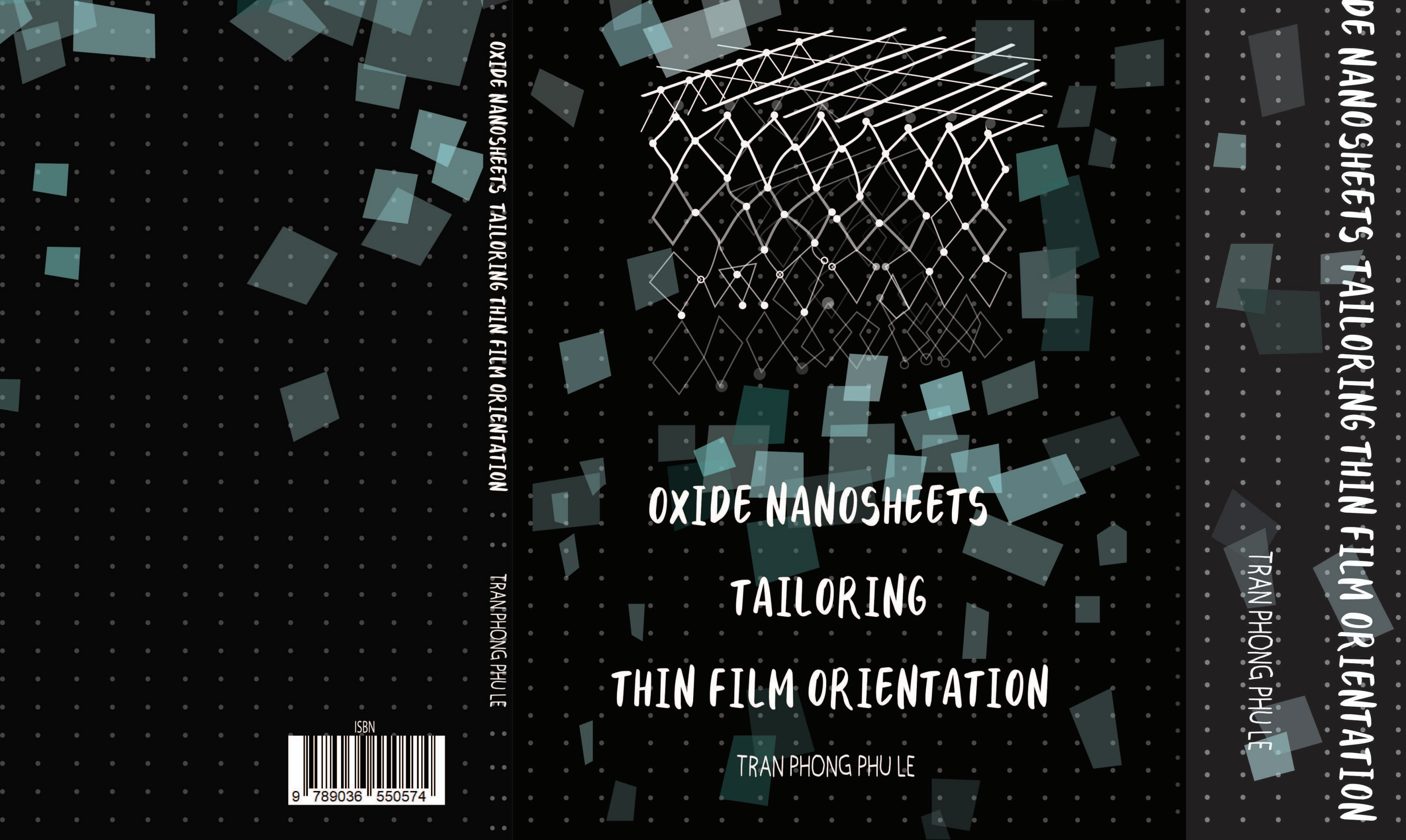


\section{Oxide nanosheets}

\section{tailoring thin film orientation}

Tran Phong Phu Le 


\section{Graduation Committee}

\section{Chairman and secretary}

Prof. dr. J.L. Herek

(University of Twente)

\section{Supervisors}

Prof. dr. ir. J.E. ten Elshof

(University of Twente)

Prof. dr. ir. G. Koster

(University of Twente)

\section{Committee Members}

Prof. dr. ir. J.W.M. Hilgenkamp

(University of Twente)

Prof. dr. J.G.E. Gardeniers

(University of Twente)

Prof. dr. ir. L. Lefferts

(University of Twente)

Prof. dr. B. Noheda

(University of Groningen)

Prof. dr. A. Hardy

(Hasselt University)

The research presented in this thesis was carried out at the Inorganic Materials Science group, Faculty of Science and Technology, MESA+ Institute of Nanotechnology, University of Twente, The Netherlands. The research was financially funded by The Netherlands Organization for Scientific Research (NWO)/CW ECHO grant ECHO.15.CM2.043.

\section{Cover}

The cover shows the artistic impression of oxide nanosheets laid on arbitrary substrate and their crystal structure. Artwork was performed by Huynh Ngoc Tan Tai.

Oxide nanosheets tailoring thin film orientation

$\mathrm{Ph} . \mathrm{D}$ thesis, University of Twente, Enschede, The Netherlands

Copyright $(\mathcal{C} 2020$ by Tran Phong Phu Le.

ISBN: 978-90-365-5057-4

DOI: $10.3990 / 1.9789036550574$

Printed by IPSKAMP, Enschede, The Netherlands 


\title{
OXIDE NANOSHEETS
}

\section{TAILORING THIN FILM ORIENTATION}

\author{
DISSERTATION
}

\author{
to obtain \\ the degree of doctor at the University of Twente, \\ on the authority of the rector magnificus, \\ Prof.dr. T.T.M. Palstra, \\ on account of the decision of the graduation committee, \\ to be publicly defended \\ on Friday, 9 October 2020, at 12:45
}

by

\section{Tran Phong Phu Le}

born on 19 February 1990

in Ho Chi Minh city, Vietnam 
This dissertation has been approved by:

\section{Supervisors}

Prof. dr. ir. J.E. ten Elshof

Prof. dr. ir. G. Koster 
Dedicated to my family, beloved wife and children 



\section{Table of Contents}

Chapter 1. Introduction ................................................................. 1

I. State of the art in 2 dimensional materials and their heterostructures with transition metal oxides ................................ 2

II. Scope and outline of thesis ........................................... 5

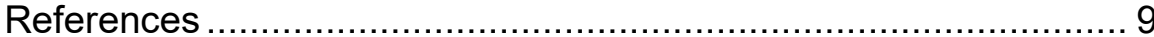

Chapter 2. Tailoring Vanadium Dioxide Film Orientation using Nanosheets: A Combined Microscopy, Diffraction, Transport and Soft X-ray in Transmission Study...................................... 13

I. Introduction .............................................................. 14

II. Results and discussion ................................................. 16

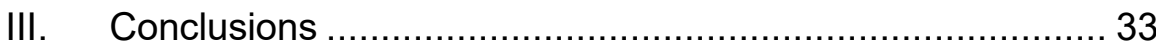

IV. Experimental section................................................... 33

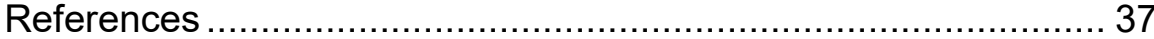

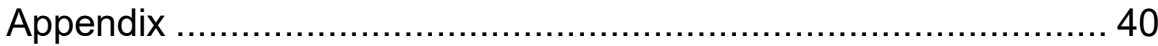

Chapter 3. Tuning the Metal Insulator Transition of Vanadium Dioxide on Oxide Nanosheets................................................... 41

I. Introduction ................................................................. 42

II. Results and discussion ................................................. 43

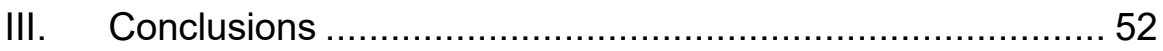

IV. Experimental section.................................................. 52

References .......................................................................... 54

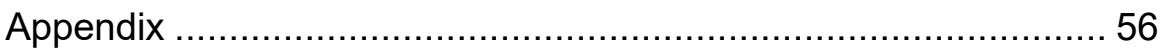

Chapter 4. Shape Control of $\mathrm{Ca}_{2} \mathrm{Nb}_{3} \mathrm{O}_{10}$ Nanosheets to Improve their In-plane Orientation..............................................................61 6

I. Introduction .................................................................... 62

II. Results and discussion ............................................... 63

III. Conclusions ................................................................... 73

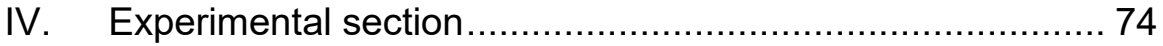


References 77

Appendix 79

Chapter 5. Epitaxial Lift-off of Freestanding (011) and (111) Oxide Perovskite Thin Films Using Water Sacrificial Layer ..... 81

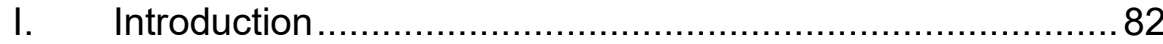

II. Results and discussion ................................................. 83

III. Conclusions..................................................................... 91

IV. Experimental section ...................................................... 91

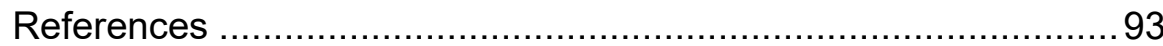

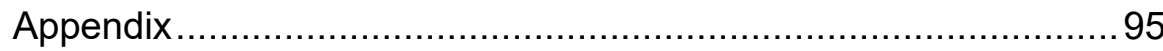

Chapter 6. Challenges and Opportunities ................................. 97

References .......................................................................... 100

Summary .................................................................................. 101

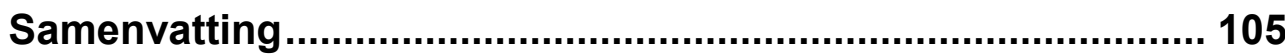

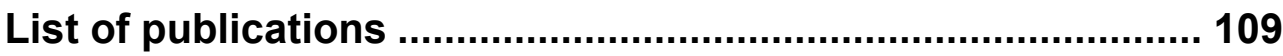

Acknowledgements................................................................ 111 


\section{List of abbreviations}

\begin{tabular}{|c|c|}
\hline ACOM & Automated crystal orientation mapping \\
\hline AFM & Atomic force microscopy \\
\hline $\mathrm{CNO}$ & $\mathrm{Ca}_{2} \mathrm{Nb}_{3} \mathrm{O}_{10}$ \\
\hline EBSD & Electron backscatter diffraction \\
\hline FIB & Focused ion beam \\
\hline FWHM & Full width at half maximum \\
\hline HCNO & $\mathrm{HCa}_{2} \mathrm{Nb}_{3} \mathrm{O}_{10}$ \\
\hline KCNO & $\mathrm{KCa}_{2} \mathrm{Nb}_{3} \mathrm{O}_{10}$ \\
\hline LAO & $\mathrm{LaAlO}_{3}$ \\
\hline LB & Langmuir-Blodgett \\
\hline MBE & Molecular beam epitaxy \\
\hline MIT & Metal-insulator transition \\
\hline NWO & $\mathrm{NbWO}_{6}$ \\
\hline PLD & Pulsed laser deposition \\
\hline PPMS & Physical Properties Measurement System \\
\hline RHEED & Reflection high energy electron diffraction \\
\hline RMS & Root mean square \\
\hline SAO & $\mathrm{Sr}_{3} \mathrm{Al}_{2} \mathrm{O}_{6}$ \\
\hline SEM & Scanning electron microscopy \\
\hline SRO & $\mathrm{SrRuO}_{3}$ \\
\hline STO & $\mathrm{SrTiO}_{3}$ \\
\hline TBAOH & tetra-n-butylammonium hydroxide \\
\hline TEM & Transmission electron microscope \\
\hline TEY & Total electron yield \\
\hline TMIT & Metal-insulator transition temperature \\
\hline TMO & Transition metal oxide \\
\hline TO & $\mathrm{Ti}_{0.87} \mathrm{O}_{2}$ \\
\hline ULE & Ultralow expansion \\
\hline XAS & X-ray absorption spectroscopy \\
\hline XPS & X-ray photoelectron spectroscopy \\
\hline XRD & X-ray diffraction \\
\hline YSZ & Yttria-stabilized zirconia \\
\hline
\end{tabular}





\section{Chapter 1. Introduction}

A brief overview of the research on two dimensional materials, or nanosheets, and their heterostructures with transition metal oxides, especially in case of oxide nanosheets, is introduced in this chapter. The scope and outline of the thesis are also presented at the end of the chapter. 


\section{State of the art in 2 dimensional materials and their heterostructures with transition metal oxides}

From the Stone Age to the Silicon Age, the development of our civilization has been driven by the fundamental advancement of Material Science. Up to now, material scientists still keep searching for new "gold" materials to push forward the frontiers of knowledge. In 2004, the first single layer of graphene was isolated, initiating intensive research in 2-dimensional (2D) materials. ${ }^{[1]}$ Although this single layer of carbon has amazed us with its exotic properties in the $2 \mathrm{D}$ structure, ${ }^{[2]}$ its superlattice at "magic angles" surprisingly exhibited superconducting and correlated insulator behavior. ${ }^{[3,4]}$ Besides graphene, inorganic 2D materials, or so-called "nanosheets", that comprise MXene phases, dichalcogenides and oxides, also exist. A common feature of nanosheets is their very high aspect ratio between the thickness of less than $5 \mathrm{~nm}$ and lateral sizes of hundreds $\mathrm{nm}$ to several $\mu \mathrm{m}$. From one perspective, one may consider nanosheets as paper sheets on nanometer scale. Nanosheets have excited researchers' interest because of a wide range of potential applications. For instance, 2D titanium carbide, a MXene nanosheet, has shown remarkable performance as supercapacitor electrode in energy storage applications. ${ }^{[5,6]}$ An enhanced superconducting transition temperature was observed in the restack of exfoliated $\mathrm{TaS}_{2}$ nanosheets. ${ }^{[7]}$ Moreover, oxide nanosheets have been potential candidates for nanoelectronics. Doped titanium oxide nanosheets have shown ferromagnetic behavior, and $\mathrm{Ca}_{3} \mathrm{Na}_{2} \mathrm{Nb}_{5} \mathrm{O}_{16}$ nanosheets have displayed ferroelectricity. ${ }^{[8,9]} \mathrm{Li}$ et al. reported that the combination of two different kinds of nanosheets into a so-called "superlattice" even exhibited multiferroic properties. ${ }^{[10]}$ Furthermore, it has been shown that the superconductivity of $\mathrm{Bi}_{2} \mathrm{Sr}_{2} \mathrm{CaCu}_{2} \mathrm{O}_{8+\delta}$ compound was preserved after it was isolated into a single layer nanosheet. ${ }^{[11]}$ 
Similarly, single crystalline thin films of transition metal oxides (TMOs) have shown a vast range of possible applications, because of their important physical properties, such as magnetism, multiferroicity, high-temperature superconductivity and metal-insulator transitions. ${ }^{[12,13]}$ These properties are the result of the interplay between intrinsic charge, spin, orbital orderings and extrinsic epitaxial strain, artificial boundaries in TMOs. A typically famous example is the high mobility $2 \mathrm{D}$ electron gas at the interface between 2 insulators $\mathrm{SrTiO}_{3}(\mathrm{STO})$ and $\mathrm{LaAlO}_{3}$ (LAO). ${ }^{[14]}$ It has been postulated that the integration of TMO thin films with Si can provide new features and resolve some major issues in current applications. ${ }^{[15,16]}$ However, the direct epitaxial growth of such TMOs on Si has been a critical challenge because of the fundamental crystal chemistry.

Such integration has been realized by introducing an appropriate buffer layer that serves as a template for growing subsequent layers. In the early 90s, the introduction of buffer layers yttria-stabilized zirconia (YSZ)(001)/(111) and $\mathrm{MgO}(001)$ on $\mathrm{Si}$ was achieved by pulsed laser deposition (PLD). ${ }^{[17,18]}$ Later, the achieved integration of a few unit cells of $\mathrm{STO}(001)$ on $\mathrm{Si}(001)$ by molecular beam epitaxy (MBE) has stimulated the development of functional

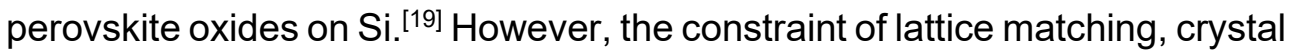
symmetry on $\mathrm{Si}$ and/or the existence of the native amorphous $\mathrm{SiO}_{2}$ have limited the number of buffer layers and functional TMOs that can be grown on Si.

Moreover, for non-Si based applications, e.g. energy storage ${ }^{[20]}$ and smart window $^{[21]}$,the commercialization of oxide-based devices has been partially hampered by high-cost and size-limited single crystal substrates. Low cost and large sized glass and plastic substrates have been commercially available, but they are amorphous substrates. It has been shown that the functional TMOs grown on such substrates are consequently polycrystalline 
with random orientations and high grain boundary density, leading to poor device performance.

Oxide nanosheets can act as buffer layers to loosen the constraints between Si/arbitrary substrate and functional TMOs. These oxide nanosheets are achieved by exfoliating ion-exchangeable layered compounds via a softchemical process. They still inherit their crystalline layered framework from the parent compounds. One may regard each individual nanosheet as an atomic-flat single crystal substrate with well-defined surface termination. In addition, oxide nanosheets span a wide range of lattice constants, including those of perovskites, and have various 2D lattice symmetries. ${ }^{[22]}$ They can be deposited on any substrate surfaces through solution-based processes. Specifically, the Langmuir-Blodgett (LB) technique is capable of assembling a monolayer of oxide nanosheets on a large-size substrate. Furthermore, it has been shown that the film orientation of TMOs can be exploited to control transport, magnetic, and ferroelectric properties. For instance, $\mathrm{La}_{0.7} \mathrm{Sr}_{0.33} \mathrm{MnO}_{3}$ film with a thickness of less than $12 \mathrm{~nm}$ was insulating along (001) and conducting along (110). ${ }^{[23]}$ The employment of oxide nanosheets enables a free choice of substrates and manipulation of film orientations, which can be utilized in both fundamental studies and practical applications.

The epitaxial growth of thin films on single crystal substrates is realized under strict conditions in term of structural similarity. Oxide nanosheets have been applied as buffer layers for TMO thin films. In 2006, Kikuta et al. deposited layered perovskite $\mathrm{Ca}_{2} \mathrm{Nb}_{3} \mathrm{O}_{10}$ nanosheets on glass to direct the growth of $\mathrm{LaNiO}_{3}$ and $\mathrm{Pb}(\mathrm{Zr}, \mathrm{Ti}) \mathrm{O}_{3}$ films into one preferred (001) orientation by chemical solution deposition. ${ }^{[24]}$ Later, other oxide thin films with preferred crystallographic directions were successfully grown on nanosheets, for example, anatase $\mathrm{TiO}_{2}$ on $\mathrm{Ca}_{2} \mathrm{Nb}_{3} \mathrm{O}_{10}$ and $\mathrm{ZnO}$ on $\mathrm{MnO}_{2}$. ${ }^{[25-33]}$ The ability of locally tuning $\mathrm{SrRuO}_{3}$ film orientations and their physical properties was demonstrated by using an alternate line pattern of $\mathrm{Ca}_{2} \mathrm{Nb}_{3} \mathrm{O}_{10}$ and $\mathrm{Ti}_{0.87} \mathrm{O}_{2}$ 
nanosheets. ${ }^{[34]}$ Single oriented $\mathrm{Nb}$-doped $\mathrm{TiO}_{2}(001)$ films were also realized on glass with $10 \%$ surface coverage of $\mathrm{Ca}_{2} \mathrm{Nb}_{3} \mathrm{O}_{10}$ nanosheets by the "socalled" lateral solid phase epitaxy, which enabled the crystal grain sizes of these films (3-10 $\mu \mathrm{m})$ to grow larger than the size of $\mathrm{Ca}_{2} \mathrm{Nb}_{3} \mathrm{O}_{10}$ seed nanosheets $(\leq 2 \mu \mathrm{m}) .{ }^{[35]}$ Next to oxide nanosheets, graphene and MXene nanosheets were recently used as promising buffer layers to grow highly oriented perovskites with a minority of undesired orientations. ${ }^{[36,37]}$

\section{Scope and outline of thesis}

The research described in this thesis was focused on the further exploration of the growth, properties and applications of TMO films on top of oxide nanosheets. Generally, the crystallinity and surface morphology of TMO films have depended on their wettability and atomic lattice matching with underlying substrates, which affects the grain size and overall defect density in TMO films and hence their physical properties. For example, the broadened metal insulator transition and large thermal hysteresis in $\mathrm{VO}_{2}$ films were caused by the overall defect density and small grain size. ${ }^{[38,39]}$ Regarding oxide nanosheets, the type of bonds between oxide nanosheets and underlying substrates and its influence on the whole stack of TMO film/oxide nanosheets have remained unknown. In order to crystallize TMO films, a heat treatment at high temperature is often necessary. The thermal expansion differences between the stack of TMO/oxide nanosheets and substrates can affect the physical properties of TMO films. For example, the thermal expansion coefficient of $\mathrm{Si}$ substrates, $2.6 \times 10^{-6} \mathrm{~K}^{-1},{ }^{[40]}$ is usually much smaller than that of TMOs, e.g. $3.23 \times 10^{-5} \mathrm{~K}^{-1}$ for $\mathrm{STO}^{[41]}$, which has caused thermal residual strain in TMO films when cooling down from high temperature. Moreover, film thickness and substrate-induced strain effects in TMOs play important roles in controlling and tuning the physical properties of TMOs. For example, the metal insulator transition temperature of the epitaxial $\mathrm{VO}_{2}$ film could be tuned by varying the film thickness and substrate- 
induced strain on single crystal substrates. ${ }^{[42-44]}$ As mentioned above in section I, each oxide nanosheet can be regarded as "micron-sized single crystal substrate". It is therefore worth to investigate whether the film thickness and strain effects exist in TMO films on oxide nanosheets.

Oxide nanosheets as templates for TMO film growth with one preferred outof-plane orientation have resulted in clear improvements of physical properties of $\mathrm{TMO}$ films. The (001) oriented $\mathrm{PbZr}_{0.52} \mathrm{Ti}_{0.48} \mathrm{O}_{3}$ film grown on $\mathrm{Ca}_{2} \mathrm{Nb}_{3} \mathrm{O}_{10}$ nanosheets on an glass substrate showed the best piezoelectric coefficient of $490 \mathrm{pm} / \mathrm{V}$ among piezoelectric films. ${ }^{[45]}$ Furthermore, the $(001)_{\mathrm{pc}}$ oriented ferromagnetic $\mathrm{SrRuO}_{3}$ film on $\mathrm{Ca}_{2} \mathrm{Nb}_{3} \mathrm{O}_{10}$ nanosheets had the outof-plane saturated moment of $1.1 \mu_{\mathrm{B}} / \mathrm{Ru}$ that was comparable with $1.25 \mu_{\mathrm{B}} / \mathrm{Ru}$ in the $\mathrm{SrRuO}_{3}(001)_{\mathrm{pc}}$ film on a single crystal STO(001). ${ }^{[34]}$ However, a common issue of TMO films on oxide nanosheets as buffer layers is that they are only singly oriented in the out-of-plane direction whereas they are nonoriented in the in-plane direction because of the randomness of oxide nanosheet deposition on substrates. Generally, the physical properties of polycrystalline TMO films are, in most cases, inferior to their epitaxial single crystalline ones. The random in-plane orientation of nanosheets leads to the misorientation of TMO crystal planes in the in-plane direction, scattering electrons (or holes) and degrading their physical properties. For example, the random in-plane orientation of $(001)_{p c}$ oriented $\mathrm{SrRuO}_{3}$ film on $\mathrm{Ca}_{2} \mathrm{Nb}_{3} \mathrm{O}_{10}$ nanosheets was one of the reasons that lead to its higher resistivity than the one on single crystal substrate $\mathrm{STO}(001){ }^{[34]}$ Moreover, large angle misorientation between grain boundaries in $\mathrm{VO}_{2}$ films would introduce large thermal hysteresis. ${ }^{[38]}$ In high mobility electron or hole systems such as LAO/STO, ${ }^{[14]}$ STO/LAO/STO ${ }^{[46]}$ and La doped $\mathrm{BaSnO}_{3},{ }^{[47]}$ the random inplane orientation can severely reduce the mobility of the charge carriers. The second aspect of this thesis discusses the strategies to improve the in-plane random orientation of oxide nanosheets and thus TMO films on arbitrary substrates. 
In order to conduct the research, I have employed synthesizing techniques ranging from chemical to physical routes as well as different characterizations. Powders of various parent compounds of oxide nanosheets were synthesized using conventional solid-state and molten salt routes. I have used LB technique to deposit oxide nanosheets on hydrophilic and hydrophobic substrates and PLD equipped with reflection high energy electron diffraction (RHEED) to grow oxide thin films in the research. In the other hand, I have investigated the structures and physical properties of oxide nanosheets and TMO thin films using atomic force microscopy (AFM), X-ray diffraction (XRD), X-ray photoelectron spectroscopy (XPS), scanning electron microscopy (SEM), electron backscatter diffraction (EBSD) and Physical Properties Measurement System (PPMS). Scanning transmission electron microscope (TEM) and X-ray absorption spectroscopy (XAS) techniques were performed by Dr. Nicolas Gauquelin (Electron Microscopy for Materials Science (EMAT), Prof. Jo Verbeeck) and by Georgios AraiziKanoutas (Quantum Materials Amsterdam group, Prof. Mark S. Golden), respectively.

Chapter 2 explores the hetero-epitaxial growth and controlled-orientation of vanadium dioxide $\left(\mathrm{VO}_{2}\right)$, a non-perovskite oxide, on two types of oxide nanosheets on arbitrary substrates. Epitaxy was realized via lattice or domain matching and 2D structures between the films and oxide nanosheets. The results showed the determining role of oxide nanosheets in $\mathrm{VO}_{2}$ film orientation and transport properties. The $\mathrm{VO}_{2}$ films on oxide nanosheets also demonstrated the possibility of X-ray or electron transparent characterizations in transmission geometry.

Chapter 3 continues on the same $\mathrm{VO}_{2}$ films on $\mathrm{NbWO}_{6}$ nanosheets on arbitrary substrates and further investigates the transport properties of this system. A tunable metal-insulator transition temperature of nanosheettemplated $\mathrm{VO}_{2}$ films was achieved by controlling the film thickness. On the 
other hand, the results showed a negligible influence of the underlying substrates on the transport properties of these films.

Chapter 4 discusses a strategy to resolve the randomness of in-plane orientation of epitaxial TMO films templated by oxide nanosheets. The equilibrium shape of $\mathrm{Ca}_{2} \mathrm{Nb}_{3} \mathrm{O}_{10}$ nanosheet parent layered compound was the key control in the self-assembly of nanosheets during LB deposition. The results showed a certain degree of the in-plane orientation control over nanosheets.

Chapter 5 describes a strategy to grow freestanding TMO films by PLD. Freestanding oxide perovskite films were released from single crystal substrates by dissolving the sacrificial layer between them. The results showed the full control over orientation in high quality TMO films, that could be transferred onto engineering substrates for further applications.

Chapter 6 presents challenges and opportunities for future work. 


\section{References}

[1] K. S. Novoselov, A. K. Geim, S. V. Morozov, D. Jiang, Y. Zhang, S. V. Dubonos, I. V. Grigorieva, A. A. Firsov, Science 2004, 306, 666.

[2] A. K. Geim, K. S. Novoselov, Nat. Mater. 2007, 6, 183.

[3] Y. Cao, V. Fatemi, S. Fang, K. Watanabe, T. Taniguchi, E. Kaxiras, P. Jarillo-Herrero, Nature 2018, 556, 43.

[4] Y. Cao, V. Fatemi, A. Demir, S. Fang, S. L. Tomarken, J. Y. Luo, J. D. Sanchez-Yamagishi, K. Watanabe, T. Taniguchi, E. Kaxiras, R. C. Ashoori, P. Jarillo-Herrero, Nature 2018, 556, 80.

[5] M. R. Lukatskaya, O. Mashtalir, C. E. Ren, Y. Dall'Agnese, P. Rozier, P. L. Taberna, M. Naguib, P. Simon, M. W. Barsoum, Y. Gogotsi, Science 2013, 341, 1502.

[6] M. Ghidiu, M. R. Lukatskaya, M.-Q. Zhao, Y. Gogotsi, M. W. Barsoum, Nature 2014, 516, 78.

[7] J. Pan, C. Guo, C. Song, X. Lai, H. Li, W. Zhao, H. Zhang, G. Mu, K. Bu, T. Lin, X. Xie, M. Chen, F. Huang, J. Am. Chem. Soc. 2017, 139, 4623.

[8] M. Osada, Y. Ebina, K. Fukuda, K. Ono, K. Takada, K. Yamaura, E. Takayama-Muromachi, T. Sasaki, Phys. Rev. B 2006, 73, 153301.

[9] B.-W. Li, M. Osada, Y.-H. Kim, Y. Ebina, K. Akatsuka, T. Sasaki, J. Am. Chem. Soc. 2017, 139, 10868.

[10] B.-W. Li, M. Osada, Y. Ebina, S. Ueda, T. Sasaki, J. Am. Chem. Soc. 2016, 138, 7621.

[11] Y. Yu, L. Ma, P. Cai, R. Zhong, C. Ye, J. Shen, G. D. Gu, X. H. Chen, Y. Zhang, Nature 2019, 575, 156.

[12] C. N. R. Rao, Annu. Rev. Phys. Chem. 1989, 40, 291.

[13] W. Eerenstein, N. D. Mathur, J. F. Scott, Nature 2006, 442, 759.

[14] A. Ohtomo, H. Y. Hwang, Nature 2004, 427, 423.

[15] H. Y. Hwang, Y. Iwasa, M. Kawasaki, B. Keimer, N. Nagaosa, Y. Tokura, Nat. Mater. 2012, 11, 103.

[16] S. Manipatruni, D. E. Nikonov, I. A. Young, Nat. Phys. 2018, 14, 338.

[17] D. K. Fork, D. B. Fenner, G. A. N. Connell, J. M. Phillips, T. H. Geballe, Appl. Phys. Lett. 1990, 57, 1137.

[18] D. K. Fork, F. A. Ponce, J. C. Tramontana, T. H. Geballe, Appl. Phys. Lett. 1991, 58, 2294.

[19] R. A. McKee, F. J. Walker, M. F. Chisholm, Phys. Rev. Lett. 1998, $81,3014$.

[20] Z. Yang, D. Choi, S. Kerisit, K. M. Rosso, D. Wang, J. Zhang, G. Graff, J. Liu, J. Power Sources 2009, 192, 588.

[21] Y. Wang, E. L. Runnerstrom, D. J. Milliron, Annu. Rev. Chem. Biomol. Eng. 2016, 7, 283.

[22] M. Osada, T. Sasaki, J. Mater. Chem. 2009, 19, 2503.

[23] A. Tebano, A. Orsini, D. Di Castro, P. G. Medaglia, G. Balestrino, Appl. Phys. Lett. 2010, 96, 092505. 
[24] K. Kikuta, K. Noda, S. Okumura, T. Yamaguchi, S. Hirano, J. Sol-Gel Sci. Technol. 2006, 42, 381.

[25] T. Shibata, K. Fukuda, Y. Ebina, T. Kogure, T. Sasaki, Adv. Mater. 2008, 20, 231.

[26] H. Tetsuka, H. Takashima, K. Ikegami, H. Nanjo, T. Ebina, F. Mizukami, Chem. Mater. 2009, 21, 21.

[27] T. Shibata, T. Ohnishi, I. Sakaguchi, M. Osada, K. Takada, T. Kogure, T. Sasaki, J. Phys. Chem. C 2009, 113, 19096.

[28] T. Shibata, Y. Ebina, T. Ohnishi, K. Takada, T. Kogure, T. Sasaki, Cryst. Growth Des. 2010, 10, 3787.

[29] B.-W. Li, M. Osada, K. Akatsuka, Y. Ebina, T. C. Ozawa, T. Sasaki, Jpn. J. Appl. Phys. 2011, 50, 09NA10.

[30] T. Shibata, H. Takano, Y. Ebina, D. S. Kim, T. C. Ozawa, K. Akatsuka, T. Ohnishi, K. Takada, T. Kogure, T. Sasaki, J. Mater. Chem. C 2013, 2, 441.

[31] M. Nijland, S. Kumar, R. Lubbers, D. H. A. Blank, G. Rijnders, G. Koster, J. E. ten Elshof, ACS Appl. Mater. Interfaces 2014, 6, 2777.

[32] A. P. Dral, M. Nijland, G. Koster, J. E. ten Elshof, APL Mater. 2015, 3, 056102.

[33] M. D. Nguyen, H. Yuan, E. P. Houwman, M. Dekkers, G. Koster, J. E. ten Elshof, G. Rijnders, ACS Appl. Mater. Interfaces 2016.

[34] M. Nijland, S. Thomas, M. A. Smithers, N. Banerjee, D. H. A. Blank, G. Rijnders, J. Xia, G. Koster, J. E. ten Elshof, Adv. Funct. Mater. 2015, 25, 5140.

[35] K. Taira, Y. Hirose, S. Nakao, N. Yamada, T. Kogure, T. Shibata, T. Sasaki, T. Hasegawa, ACS Nano 2014, 8, 6145.

[36] S. A. Lee, J.-Y. Hwang, E. S. Kim, S. W. Kim, W. S. Choi, ACS Appl. Mater. Interfaces 2017, 9, 3246.

[37] A. L. Bennett-Jackson, M. Falmbigl, K. Hantanasirisakul, Z. Gu, D. Imbrenda, A. V. Plokhikh, A. Will-Cole, C. Hatter, L. Wu, B. Anasori, Y. Gogotsi, J. E. Spanier, Nanoscale 2019, 11, 622.

[38] J. Narayan, V. M. Bhosle, J. Appl. Phys. 2006, 100, 103524.

[39] D. Brassard, S. Fourmaux, M. Jean-Jacques, J. C. Kieffer, M. A. El Khakani, Appl. Phys. Lett. 2005, 87, 051910.

[40] W. M. Yim, R. J. Paff, J. Appl. Phys. 1974, 45, 1456.

[41] D. de Ligny, P. Richet, Phys. Rev. B 1996, 53, 3013.

[42] N. B. Aetukuri, A. X. Gray, M. Drouard, M. Cossale, L. Gao, A. H. Reid, R. Kukreja, H. Ohldag, C. A. Jenkins, E. Arenholz, K. P. Roche, H. A. Dürr, M. G. Samant, S. S. P. Parkin, Nat. Phys. 2013, 9, 661 .

[43] L. L. Fan, S. Chen, Z. L. Luo, Q. H. Liu, Y. F. Wu, L. Song, D. X. Ji, P. Wang, W. S. Chu, C. Gao, C. W. Zou, Z. Y. Wu, Nano Lett. 2014, 14, 4036.

[44] Y. Yang, X. Mao, Y. Yao, H. Huang, Y. Lu, L. Luo, X. Zhang, G. Yin, T. Yang, X. Gao, J. Appl. Phys. 2018, 125, 082508. 
[45] M. D. Nguyen, E. P. Houwman, G. Rijnders, Sci. Rep. 2017, 7, 1.

[46] H. Lee, N. Campbell, J. Lee, T. J. Asel, T. R. Paudel, H. Zhou, J. W. Lee, B. Noesges, J. Seo, B. Park, L. J. Brillson, S. H. Oh, E. Y. Tsymbal, M. S. Rzchowski, C. B. Eom, Nat. Mater. 2018, 17, 231.

[47] H. J. Kim, U. Kim, H. M. Kim, T. H. Kim, H. S. Mun, B.-G. Jeon, K. T. Hong, W.-J. Lee, C. Ju, K. H. Kim, K. Char, Appl. Phys. Express 2012, 5, 061102. 



\section{Chapter 2. Tailoring Vanadium Dioxide Film Orientation using Nanosheets: A Combined Microscopy, Diffraction, Transport and Soft X-ray in Transmission Study}

$\mathrm{VO}_{2}$ is a much-discussed material for oxide electronics and neuromorphic computing applications. Here, heteroepitaxy of vanadium dioxide $\left(\mathrm{VO}_{2}\right)$ was realized on top of oxide nanosheets that cover either the amorphous silicon dioxide surfaces of $\mathrm{Si}$ substrates or X-ray transparent silicon nitride membranes. The out-of-plane orientation of the $\mathrm{VO}_{2}$ thin films was controlled at will between $(011)_{\mathrm{M}_{1}} /(110)_{\mathrm{R}}$ and $(-402)_{\mathrm{M}_{1} /(002)_{\mathrm{R}}}$ by coating the bulk substrates with $\mathrm{Ti}_{0.87} \mathrm{O}_{2}$ and $\mathrm{NbWO}_{6}$ nanosheets, respectively, prior to $\mathrm{VO}_{2}$ growth. Temperature-dependent $\mathrm{X}$-ray diffraction and automated crystal orientation mapping in microprobe transmission electron microscope mode (ACOM-TEM) characterized the high phase purity, the crystallographic and orientational properties of the $\mathrm{VO}_{2}$ films. Transport measurements and soft $\mathrm{X}$-ray absorption in transmission are used to probe the $\mathrm{VO}_{2}$ metal-insulator transition, showing results of a quality equal to those from epitaxial films on bulk single-crystal substrates. Successful local manipulation of two different $\mathrm{VO}_{2}$ orientations on a single substrate is demonstrated using $\mathrm{VO}_{2}$ grown on lithographically-patterned lines of $\mathrm{Ti}_{0.87} \mathrm{O}_{2}$ and $\mathrm{NbWO}_{6}$ nanosheets investigated by electron backscatter diffraction. Finally, the excellent suitability of these nanosheet-templated $\mathrm{VO}_{2}$ films for advanced lens-less imaging of the metal-insulator transition using coherent soft $\mathrm{X}$-rays is discussed.

*This chapter is based on the published article: "Tailoring Vanadium Dioxide Film Orientation Using Nanosheets: A Combined Microscopy, Diffraction, Transport, and Soft X-Ray in Transmission Study." Adv. Funct. Mater. 2020, 30 (1), 1900028. Author contribution was described in List of publications. 


\section{Introduction}

Vanadium dioxide $\left(\mathrm{VO}_{2}\right)$ has been drawing attention since the discovery of its metal-insulator transition (MIT), signaled by a several orders of magnitude resistivity change close to $340 \mathrm{~K}^{[1,2]}$. Given these remarkable properties, it may not be a surprise that $\mathrm{VO}_{2}$ is a leading candidate material for the development of oxide devices for both low power electronics (high offresistance), either in a more conventional field effect type of device or alternatively, neuromorphic electronic architectures ${ }^{[3,4]}$ as a memristive material. It has been known that the MIT occurs alongside an abrupt, firstorder structural phase transformation from a metallic, tetragonal rutile $(R)$ phase $\left(P 4_{2} / \mathrm{mnm}\right)$, to an insulating, monoclinic (M1) phase $\left(P 2_{1} / C\right)$. Recent work $^{[5]}$ points out that this transition is preceded by a purely electronic softening of Coulomb correlations within the $V-V$ singlet dimers that characterize the insulating state, setting the energy scale for driving the nearroom-temperature insulator-metal transition in this paradigm complex, correlated oxide.

Up to now, most studies of epitaxial $\mathrm{VO}_{2}$ thin films have used $\mathrm{Al}_{2} \mathrm{O}_{3}$ and $\mathrm{TiO}_{2}$ single crystal substrates to control film orientation ${ }^{[6,7]}$, bringing along challenges of cost, limited size and incompatibility with the current Si-based technology for future $\mathrm{VO}_{2}$-based devices. Direct deposition of $\mathrm{VO}_{2}$ on glass or Si substrates with a native amorphous silicon dioxide layer leads to a polycrystalline film with predominant $(011)_{\mathrm{M} 1}$ orientation ${ }^{[8]}$, whereas $\mathrm{VO}_{2}$ is favorably grown (010) $)_{M 1}$-oriented when a buffer layer of $\mathrm{Pt}(111)$ is used on a $\mathrm{Si}$ substrate ${ }^{[9]}$. Epitaxial growth of $\mathrm{VO}_{2}$ with $(010)_{\mathrm{M} 1}$ orientation is possible on epitaxial layers of yttria-stabilized zirconia - YSZ(001) - on Si(001) ${ }^{[10,11]}$.

Ideally, one would wish for direct control over $\mathrm{VO}_{2}$ film orientation on $\mathrm{Si}$ or even on arbitrary substrates at will, without any concessions being made on the $\mathrm{VO}_{2}$ film quality. Oriented growth is not only an important enabler for the fundamental study of the mechanism of the $\mathrm{VO}_{2} \mathrm{MIT}^{[12]}$, but also for potential 
Tailoring Vanadium Dioxide Film Orientation using Nanosheets: A Combined Microscopy, Diffraction, Transport and Soft X-ray in Transmission Study

applications for next-generation transistors ${ }^{[13]}$, memory metamaterials ${ }^{[14]}$, sensors $^{[15]}$, and novel hydrogen storage technology ${ }^{[16]}$. Recently, various metal oxide films have been successfully grown on glass and Si substrates using epitaxy on so-called oxide nanosheets ${ }^{[17-20]}$. Oxide nanosheets are essentially two dimensional (2D) single crystals with a thickness of a few nanometers or less, and lateral size in the micrometer range. They can be made spanning a wide range of crystal lattices and 2D structural symmetries [21], allowing for new possibilities to tailor the important structural parameters and properties of thin films on arbitrary - and thus also technologicallyrelevant - bulk substrates. Successful implementation of nanosheets in fact means that the choice of the bulk substrate becomes a free parameter that can enter the engineering cycle of each individual application.

In the research presented here, $\mathrm{Ti}_{0.87} \mathrm{O}_{2}$ (TO) and $\mathrm{NbWO}_{6}$ (NWO) nanosheets have been identified as being ideal templates for the orientation of thin films of the important complex oxide $\mathrm{VO}_{2}$ on varying substrates. Monolayers of nanosheets were deposited on Si substrates and alternatively on $20 \mathrm{~nm}$ thick $\mathrm{Si}_{3} \mathrm{~N}_{4}$ transmission electron microscope (TEM) grids using the LangmuirBlodgett (LB) method. Then, utilizing pulsed laser deposition (PLD), singlephase $\mathrm{VO}_{2}$ thin films were grown epitaxially on both $\mathrm{TO}$ and NWO nanosheets with $(011)_{\mathrm{M} 1}\left[(110)_{\mathrm{R}}\right]$ and $(-402)_{\mathrm{M} 1}\left[(002)_{\mathrm{R}}\right]$ out-of-plane orientation of the low temperature monoclinic $\mathrm{M} 1$ phase [high-T rutile phase], respectively. The high structural and orientational quality of the $\mathrm{VO}_{2}$ made possible by the nanosheet epitaxy was proven using TEM and X-ray diffraction across the Mott MIT, as well as by electron backscatter diffraction (EBSD) studies. In addition, both transport and soft X-ray spectroscopic probes of the MIT showed data of excellent quality, matching those for $\mathrm{VO}_{2}$ grown on bulk single-crystalline substrates. Importantly, the use of a nanosheet-coated $\mathrm{Si}_{3} \mathrm{~N}_{4}$ membrane as a PLD substrate allowed soft X-ray absorption spectroscopy (XAS) to be carried out in the fully bulk-sensitive and highly direct transmission mode. Finally, the nanosheet-approach is 
shown to provide a high degree of control of the crystallographic orientation of the $\mathrm{VO}_{2}$ film. This is illustrated by the use of a single film-growth run to generate two different orientations on a single substrate deterministically, by arranging both TO and NWO nanosheets in an alternating, stripe-like pattern using lithography.

\section{Results and discussion}

Figure 1 shows a plan view of the TO and NWO nanosheet planes in panels (a) and (d), respectively. For the TO[NWO] nanosheets, the relevant 2D unit cell is highlighted in green[pink]. In panels (b) and (c), the relevant $\mathrm{VO}_{2}$ planes are shown for the $M 1$ and $R$ structures with the $2 \mathrm{D}$ unit cell of the TO nanosheets superimposed. Likewise, in panels (e) and (f) the 2D unit cell of the NWO nanosheets is superimposed on the relevant planes in the M1 and $\mathrm{R} \mathrm{VO}_{2}$ phases. What these figures show, backed up by the data of Table 1, is that the $(011)_{\mathrm{M} 1}\left[(110)_{\mathrm{R}}\right]$ and $(-402)_{\mathrm{M} 1}\left[(002)_{\mathrm{R}}\right]$ out-of-plane orientations of $\mathrm{M} 1[\mathrm{R}] \mathrm{VO}_{2}$ are compatible with the $\mathrm{TO}$ and NWO nanosheet symmetry and lattice constants, respectively.

In the following, the reasoning and data that led to this conclusion are gone through in a step-by-step manner. A closer examination of Figure 1 shows that - considering the oxygen sub-lattices as the dominating structural entities driving potential epitaxy between the $\mathrm{VO}_{2}$ and the nanosheets - the two distinct O-O distances of $2.90 \AA$ and $2.84 \AA$ for the $\mathrm{VO}_{2}(011)_{\mathrm{M} 1}$ plane are close to the O-O distance of $2.97 \AA$ for the TO nanosheet in the $b$ direction. In the a direction, there are also two distinct O-O distances for the $\mathrm{VO}_{2}$ $(011)_{\mathrm{M} 1}$ plane, i.e. $3.38 \AA$ and $4.51 \AA$, respectively, which are very different from the $\mathrm{O}-\mathrm{O}$ distance of $3.82 \AA$ for TO nanosheets. Highly relevant in this regard is the concept of domain matching epitaxy ${ }^{[22]}$, which can be seen as a generalization of the more common lattice match epitaxy. In domain matching epitaxy, integral multiples of lattice planes match across the filmsubstrate interface, with the size of the domain (equaling integral multiples 
Tailoring Vanadium Dioxide Film Orientation using Nanosheets: A Combined Microscopy, Diffraction, Transport and Soft X-ray in Transmission Study

of planar spacing), determined by the degree of mismatch. This can yield epitaxy when mismatches exceed the usual $7-8 \%$ limit for regular lattice epitaxy $^{[22]}$.

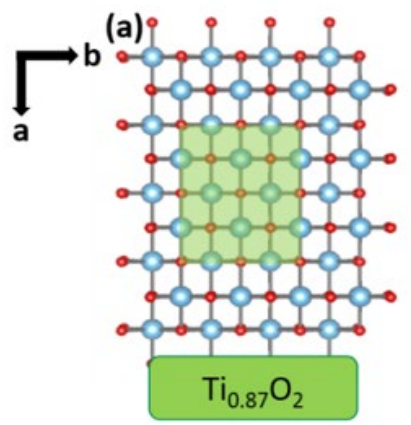

(d)

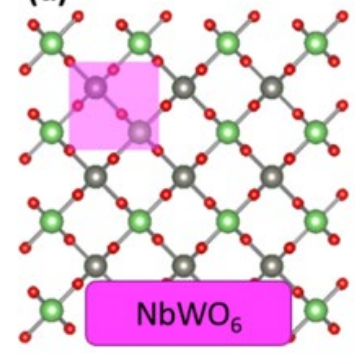

$\circ 0$

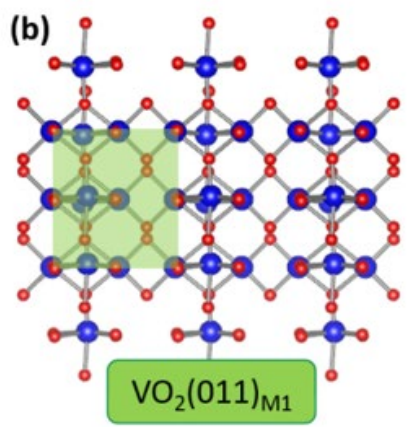

(e)

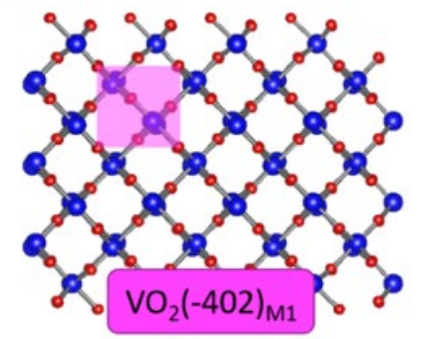

○ $\mathrm{v}$

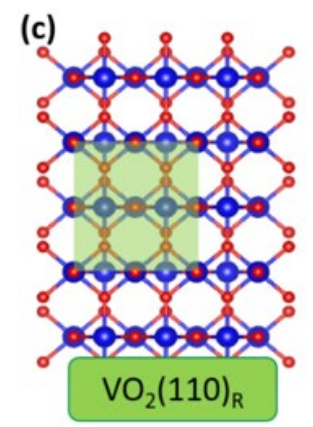

(f)

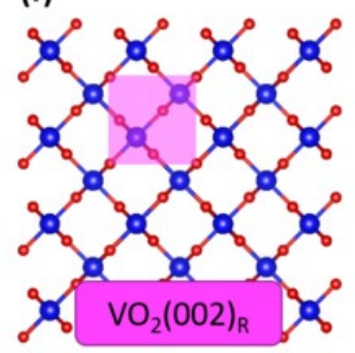

$\mathrm{Nb}$

○ $\mathrm{w}$

Figure 1. Excellent epitaxy conditions for nanosheets and $\mathrm{VO}_{2}$. Schematic illustration of atomic structures for (a) TO nanosheet, (b) $\mathrm{VO}_{2}(011)_{\mathrm{M} 1}$, (c) $\mathrm{VO}_{2}(110)_{\mathrm{R}}$. A suitable TO unit cell is shown shaded in green. (d) NWO nanosheet, (e) $\mathrm{VO}_{2}$ (402) $)_{\mathrm{M} 1}$ and (f) $\mathrm{VO}_{2}(002)_{\mathrm{R}}$. A suitable NWO unit cell is shown shaded in pink.

If one considers the domain epitaxy approach, it can be seen that the slightly distorted (only $0.35^{\circ}$ away from a right-angle) rectangular oxygen domain of $7.56 \times 5.74 \AA^{2}$ for the $\mathrm{VO}_{2}(011)_{\mathrm{M} 1}$ plane is close to that of $7.64 \times 5.94 \AA^{2}$ for the TO nanosheets. This results in a small domain mismatch of only $1 \%$ and $3.4 \%$ in the $a$ - and $b$-directions at room temperature, respectively, suggesting that the M1 monoclinic phase of $\mathrm{VO}_{2}(011)_{\mathrm{M} 1}$ film can be stabilized by TO nanosheets at room temperature. At the growth temperature of $520^{\circ} \mathrm{C}$, it is the rutile phase of $\mathrm{VO}_{2}$ that is being formed ${ }^{[2]}$, and analogous considerations 
show that as the $(110)_{R}$ plane is very closely related to the room temperature $(011)_{\mathrm{M} 1}$ plane of $\mathrm{VO}_{2}$ a similar domain epitaxial relationship will be at work.

Table 1. Symmetry and lattice constants of TO and NWO nanosheets.

\begin{tabular}{ccc}
\hline Nanosheet & 2D structure & Lattice constant $(\AA)$ \\
\hline $\mathrm{Ti}_{0.87 \mathrm{O}_{2}}{ }^{0.52-}$ & Rectangular & $a=3.76 ; b=2.97$ \\
$\mathrm{NbWO}_{6}-$ & Square & $a=4.68$ \\
\hline
\end{tabular}

In addition to the domain epitaxy ideas, it is also worth to point out that as the nanosheets are exfoliated layered materials without chemically active dangling bonds, there are only isotropic Coulomb and/or Van der Waals interactions between the growing film and the nanosheet surface. Consequently, lateral adatom-adatom interactions are significant drivers of the energetics of the early stages of (epitaxial) growth, thus helping to favor epitaxial growth also in the presence of relatively large lattice mismatch. In this manner, retention of epitaxy with lattice mismatch as high as $13 \%$ have been reported ${ }^{[19,23]}$, supporting the ability of TO nanosheets to successfully template the $(110)_{\mathrm{R}}$ growth of the rutile phase of $\mathrm{VO}_{2}$.

Regarding to the NWO nanosheet case, epitaxial growth of $(-402)_{\mathrm{M} 1}$ or $(002)_{\mathrm{R}}$ $\mathrm{VO}_{2}$ films are expected via straightforward lattice matching considerations. The $2 \mathrm{D}$ atomic structure of the $(-402)_{\mathrm{M} 1}$ plane is distorted away from a square planar symmetry (by $3^{\circ}$ off the right-angle). The lattice mismatch between this plane and the nanosheets is $3.6 \%$ and $7.9 \%$ in the $a$ - and $b$-directions, respectively, which - especially given the arguments above as regards the non-directional nature of the adatom-nanosheet interactions - one would expect to support epitaxial growth with the $\mathrm{VO}_{2}$ film oriented in the [-402] $]_{\mathrm{M} 1}$ direction at room temperature. For the NWO case, the high-T situation is simpler still, as the lattice mismatch between the high temperature $(002)_{R}$ plane and the NWO nanosheet is only $3.2 \%$, with the same 2D square atomic structure present in both cases. 
Tailoring Vanadium Dioxide Film Orientation using Nanosheets: A Combined Microscopy, Diffraction, Transport and Soft X-ray in Transmission Study

To summarize this section: detailed consideration of the oxygen sub-latticedriven epitaxial relationships shows that for TO nanosheets, a combination of domain matching epitaxy and the weak adatom-nanosheet interactions should enable epitaxial growth of $\mathrm{VO}_{2}$, with the out-of-plane orientation being $(011)_{\mathrm{M} 1}$ and $(110)_{\mathrm{R}}$ at room temperature and elevated temperature, respectively. For the NWO nanosheets, the $\mathrm{VO}_{2}$ orientation is expected to be $(-402)_{\mathrm{M} 1}$ and $(002)_{\mathrm{R}}$.

Turning to the first step of the nanosheet-templated film growth process in practice, Figure 2 shows AFM images of the morphology of the barenanosheets of TO and NWO in panels (a) and (b). It is clear that monolayers of TO and NWO nanosheets can be fabricated on Si substrates successfully with a surface coverage exceeding $95 \%$. The lateral size of the individual nanosheets is $3-5 \mu \mathrm{m}$ for both TO and NWO, which is partly governed by the grain size of the parent layered crystals obtained by solid state reaction ${ }^{[24]}$. The exfoliated nanosheets were deposited using a LB-method to form a monolayer film on $\mathrm{Si}$ substrates and on $\mathrm{Si}_{3} \mathrm{~N}_{4}$ membranes.
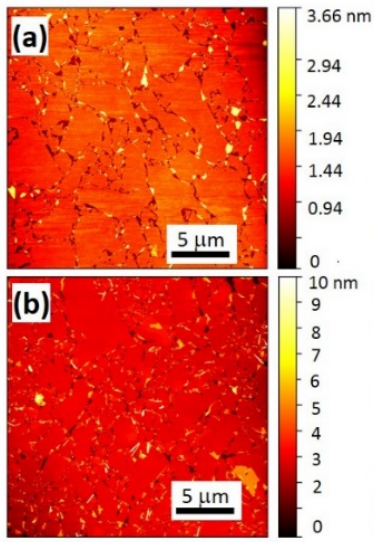
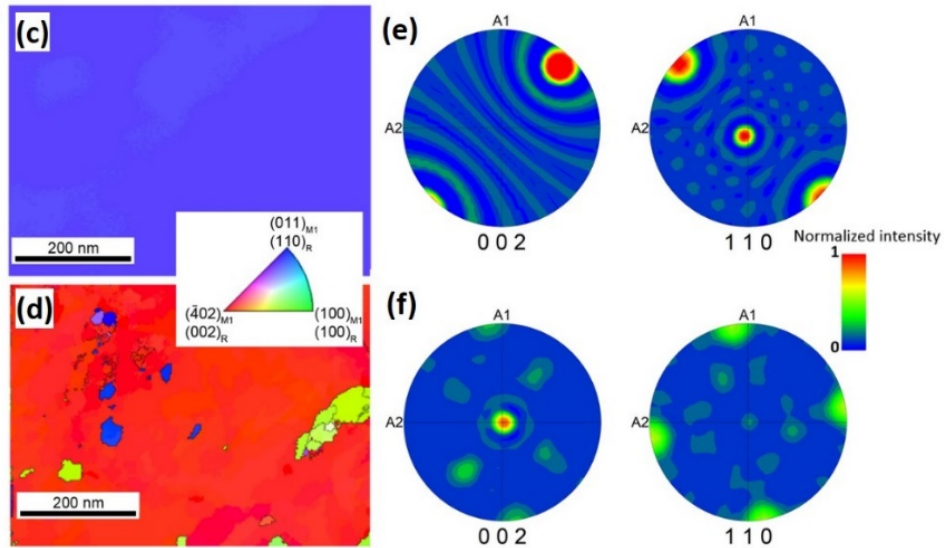

Figure 2. AFM of nanosheets and automated crystal orientation mapping of $\mathrm{VO}_{2}$ using TEM. The top [bottom] row of figures is from samples with TO[NWO]templates. AFM images of the (a) TO and (b) NWO nanosheets showing the homogeneous coverage (scale bar: $5 \mu \mathrm{m}$ ). Panels (c) and (d) show high temperature automated crystal orientation mapping TEM mode (ACOM-TEM) characterization of 
the rutile $\mathrm{VO}_{2}$ phase at $423 \mathrm{~K}$ (scale bar: $200 \mathrm{~nm}$ ). (e) and (f) correspond to pole figures for the $(110)_{R}$ and $(002)_{R}$ directions, respectively, with a color-scaled intensity as shown in the index on the right side. Including is the triangular color scale wedge for the ACOM-TEM data, which also shows the orientational relationship between the $M_{1}$ and $R$ phases. (Panels (c)-(f) are collected and analyzed by collaborators, Electron Microscopy for Materials Science (EMAT) group, University of Antwerp, Belgium)

Using these nanosheet layers on $\mathrm{Si}_{3} \mathrm{~N}_{4}$ TEM grids as substrates, thin films of $\mathrm{VO}_{2}$ were grown using PLD. In order to determine the homogeneity and epitaxial quality of the $\mathrm{VO}_{2}$ films with $\mathrm{nm}$ lateral spatial precision, orientation maps were recorded using TEM, the results of which are shown in Figure 2(c)-(f). The data were measured in the rutile $\mathrm{VO}_{2}$ phase at a temperature of 423K. For the TO-templated system, a remarkably homogeneous $(110)_{R}$ orientation of the $\mathrm{VO}_{2}$ film results (Figure 2(c)), and apart from a very few rogue patches, Figure 2(d) shows that the NWO nanosheets perform just as well, generating $(002)_{R} V_{2}$. These results are confirmed in the pole figures for these two rutile orientations shown in panels $(e)$ and (f). With this nanoscopic confirmation of the excellent epitaxial growth on each individual nanosheet, the next step is a more global measure of the $\mathrm{VO}_{2}$ structure, in both the rutile and monoclinic phases using $X$-ray diffraction (XRD).

Figure 3 presents the XRD data measured below and above $\mathrm{T}_{\mathrm{MIT}}$ of $\mathrm{VO}_{2}$ films grown using PLD at $520^{\circ} \mathrm{C}$ on monolayers of TO (panel (a)) and NWO nanosheets (panel(b)) on Si substrates. At $303 \mathrm{~K}$, the peaks seen at $2 \theta$ values of $27.90^{\circ}$ and $57.72^{\circ}$ in Figure $3(\mathrm{a})$ are from the $(011)_{\mathrm{M} 1}$ and $(022)_{\mathrm{M} 1}$ $\mathrm{VO}_{2}$ reflections, respectively. In Figure $3(\mathrm{~b})$, the peak at $65.07^{\circ}$ corresponds to the $(-402)_{\mathrm{M} 1} \mathrm{VO}_{2}$ reflection. At $403 \mathrm{~K}$ - above the MIT temperature - peaks measured at $27.70^{\circ}, 57.27^{\circ}$ and $65.28^{\circ}$ now correspond to the $(110)_{R},(220)_{R}$ and $(002)_{R}$ Bragg peaks of rutile $\mathrm{VO}_{2}$, respectively. These XRD data confirm the excellent orientational integrity of the $\mathrm{VO}_{2}$ films at the macroscopic scale, confirming what was seen in the TEM data. This points towards the major 
Tailoring Vanadium Dioxide Film Orientation using Nanosheets: A Combined Microscopy, Diffraction, Transport and Soft X-ray in Transmission Study

role of the oxygen framework in the determination of the epitaxial relationships between both nanosheet systems and the $\mathrm{VO}_{2}$ overlayer, as discussed earlier.
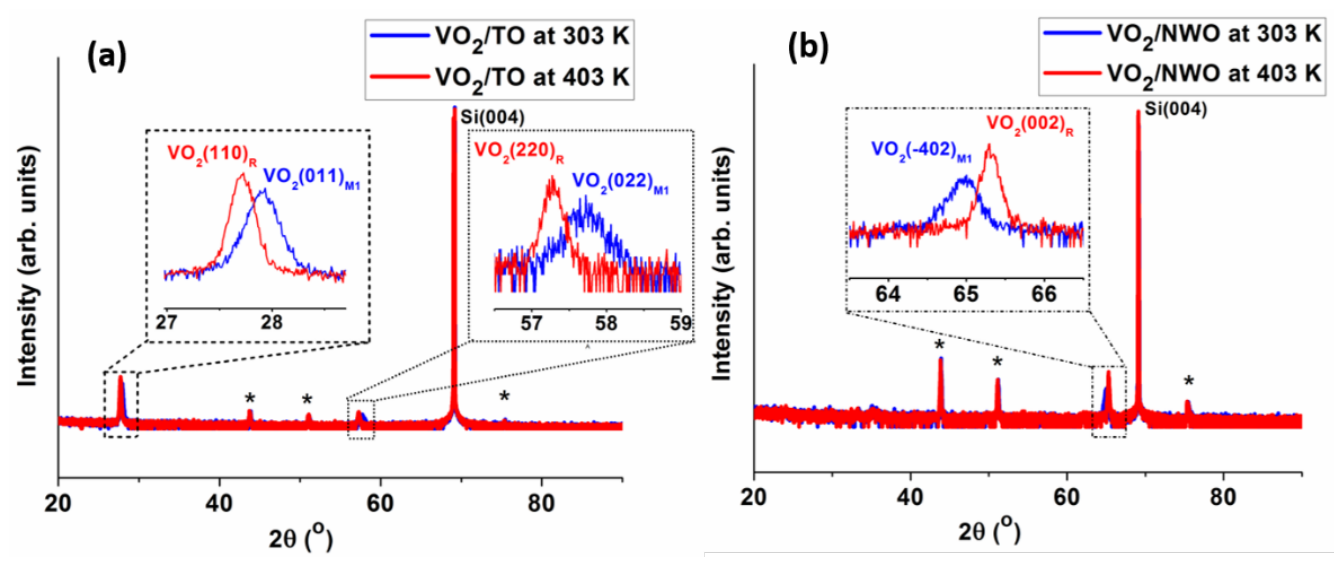

Figure 3. Temperature-dependent identification of the $\mathrm{VO}_{2}$ structural phases using X-ray diffraction. XRD patterns of $\mathrm{VO}_{2}$ films on (a) TO and (b) NWO nanosheets, measured at $303 \mathrm{~K}$ (M1 phase) and $403 \mathrm{~K}$ (R phase). The three peaks labelled '*' originate from the Inconel alloy 625/718 clamps holding the sample on the diffractometer heating stage. The $\mathrm{VO}_{2}$ Bragg peaks can be indexed using the film orientation discussed in the text, fully in agreement with the TEM data of Figure 2 and literature values of the temperature-dependence of the $\mathrm{VO}_{2}$ crystal structure.

One of the motivations for choosing $\mathrm{VO}_{2}$ for this study was its dual role as a model system for both understanding strongly correlated MIT, as well as its tunable/switchable large resistance change near room temperature ${ }^{[3]}$. Consequently, the transport behavior of $\mathrm{VO}_{2}$ grown using PLD on nanosheet templates is of great interest, and these data are shown in Figure 4. Defining the midpoint of the transition in the resistance curve measured upon heating as the phase transition temperature, $T_{\mathrm{MIT}}$, our data show transition temperatures close to the canonical value of $341 \mathrm{~K}$ for bulk $\mathrm{VO}_{2}$ single crystals $^{[1,2]}$. The $T_{\text {MIT }}$ of the films with out-of-plane $(110)_{R}$ texture (rutile c-axis in-plane) grown on TO nanosheets was $347 \mathrm{~K}$, whereas for the out-of-plane $(002)_{\mathrm{R}}$ textured film on NWO nanosheets $T_{\mathrm{MIT}}$ was $332 \mathrm{~K}$. These values are 
in agreement with what has been found in the literature on the orientation dependence of $T_{\text {MIT }}$ on different bulk $\mathrm{TiO}_{2}$ substrates ${ }^{[25]}$.

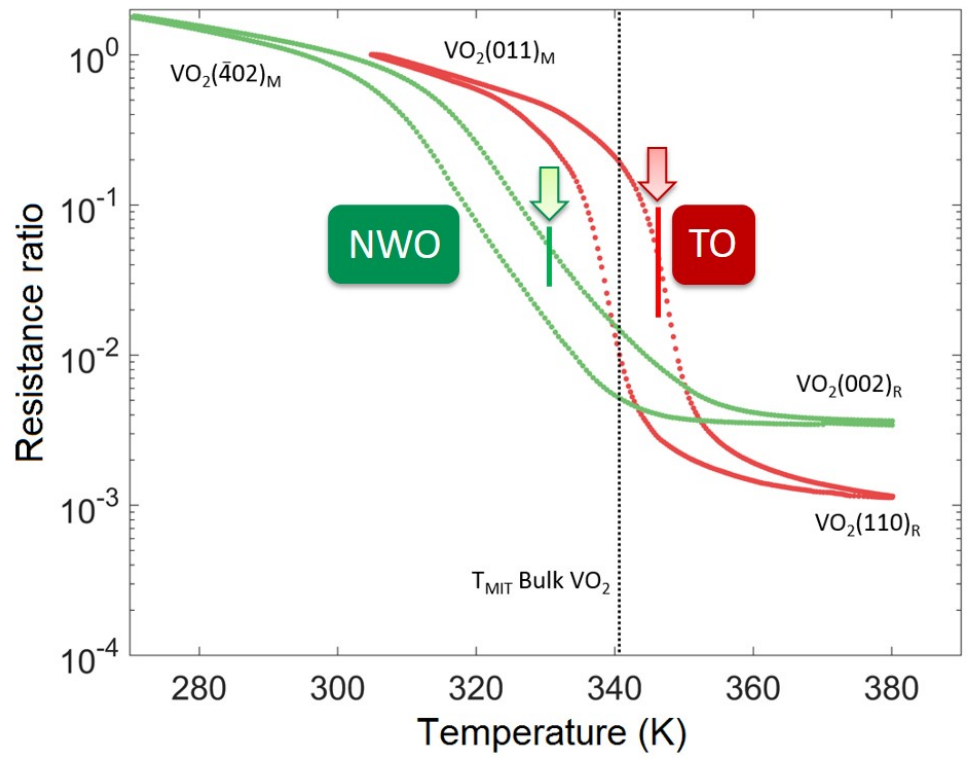

Figure 4. Transport characterization of the Mott metal-insulator transition of $\mathrm{VO}_{2}$. Resistance ratio (R[R phase]/R[M1 phase]) of $\mathrm{VO}_{2}$ films grown on $\mathrm{TO}$ and $\mathrm{NWO}$ nanosheets as a function of temperature. For the $\mathrm{M} 1$ phase, the resistance was 2.6 $\times 10^{5} \Omega\left[5.6 \times 10^{4} \Omega\right]$ for TO [NWO] nanosheet-templated $\mathrm{VO}_{2}$, respectively. The resistance in the $\mathrm{VO}_{2}-\mathrm{R}$ phase was a factor 810 [280] times lower than in the $\mathrm{M}_{1-}$ phase for $\mathrm{TO}$ [NWO] nanosheet-templated $\mathrm{VO}_{2}$ growth, respectively.

The $T_{\mathrm{MIT}}$ in $\mathrm{VO}_{2}$ is related to the $\mathrm{V}-\mathrm{V}$ distance along the rutile $c$-axis, which affects the orbital overlap and the metallicity in the rutile phase ${ }^{[26]}$. In the past, this had been studied as a function of film orientation ${ }^{[25]}$, chemical doping ${ }^{[26]}$, thickness ${ }^{[27]}$ and strain $(001)_{R}{ }^{[28]}$ for films grown on single crystal substrates. For example, under compressive strain, the $T_{\mathrm{MIT}}$ of a $24 \mathrm{~nm}$ thick $(001)_{\mathrm{R}} \mathrm{VO}_{2}$ film grown on $\mathrm{TiO}_{2}$ decreased to $330 \mathrm{~K}$, while it was the same as the bulk $\mathrm{VO}_{2}$ value of $341 \mathrm{~K}$ for a fully-relaxed $74 \mathrm{~nm}$ thick film ${ }^{[27]}$. When the rutile caxis is under tensile strain, similar to using $\mathrm{TiO}_{2}$ (110) single crystal substrates, $T_{\mathrm{MIT}}$ is seen to increase to $350-369 \mathrm{~K}^{[25]}$. Therefore, as $T_{\mathrm{MIT}}$ for $\mathrm{VO}_{2}$ grown on TO nanosheets is higher than that of strain-free, bulk $\mathrm{VO}_{2}$, this 
Tailoring Vanadium Dioxide Film Orientation using Nanosheets: A Combined Microscopy, Diffraction, Transport and Soft X-ray in Transmission Study

indicates that the $\mathrm{R}-\mathrm{VO}_{2} \mathrm{c}$-axis (2.86 $\AA$ when unstrained) is under a degree of tensile strain in the [010] direction of the TO nanosheet which has $b=2.97$ $\AA$. The situation is the other way around for the $\mathrm{VO}_{2}$ grown on NWO nanosheets: here $T_{\mathrm{MIT}}$ is lower, suggesting compressive strain along the rutile $c$-axis, as could be expected from the Poisson effect given the tensile strain along the [100] and [010] directions of $\mathrm{VO}_{2}(a=4.53 \AA)$ due to coupling to the NWO nanosheet $(a=4.68 \AA)$.

The MIT for the TO-templated $\mathrm{VO}_{2}$ shows a steep-sided hysteresis curve. In comparison, the data of Figure 4 shows that the $\mathrm{VO}_{2}$ grown on NWO nanosheets displays a relatively broad MIT. A possible explanation for this observation could be related to the fact that the NWO-templated $\mathrm{VO}_{2}$ possesses a surface roughness of order $10 \mathrm{~nm}$, compared to $2 \mathrm{~nm}$ for the TO-templated $\mathrm{VO}_{2}$ films (see Figure $\mathrm{A} 1$ for $\mathrm{AFM}$ data from the $\mathrm{VO}_{2}$ films). As the MIT in $\mathrm{VO}_{2}$ possesses a strongly percolative character ${ }^{[29]}$, the increased roughness, on top of an increased density of grain boundaries due to internanosheet boundaries ${ }^{[17]}$ can be at least a partial explanation of the broader transition for the case of $\mathrm{VO}_{2}$ grown on NWO nanosheet templates. In addition, the larger deviation from $90^{\circ}$ bond angles of the $2 \mathrm{D}$ atomic structure of the (-402) $)_{\mathrm{M} 1}$ plane in the NWO case compared to the $(011)_{\mathrm{M} 1}$ plane for TOtemplated growth (see Figure 1) is also compatible with a larger domain/grain boundary contribution to the transport for the NWO-templated $\mathrm{VO}_{2}$.

From the experimental data thus far, it is clear that the nanosheets provide an elegant and effective method to control the orientation of $\mathrm{VO}_{2}$ films on two widely different bulk substrates. In order to both emphasize the added possibilities that freedom from 'hard' substrate epitaxy enables, as well as to illustrate how this can also be controlled on the micron scale, the next section reports a new strategy to manipulate different orientations of $\mathrm{VO}_{2}$ on a single, arbitrary substrate. To do this, NWO nanosheets were lithographically linepatterned on top of a monolayer of TO nanosheets, with subsequent $\mathrm{VO}_{2}$ 
growth on this structured template layer to demonstrate the local manipulation of the orientation of the resulting high-quality $\mathrm{VO}_{2}$ film.

Figure 5 presents the high-resolution scanning electron microscopy (HRSEM) cross-sectional view of the line-patterned $\mathrm{VO}_{2}$, showing in panel (a) that the film thickness was roughly $50 \mathrm{~nm}$ on both types of nanosheets. In addition, the HR-SEM plan-view (Figure 5(b)) clearly reveals the different surface morphologies alluded to earlier on either side of the nanosheet boundary, consistent with the AFM data of $\mathrm{VO}_{2}$ films grown on 'single species' TO and NWO nanosheets (see Figure A1). In both situations the resulting $\mathrm{VO}_{2}$ film has a smoother surface on TO than on NWO nanosheets. 
Tailoring Vanadium Dioxide Film Orientation using Nanosheets: A Combined Microscopy, Diffraction, Transport and Soft X-ray in Transmission Study
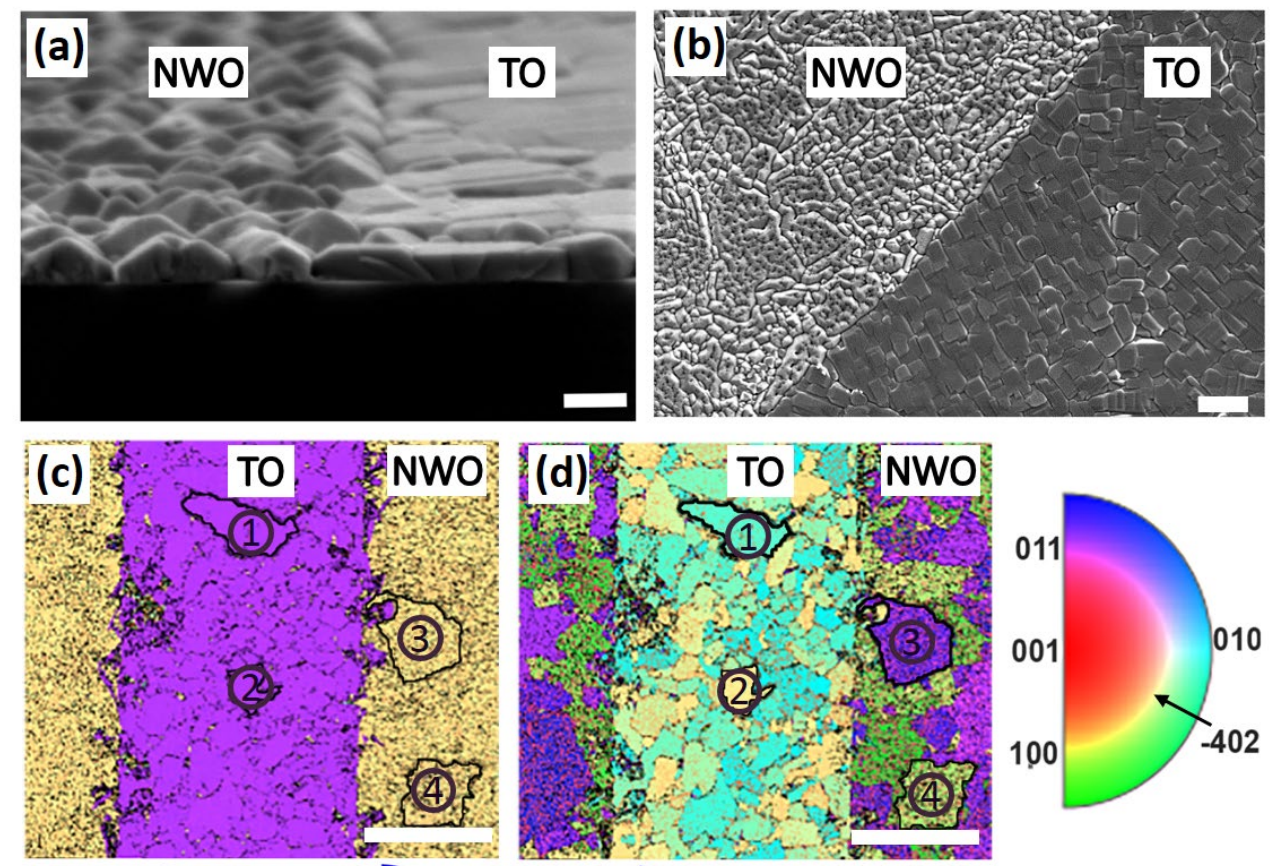

(e)

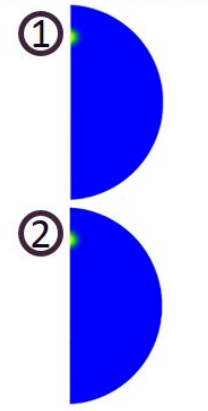

(3)

(4)
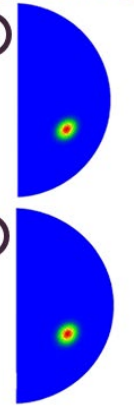

(f)

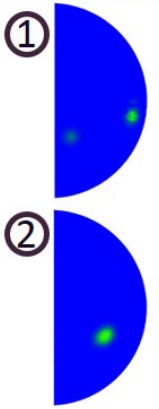

(3)

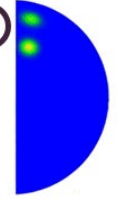

(4)

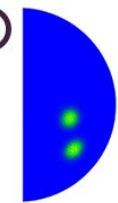

Normalized intensity (out-of-plane)

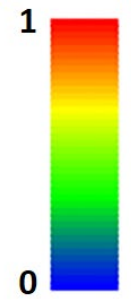

Figure 5. Micron-level, deterministic control over the $\mathrm{VO}_{2}$ orientation on a single substrate. Room temperature HR-SEM images of the cross-section (a) and plan (b) views at the line boundary of $\mathrm{VO}_{2}$ film (left side is $\mathrm{VO}_{2}$ grown on $\mathrm{NWO}$ nanosheet; right side is growth on TO nanosheet). (c) and (d) show inverse pole figure maps, measured using EBSD at room temperature, displaying the $\mathrm{VO}_{2}$ film orientation in the out-of-plane (c) and in-plane (d) directions. In panel (c), the left- and right-side of the image shows growth on NWO nanosheet (gold color). Here, the film normal is the monoclinic $(-402)$ axis $\left(\rightarrow(002)_{R}\right)$. The central, purple-colored strip represents growth on TO nanosheet where the film normal is $(011)_{\mathrm{M} 1}$, equivalent to $(110)_{\mathrm{R}}$. Panel (d) shows the in-plane texture of the $\mathrm{VO}_{2}$ films along the horizontal direction (x). The scale bars represent $100 \mathrm{~nm}$ in (a), $500 \mathrm{~nm}$ in (b) and $10 \mu \mathrm{m}$ in both (c) and 
(d). Panel (e) shows out-of-plane inverse pole figures corresponding to the four different regions marked on panel (c). The out-of-plane orientation is clearly controlled by the type of nanosheets used. Panel (f) displays in-plane inverse pole figures corresponding to the same four regions marked in panel (d). Four different domains on each individual nanosheet result from the reduced monoclinic symmetry compared to the tetragonal rutile case. Only half of the stereographic projection is shown due to symmetry resulting in only two spots.

In addition to SEM imaging, electron backscatter diffraction (EBSD) maps were recorded, providing crystallographic information on the $\mathrm{VO}_{2}$ film on the lithographically patterned nanosheet layers, shown in Figure 5(c) and (d). As these data were recorded at room temperature, the crystallographic notation uses the M1 film orientations (the corresponding R-phase orientation was shown in Figure 2). The inverse pole figure maps reveal the out-of-plane orientations $(-402)_{\mathrm{M} 1}$ (shown in gold color, becoming $(002)_{\mathrm{R}}$ at elevated temperature) and $(011)_{\mathrm{M} 1}$ (shown in purple, becoming $(110)_{\mathrm{R}}$ at elevated temperature). Taking a closer look at a domain on single-typed nanosheet regions, the four inverse pole figures of Figure 5(e) correspond to the four chosen regions indicated in Figure 5(c). These show the presence of a single out-of-plane orientation for each type of nanosheet. It is evident that the $\mathrm{VO}_{2}$ film out-of-plane orientations follow the underlying nanosheets with high fidelity, down to the micron level as it was designed.

The in-plane EBSD orientation map displayed in Figure 5(d) shows a random orientational distribution, resulting from the randomness of in-plane orientation of nanosheets during LB deposition. On each single nanosheet, the reduced symmetry of the monoclinic $\mathrm{VO}_{2}$ lattice when cooling down from the high-temperature rutile phase is expected to induce the formation of four in-plane structural domains ${ }^{[30]}$. The inverse pole figures shown in Figure 5(f) show two of these because, due to symmetry (presence of a mirror plane) of the monoclinic phase, only half of the complete stereographic projection is 
Tailoring Vanadium Dioxide Film Orientation using Nanosheets: A Combined Microscopy, Diffraction, Transport and Soft X-ray in Transmission Study

displayed. Furthermore, in domain 2, only 1 orientation is seen as one is looking along the $2_{1}$ axis.

Having proven the excellent crystalline quality and the exquisite control over the orientation of $\mathrm{VO}_{2}$ grown on nanosheets of different types, spectroscopy in the soft X-ray regime is now used to benchmark the epitaxial samples grown on TO nanosheets and provide comparison of the sample quality to what is known in the literature. As shown in the data of Figure 2(c)-(f), the nanosheet approach enables deposition of high-quality $\mathrm{VO}_{2}$ on $\mathrm{Si}_{3} \mathrm{~N}_{4}$ membranes that are soft $\mathrm{X}$-ray transparent, opening a route to conducting XAS in transmission. This yields a bulk-sensitive and direct measure of the absorption that can directly be correlated with local measurements carried out in the TEM. The majority of previous XAS studies of $\mathrm{VO}_{2}$ have used indirect methods such as Total Electron Yield (TEY) to monitor the X-Ray absorption process ${ }^{[5,31-35]}$.
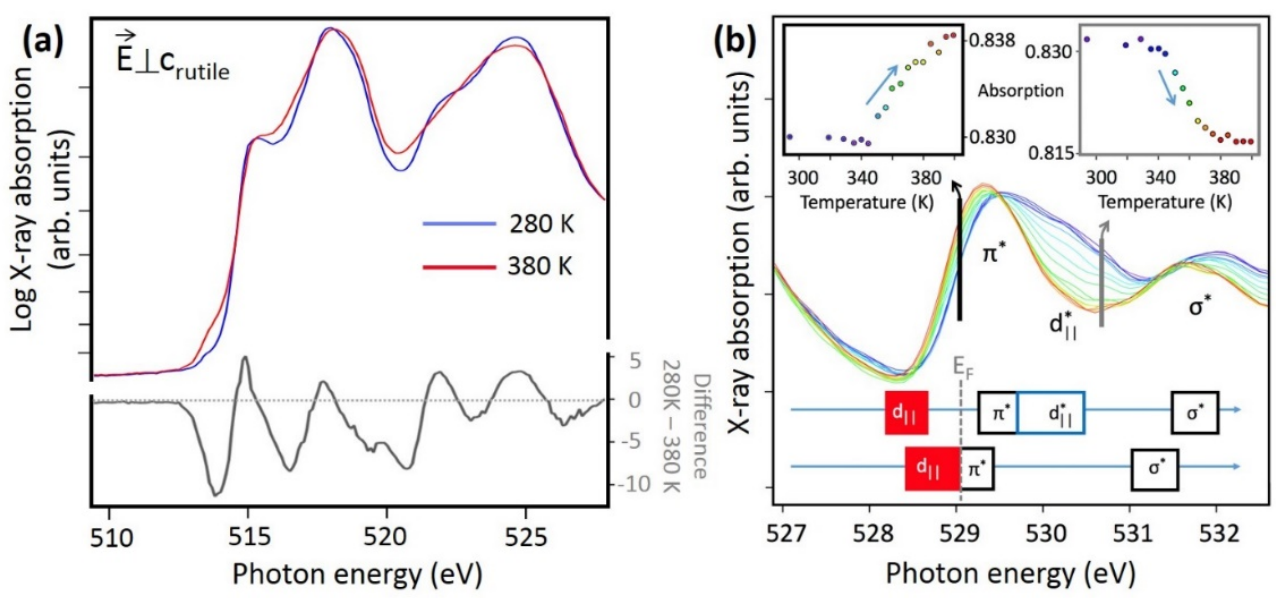

Figure 6. Soft X-ray absorption in transmission. V-L $\mathrm{L}_{2,3} \mathrm{XAS}$ of nanosheet-supported $\mathrm{VO}_{2}$ recorded in transmission at the temperatures shown for grazing incidence of the linearly polarized X-rays. Subtle yet clear differences in the spectral features mirror alterations in the electronic structure, reflecting changes in orbital energies as the $\mathrm{V}$ $d_{\|}$states split and an energy gap opens in the insulating, low temperature phase. The details of the difference spectrum agree very well with published polarization- 
dependent $\mathrm{V}-\mathrm{L} 2,3 \mathrm{X}$-ray absorption data from $\mathrm{VO}_{2}$ grown epitaxially on bulk single crystalline substrates. ${ }^{[27]}$ Panel (b) shows the O-K edge recorded at normal incidence as a function of temperature. The insets - whose data-points are color-coded to match the spectra from which they are taken - show the T-dependence of the two main absorption features signaling the MIT. Increasing leading edge intensity (black arrow/inset) tracks the closing of the insulating gap as the rutile phase is reached, and a different aspect of the same physics yields to the decrease of the $d_{\|}{ }^{*}$ feature at $530.6 \mathrm{eV}$ (grey arrow/inset). The identity of the different peaks, together with a schematic representation of the corresponding density of states is given under the data of panel (b). (Data are collected and analyzed by collaborators, Quantum Materials Amsterdam group, Van der Waals-Zeeman Institute, Institute of Physics, The Netherlands)

Linking to the transport data presented in Figure 4, XAS experiments at the vanadium- $L_{2,3} \quad(2 p \rightarrow 3 d$ transitions $)$ and oxygen-K $(1 s \rightarrow 2 p$ transitions $)$ absorption edges also directly probe the MIT, and are readily accessible using soft X-rays provided by a synchrotron light source. In correlated transition metal oxides such as $\mathrm{VO}_{2}$, the ability of soft XAS to provide detailed information on the manifold and coupled degrees of freedom (e.g. lattice, spin, charge and orbital) using the transition metal- $\mathrm{L}_{2,3}$ and $\mathrm{O}-\mathrm{K}$ edges have been studied extensively ${ }^{[5,30-35]}$. Panel (a) of Figure 6 shows $V-L_{2,3}$ edge data both for the metallic (rutile) and insulating (monoclinic) phases for the TO nanosheet templated $\mathrm{VO}_{2}$. As reported by Aetukuri et al. ${ }^{[27]}$, the changes seen to occur across the MIT are related to the orbital occupation, and in particular they underscore the transformation of the three-dimensional rutile situation to one in which $\mathrm{V}$-dimers form along the direction of the rutile c-axis, leading to shifts and splitting of electronic states related to the orbitals polarized in this direction, referred to as the $d_{\|}$states. For grazing incidence $\left(E \perp c_{\text {rutile }}\right)$ the temperature dependent changes shown in Figure 6(b) agree excellently with published data on films grown on single crystalline, bulk substrates ${ }^{[27]}$, attesting to the quality of the nanosheet templated $\mathrm{VO}_{2}$ thin films. Closer examination of the insets yields that the bulk (transmission) XAS 
Tailoring Vanadium Dioxide Film Orientation using Nanosheets: A Combined Microscopy, Diffraction, Transport and Soft X-ray in Transmission Study

shows an onset of the MIT on warming at $340 \mathrm{~K}$, and that ca. $40 \mathrm{~K}$ of further heating are required to complete the conversion to the rutile phase. The transport data shown in Figure 4 from fully analogous $\mathrm{VO}_{2}$ films, show an earlier onset and faster completion of the transformation on heating. This can be understood straightforwardly as resulting from the percolative nature of the transport probe on the one hand and to the bulk-sensitive, volumefraction-driven absorption of soft X-ray radiation on the other hand.

One of the clear order parameters for the MIT is the opening of an energy gap in the insulating phase. This can be clearly seen in XAS at the O-K edge, as shown in Figure 6(b) and panels (b) and (c) of Figure 7, and reported in the literature recently ${ }^{[5]}$. With reference to the electronic structure schematic shown under the data of Figure 6(b), the most marked spectroscopic changes in the $\mathrm{O}-\mathrm{K}$ edge spectra while entering the metallic phase are due to the closure of the gap, and the disappearance of the unoccupied $d_{\|}{ }^{*}$ states, the latter present in the monoclinic phase due to a splitting of the highly directional $d_{\|}$states. The insets to Figure $6(b)$ show how these changes to the gap [ $d_{\|}{ }^{*}$ states] leads to an increase [decrease] of the XAS absorption at the characteristic energy of 529.1 [530.6] eV.

Figure 7(a) illustrates the experimental configuration used for polarized XAS in transmission. For the TO-nanosheet-templated $\mathrm{VO}_{2}$ films, the rutile c-axis is in the film plane, and its in-plane orientation varies from one nanosheet to the next. The synchrotron X-ray beam is large enough to average over a large number of nanosheets, meaning that one can consider vertically polarized radiation (LV) at grazing incidence to yield an unpolarized spectrum. Horizontally polarized radiation (LH) aligns the E-vector perpendicular to the film plane and hence $E \perp c_{\text {rutile }}$ is always realized, regardless of the direction of the in-plane orientation of the rutile c-axis in each individual nanosheet-templated epitaxial grain. In Figure 7(b) and 7(c), polarization-dependent XAS spectra are shown for both grazing and normal 
incidence of the beam, respectively. As is clear from the earlier discussion, for normal incidence (Figure 7(c)), whether LV or LH radiation is used makes no difference to the absorption spectra, as in all cases a mixture of E\|| crutile $_{\text {e }}$ and $E \perp c_{\text {rutile }}$ is the result. For grazing incidence (Figure $7(b)$ ) and LH radiation, the $E$ vector is $E \perp c_{\text {rutile, }}$, compared to mixed $E \perp c_{\text {rutile }}$ and $E \| c_{\text {rutile }}$ for linear vertical. This is of high relevance for future experiments such as those outlined in Figure 8 in the next section. The major advantages are the presence of: (i) the O-K leading edge shift at $\sim 529 \mathrm{eV}$ (ii) the directional $\mathrm{d}_{\|}{ }^{*}$ states in the monoclinic phase at $\sim 530.5 \mathrm{eV}$ and (iii) the $\sigma^{*}$ states in the rutile phase at $\sim 531.5 \mathrm{eV}$ which all show up clearly in the transmission XAS measurements, also without the need of a full suite of polarization-dependent measurements.
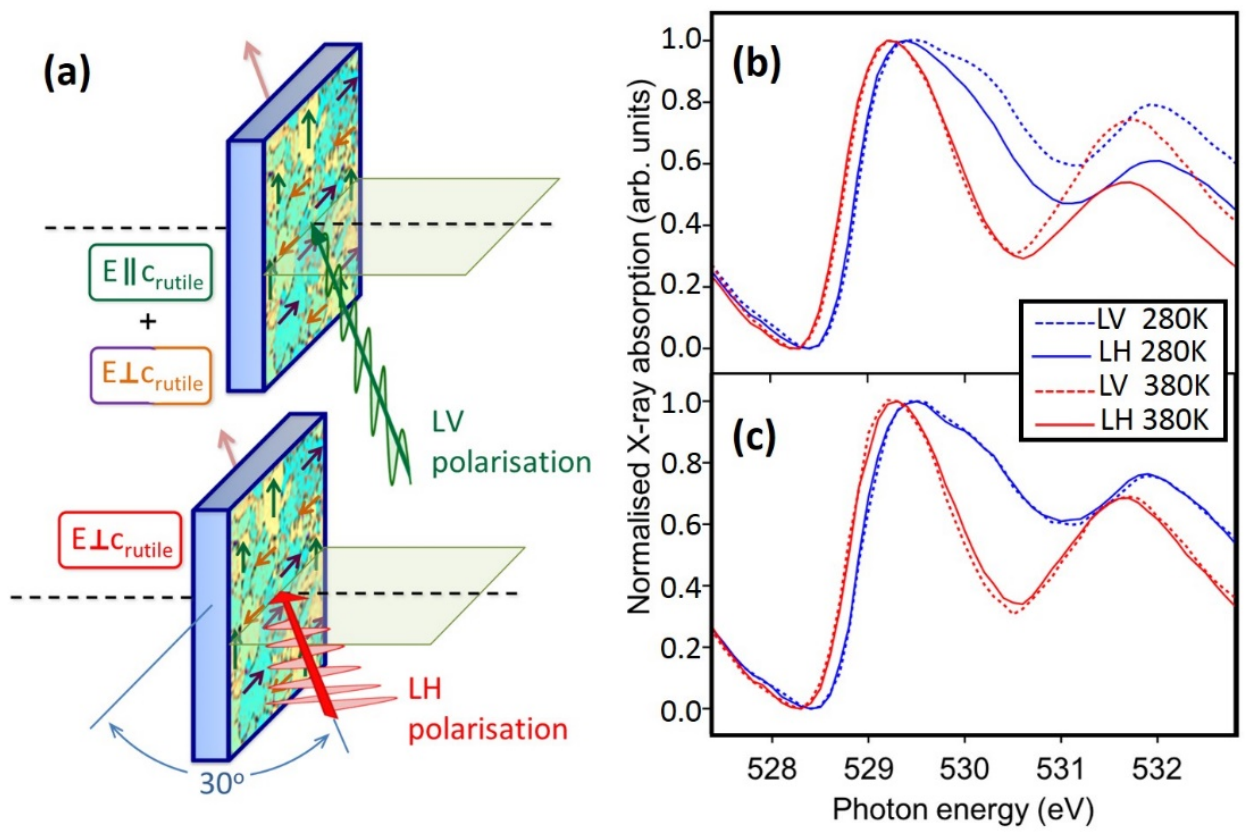

Figure 7. V orbital occupancy across the MIT. (a) Schematic of soft X-ray absorption experiments on TO-nanosheet-supported $\mathrm{VO}_{2}$ thin films grown on $20 \mathrm{~nm}$ thick silicon nitride TEM windows. Linearly polarized synchrotron radiation impinges in grazing incidence, as indicated (the transmitted beam is measured using a diode 
Tailoring Vanadium Dioxide Film Orientation using Nanosheets: A Combined Microscopy, Diffraction, Transport and Soft X-ray in Transmission Study

downstream of the sample, not shown). The c-axis of the $(110)_{\mathrm{R}}-\mathrm{VO}_{2}$ film is oriented differently in each of the nanosheet domains, but is always in the plane of the film. Therefore, $L H$ fixes $E \perp C_{\text {rutile }}$ and $L V$ polarization probes a mix of $E \perp c_{\text {rutile }}$ and $E \| c_{\text {rutile. }}$ Polarization dependent measurements at the $\mathrm{O}$ K-edge above and below the transition for both grazing [panel (b)] and normal [panel (c)] incidence show the inplane polarization of the unoccupied portion of the highly directionally aligned $d_{\|}$ states. (Data are collected and analyzed by collaborators, Quantum Materials Amsterdam group, Van der Waals-Zeeman Institute, Institute of Physics, The Netherlands)

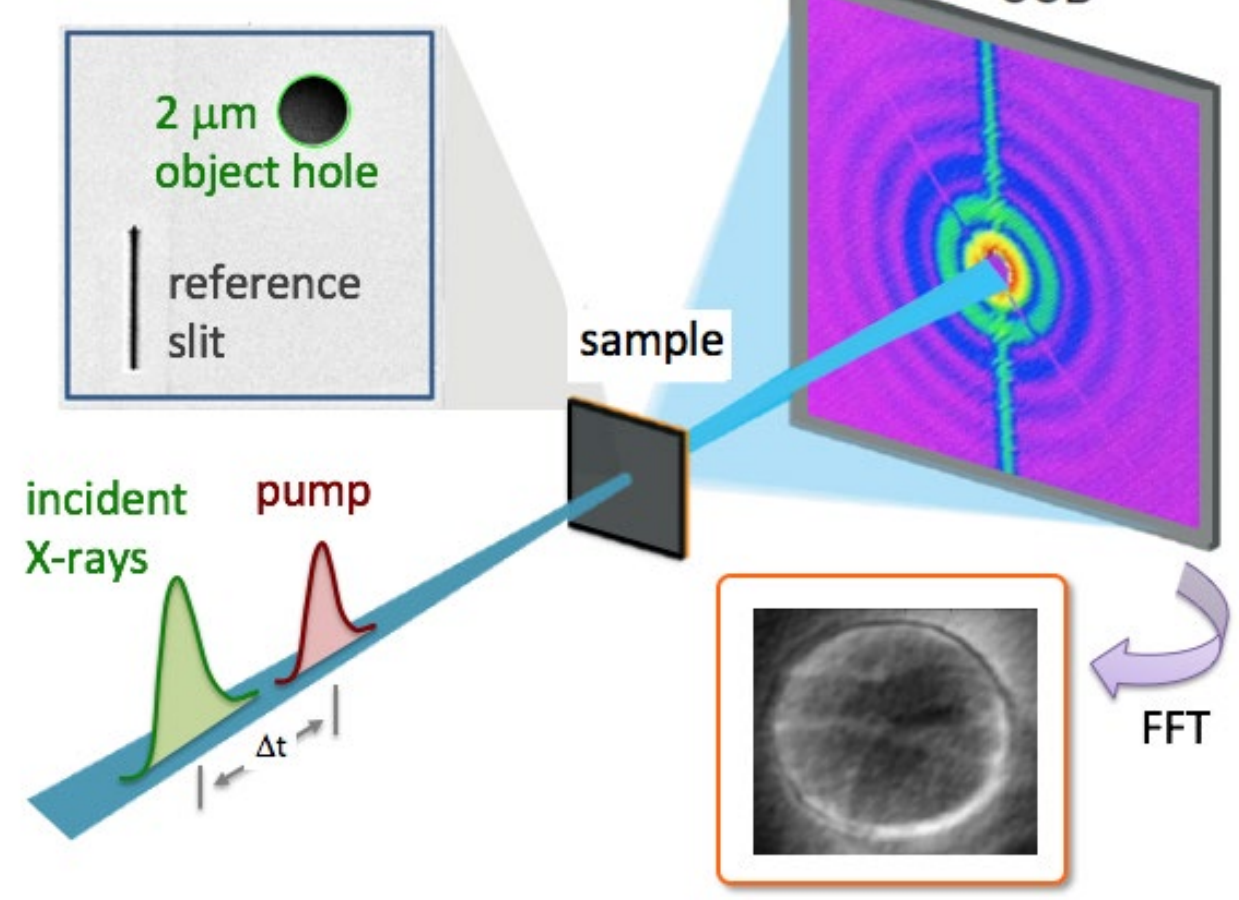

Figure 8. Lens-less imaging of the MIT of $\mathrm{VO}_{2}$. Schematic of a soft X-ray holography experiment on nanosheet-supported $\mathrm{VO}_{2}$ thin films which incorporate with a gold mask structure. The $\mathrm{VO}_{2}$ films can be grown using PLD on TO nanosheets that are deposited on commercial, $200 \mathrm{~nm}$ thick silicon nitride TEM windows (e.g. Simpore). A gold mask is subsequently deposited and a sample window (diameter $2 \mu \mathrm{m}$ ) + reference slit are machined into the mask using a focused ion beam (FIB). The 
window reveals the $\mathrm{VO}_{2}$ film, whereas the slit goes right through the whole structure (including the $\mathrm{VO}_{2}$, the nanosheets and silicon nitride, too). Illumination with coherent $\mathrm{X}$-rays yields a far-field diffraction pattern, and using a differential filter and fast Fourier transform it is possible to reconstruct a real space image of the different phases of $\mathrm{VO}_{2}$ during the MIT. At an X-ray free electron laser, sufficient intensity in a single ultrafast flash of X-rays would also allow a pump-probe version of this experiment, so enabling a stop-motion film to be built up of how $\mathrm{VO}_{2}$ switches on both the fs timescale and nm length scales. (Schematic experiment by collaborators, Quantum Materials Amsterdam group, Van der Waals-Zeeman Institute, Institute of Physics, The Netherlands)

Summarizing, the research reports on the successful deposition of highquality vanadium dioxide thin films on $\mathrm{Si}$ substrates and $\mathrm{Si}_{3} \mathrm{~N}_{4}$ membranes using oxide nanosheets of $\mathrm{Ti}_{0.87} \mathrm{O}_{2}$ (TO) and $\mathrm{NbWO}_{6}$ (NWO) as a templating layer. Each nanosheet is a single crystal template, able to orient the growth direction of the $\mathrm{VO}_{2}$ film as a result of lattice match of the oxygen frameworks of the two systems and compatibility of the $2 \mathrm{D}$ atomic structure between the nanosheets and the $\mathrm{VO}_{2}$ crystal planes. X-ray diffraction, SEM imaging, EBSD and ACOM-TEM data all agree on the film orientation, attesting to the epitaxial relationship such that TO nanosheets template $(110)_{R}$ growth and NWO templates $(002)_{R}$ growth of $\mathrm{VO}_{2}$. It was also shown that even micronscale, local control over the $\mathrm{VO}_{2}$ orientation is achievable, when using lithographically patterned nanosheet templates on a single, monolithic substrate.

The second main strand in the research presented deals with the MIT of the nanosheet templated $\mathrm{VO}_{2}$ films. Due to strain effects along the $c$-axis of $\mathrm{VO}_{2}$ rutile phase, $\mathrm{T}_{\mathrm{MIT}}$ was $10 \mathrm{~K}$ higher [ $9 \mathrm{~K}$ lower] on TO [NWO] nanosheets, compared to bulk $\mathrm{VO}_{2}$ single crystal values. Truly bulk-sensitive soft $\mathrm{X}$-ray experiments carried out in transmission also underlined the excellent quality of the $\mathrm{VO}_{2}$ thin films, which displayed all the hallmarks of the MIT known from films grown on bulk substrates. The significant soft X-ray transmission 
Tailoring Vanadium Dioxide Film Orientation using Nanosheets: A Combined Microscopy, Diffraction, Transport and Soft X-ray in Transmission Study

contrast - for example at the O-K leading edge, or at the position of $d_{\|}{ }^{*}$ feature - combined with the ability to work in transmission, means such nanosheet templated $\mathrm{VO}_{2}$ films are ideal for advanced soft $\mathrm{X}$-ray techniques such as lens-less imaging of the MIT with spatial resolution of tens of $\mathrm{nm}$. Such techniques involve holographic reconstruction of the real-space patterns formed during the MIT, and can be carried out on a modified version of the samples used for the studies reported here. Figure 8 shows a schematic for such an experiment. It is the first step towards such experiments and have recently successfully reconstructed first images during the MIT of $\mathrm{VO}_{2}$ using the holography with extended reference by autocorrelation linear differential operator reconstruction technique ${ }^{\text {[36-38]. }}$

\section{Conclusions}

To conclude, this chapter has shown that nanosheets can act as templates for heteroepitaxial growth of high-quality $\mathrm{VO}_{2}$ thin films on arbitrary substrates. The latter can be amorphous or have a very different crystallographic structure compared to the target material $\mathrm{VO}_{2}$ itself. This approach allows this important test-case material for oxide-based devices and switching to be grown tailored for specific device applications and for fundamental research. An example is given of how micro-structured areas of differing $\mathrm{VO}_{2}$ orientation can be generated, and how the nanosheettemplated growth approach can be used to enable soft X-ray holographic lens-less imaging of the MIT in $\mathrm{VO}_{2}$.

\section{Experimental section}

\section{Preparation of nanosheet films}

Potassium carbonate $\mathrm{K}_{2} \mathrm{CO}_{3}$ (Fluka), lithium carbonate $\mathrm{Li}_{2} \mathrm{CO}_{3}$ (Riedel-de Haen), titanium (IV) dioxide $\mathrm{TiO}_{2}$ (Sigma-Aldrich), niobium (V) oxide $\mathrm{Nb}_{2} \mathrm{O}_{5}$ (Alfa Aesar), and tungsten (VI) oxide $\mathrm{WO}_{3}$ (Alfa Aesar) had a purity of $99.0 \%$ or higher and were used as received. Nitric acid $\mathrm{HNO}_{3}(65 \%, \mathrm{ACROS}$ 
Organics) and tetra-n-butylammonium hydroxide TBAOH (40\% wt. $\mathrm{H}_{2} \mathrm{O}$, Alfa Aesar) were used as received. Demineralized water was used throughout the experiments.

$\mathrm{K}_{0.8} \mathrm{Ti}_{1.73} \mathrm{Li}_{0.27} \mathrm{O}_{4}$ and $\mathrm{LiNbWO}_{6}$ were synthesized as reported in the literature [39,40], and the layered protonated titanate, $\mathrm{H}_{1.07} \mathrm{Ti}_{1.73} \mathrm{O}_{4} \cdot \mathrm{H}_{2} \mathrm{O}$, and protonated $\mathrm{HNbWO}_{6} \cdot \mathrm{xH}_{2} \mathrm{O}$ were obtained by treating with $2 \mathrm{M} \mathrm{HNO}_{3}$ for 3 days and replacing new acid solution every day. The rapid exfoliation with TBAOH, which has been reported for $\mathrm{H}_{1.07} \mathrm{Ti}_{1.73} \mathrm{O}_{4} \cdot \mathrm{H}_{2} \mathrm{O}$ [41] was also observed for $\mathrm{HNbWO}_{6} \cdot \mathrm{xH}_{2} \mathrm{O}$. Full-coverage TO and NWO nanosheet films were generated on $\mathrm{Si}$ substrates and $\mathrm{Si}_{3} \mathrm{~N}_{4}$ TEM grips using the LB method.

The micron-scale patterned nanosheet template combining TO and NWO nanosheets was prepared as follows. A monolayer of TO nanosheets was deposited on a Si substrate. On top of this monolayer, hexamethyldisiloxane (Merck) was spin-coated at $3000 \mathrm{rpm}$ for $30 \mathrm{~s}$ and then a thick layer of photoresist (OiR 907-12 from Olin Microelectronic Materials Inc.) was spincoated at $3000 \mathrm{rpm}$ for $30 \mathrm{~s}$. After heating at $90^{\circ} \mathrm{C}$ for $2 \mathrm{~min}$, the sample was exposed to a $\mathrm{Hg}$ lamp with a wavelength of $365 \mathrm{~nm}$ for $10 \mathrm{~s}$ under a $20 \mu \mathrm{m}$ spaced line grating mask (in a Karl Suss MA56 Mask Aligner). The photoresist was developed for $1 \mathrm{~min}$ (in OPD 4262 from Arch Chemicals) and baked at $110^{\circ} \mathrm{C}$ for $2 \mathrm{~min}$. Subsequently, a monolayer of NWO nanosheets was deposited on this line-patterned sample. Lastly, the sample was dipped and held upside-down in acetone for $1 \mathrm{~min}$ for lift-off, in order to remove the NWO nanosheets on top of the photoresist. The sample was then rinsed with ethanol and dried in a $\mathrm{N}_{2}$ gas stream.

\section{Pulsed laser deposition of $\mathrm{VO}_{2}$ thin films}

PLD was carried out in a vacuum system equipped with a $\mathrm{KrF}$ excimer laser, with a wavelength of $248 \mathrm{~nm}$ (COMPEX from Coherent Inc.). The central part of the laser beam was selected with a mask and focused on a polycrystalline $\mathrm{V}_{2} \mathrm{O}_{5}$ target. The deposition conditions of the $\mathrm{VO}_{2}$ films were: laser repetition 
Tailoring Vanadium Dioxide Film Orientation using Nanosheets: A Combined Microscopy, Diffraction, Transport and Soft X-ray in Transmission Study

rate $4 \mathrm{~Hz}$, energy density $1.3 \mathrm{~J} \mathrm{~cm}^{-2}$, spot size $1.8 \mathrm{~mm}^{2}$, oxygen pressure 7.5 mTorr, deposition temperature $520^{\circ} \mathrm{C}$, number of pulses 15000 , and substrate-target distance $50 \mathrm{~mm}$. After deposition, the samples were cooled down to room temperature at a maximum rate of $5^{\circ} \mathrm{C} \mathrm{min}^{-1}$ at the deposition pressure.

\section{Analysis and characterization}

The surfaces of the nanosheet films and of the $\mathrm{VO}_{2}$ on $\mathrm{Si}$ substrates were investigated using atomic force microscopy (AFM, Bruker Dimension ICON) operating in tapping mode and the data were processed using Gwyddion software (version 2.48) ${ }^{[42]}$. The relative coverage of nanosheets on substrates was determined at four different locations. The temperature dependent crystal structure of $\mathrm{VO}_{2}$ thin films was analyzed using X-ray diffraction $\theta-2 \theta$ scans (XRD, PANalytical X'Pert Pro MRD) equipped with an Anton Paar DHS 1100 Domed Hot Stage. The temperature dependence of the resistance was measured using a Quantum Design Physical Properties Measurement System. A two-probe measurement was performed to extract the MIT behavior, hysteresis, and transition temperature. High resolution scanning electron microscopy (HR-SEM) and electron backscattering diffraction (EBSD) were performed on a Merlin field emission microscope (Zeiss 1550) equipped with an angle-selective backscatter detector at room temperature. The automated crystal orientation maps in microprobe TEM mode (ACOM-TEM) were acquired on a FEI Tecnai G2 microscope (FEG, $200 \mathrm{kV}$ ), equipped with the ASTAR system from Nanomegas. Electron precession was applied to acquire quasi-kinematical data and to facilitate automated indexation. The precession angle used of $0.4^{\circ}$ yielded an electron probe size of $\sim 1.5 \mathrm{~nm}$. Interface mapping was achieved in post treatment with the orientation imaging microscopy (OIM) analysis software from Ametek EDAX company, including noise reduction and texture analysis. Misindexed or non-indexed points were corrected using a standard EBSD 
cleanup procedure. Furthermore, grains smaller than 5 pixels or with a low reliability $(<10 \%)$ were removed from the analysis. The pole figures were calculated using the harmonic series expansion and were generated along the common directions $(001,110$, etc. $)$ with the Gaussian half-width set at 5 degrees. The average orientation was taken from every identified grain.

Soft X-ray transmission experiments were carried out at the UE56-PGM1 beamline at the BESSY II synchrotron source located at the Helmholtz Centre HZB in Berlin. Linearly polarized X-rays (horizontal and vertical) were generated using the UE56 helical undulator, and the energy resolution of the beamline was set to $80 \mathrm{meV}$. The sample temperature was carefully controlled using a Janis cryostat, and the transmission of $\mathrm{X}$-rays was monitored by comparing photon flux monitors before (refocusing mirror current) and after the sample (on a diode), and included correction for mirror/diode contamination by division with an 'empty scan' in which no $\mathrm{VO}_{2}$ sample is held in the beam path. The soft X-ray lensless imaging exepriments were conducted using the COMET end-station at the SEXTANTS beamline of the SOLEIL synchrotron ${ }^{[43]}$. 
Tailoring Vanadium Dioxide Film Orientation using Nanosheets: A Combined Microscopy, Diffraction, Transport and Soft X-ray in Transmission Study

\section{References}

[1] F. J. Morin, Phys. Rev. Lett. 1959, 3, 34.

[2] J. B. Goodenough, Journal of Solid State Chemistry 1971, 3, 490.

[3] Z. Yang, C. Ko, S. Ramanathan, Annual Review of Materials Research 2011, 41, 337.

[4] Y. Zhou, S. Ramanathan, Proceedings of the IEEE 2015, 103, 1289.

[5] A. X. Gray, J. Jeong, N. P. Aetukuri, P. Granitzka, Z. Chen, R. Kukreja, D. Higley, T. Chase, A. H. Reid, H. Ohldag, M. A. Marcus, A. Scholl, A. T. Young, A. Doran, C. A. Jenkins, P. Shafer, E. Arenholz, M. G. Samant, S. S. P. Parkin, H. A. Dürr, Phys. Rev. Lett. 2016, 116, 116403.

[6] H.-T. Zhang, L. Zhang, D. Mukherjee, Y.-X. Zheng, R. C. Haislmaier, N. Alem, R. Engel-Herbert, Nature Communications 2015, 6, ncomms9475.

[7] K. Martens, N. Aetukuri, J. Jeong, M. G. Samant, S. S. P. Parkin, Appl. Phys. Lett. 2014, 104, 081918.

[8] J. Jian, A. Chen, W. Zhang, H. Wang, Journal of Applied Physics 2013, 114, 244301.

[9] J. Sakai, M. Zaghrioui, V. Ta Phuoc, S. Roger, C. Autret-Lambert, K. Okimura, Journal of Applied Physics 2013, 113, 123503.

[10] A. Gupta, R. Aggarwal, P. Gupta, T. Dutta, R. J. Narayan, J. Narayan, Appl. Phys. Lett. 2009, 95, 111915.

[11] R. Molaei, M. R. Bayati, J. Narayan, Journal of Materials Research 2012, 27, 3103.

[12] V. R. Morrison, R. P. Chatelain, K. L. Tiwari, A. Hendaoui, A. Bruhács, M. Chaker, B. J. Siwick, Science 2014, 346, 445.

[13] M. Nakano, K. Shibuya, D. Okuyama, T. Hatano, S. Ono, M. Kawasaki, Y. Iwasa, Y. Tokura, Nature 2012, 487, 459.

[14] T. Driscoll, H.-T. Kim, B.-G. Chae, B.-J. Kim, Y.-W. Lee, N. M. Jokerst, S. Palit, D. R. Smith, M. D. Ventra, D. N. Basov, Science 2009, 325, 1518.

[15] E. Strelcov, Y. Lilach, A. Kolmakov, Nano Lett. 2009, 9, 2322.

[16] H. Yoon, M. Choi, T.-W. Lim, H. Kwon, K. Ihm, J. K. Kim, S.-Y. Choi, J. Son, Nat Mater 2016, 15, 1113.

[17] M. D. Nguyen, H. Yuan, E. P. Houwman, M. Dekkers, G. Koster, J. E. ten Elshof, G. Rijnders, ACS Appl. Mater. Interfaces 2016 8, 31120.

[18] M. Nijland, S. Thomas, M. A. Smithers, N. Banerjee, D. H. A. Blank, G. Rijnders, J. Xia, G. Koster, J. E. ten Elshof, Adv. Funct. Mater. 2015, 25, 5140 .

[19] T. Shibata, H. Takano, Y. Ebina, D. S. Kim, T. C. Ozawa, K. Akatsuka, T. Ohnishi, K. Takada, T. Kogure, T. Sasaki, J. Mater. Chem. C 2013, 2, 441 .

[20] T. Shibata, Y. Ebina, T. Ohnishi, K. Takada, T. Kogure, T. Sasaki, Crystal Growth \& Design 2010, 10, 3787. 
[21] M. Osada, T. Sasaki, J. Mater. Chem. 2009, 19, 2503.

[22] J. Narayan, B. C. Larson, Journal of Applied Physics 2002, 93, 278.

[23] T. Shibata, K. Fukuda, Y. Ebina, T. Kogure, T. Sasaki, Adv. Mater. 2008, 20, 231.

[24] H. Yuan, M. Nguyen, T. Hammer, G. Koster, G. Rijnders, J. E. ten Elshof, ACS Appl. Mater. Interfaces 2015, 7, 27473.

[25] a) J. Li, J. Dho, Journal of Crystal Growth 2014, 404, 84; b) Y. Muraoka, Z. Hiroi, Appl. Phys. Lett. 2002, 80, 583.

[26] a) D. Okuyama, K. Shibuya, R. Kumai, T. Suzuki, Y. Yamasaki, H. Nakao, Y. Murakami, M. Kawasaki, Y. Taguchi, Y. Tokura, and T. Arima, Phys. Rev. B 2015, 91, 064101-8; b) K. Shibuya, M. Kawasaki, \& Y. Tokura, Appl. Phys. Lett. 2010 96, 022102;

[27] N. B. Aetukuri, A. X. Gray, M. Drouard, M. Cossale, L. Gao, A. H. Reid, R. Kukreja, H. Ohldag, C. A. Jenkins, E. Arenholz, K. P. Roche, H. A. Dürr, M. G. Samant, S. S. P. Parkin, Nature Physics 2013, 9, 661.

[28] L. L. Fan, S. Chen, Z. L. Luo, Q. H. Liu, Y. F. Wu, L. Song, D. X. Ji, P. Wang, W. S. Chu, C. Gao, C. W. Zou, Z. Y. Wu, Nano Lett. 2014, 14, 4036.

[29] A. Sohn, T. Kanki, K. Sakai, H. Tanaka, D.-W. Kim, Scientific Reports 2015, 5, srep10417.

[30] C. Leroux, G. Nihoul, G. Van Tendeloo, Phys. Rev. B 1998, 57, 5111.

[31] M. W. Haverkort, Z. Hu, A. Tanaka, W. Reichelt, S. V. Streltsov, M. A. Korotin, V. I. Anisimov, H. H. Hsieh, H.-J. Lin, C. T. Chen, D. I. Khomskii, L. H. Tjeng, Phys. Rev. Lett. 2005, 95, 196404.

[32] T. C. Koethe, Z. Hu, M. W. Haverkort, C. Schüßler-Langeheine, F. Venturini, N. B. Brookes, O. Tjernberg, W. Reichelt, H. H. Hsieh, H.-J. Lin, C. T. Chen, L. H. Tjeng, Phys. Rev. Lett. 2006, 97, 116402.

[33] F. M. F. de Groot, M. Grioni, J. C. Fuggle, J. Ghijsen, G. A. Sawatzky, H. Petersen, Phys. Rev. B 1989, 40, 5715.

[34] M. Abbate, F. M. F. de Groot, J. C. Fuggle, Y. J. Ma, C. T. Chen, F. Sette, A. Fujimori, Y. Ueda, K. Kosuge, Phys. Rev. B 1991, 43, 7263.

[35] N. F. Quackenbush, J. W. Tashman, J. A. Mundy, S. Sallis, H. Paik, R. Misra, J. A. Moyer, J.-H. Guo, D. A. Fischer, J. C. Woicik, D. A. Muller, D. G. Schlom, L. F. J. Piper, Nano Lett. 2013, 13, 4857.

[36] M. Guizar-Sicairos, J. R. Fienup, Opt. Express, OE 2007, 15, 17592.

[37] D. Zhu, M. Guizar-Sicairos, B. Wu, A. Scherz, Y. Acremann, T. Tyliszczak, P. Fischer, N. Friedenberger, K. Ollefs, M. Farle, J. R. Fienup, J. Stöhr, Phys. Rev. Lett. 2010, 105, 043901.

[38] L. Vidas, C. M. Günther, T. A. Miller, B. Pfau, M. Schneider, E. Guehrs, R. E. Marvel, K. A. Hallman, R. F. Haglund Jr, S. Eisebitt, S. Wall, Nano Letters 2018, 18, 3449.

[39] T. Sasaki, F. Kooli, M. lida, Y. Michiue, S. Takenouchi, Y. Yajima, F. Izumi, B. C. Chakoumakos, M. Watanabe, Chem. Mater. 1998, 10, 4123. 
Tailoring Vanadium Dioxide Film Orientation using Nanosheets: A Combined Microscopy, Diffraction, Transport and Soft X-ray in Transmission Study

[40] J. L. Fourquet, A. Le Bail, P. A. Gillet, Materials Research Bulletin 1988, 23, 1163.

[41] H. Yuan, D. Dubbink, R. Besselink, J. E. ten Elshof, Angew. Chem. Int. Ed. 2015, 54, 9239.

[42] D. Nečas, P. Klapetek, Cent. Eur. J. Phys. 2012, 10, 181

[43] H. Popescu, J. Perron, B. Pilette, R. Vacheresse, V. Pinty, R. Gaudemer, M. Sacchi, R. Delaunay, F. Fortuna, K. Medjoubi, K. Desjardins, J. Luning and N. Jaouen, J. Synchrotron Radiat. 2019 26, 280. 


\section{Appendix}
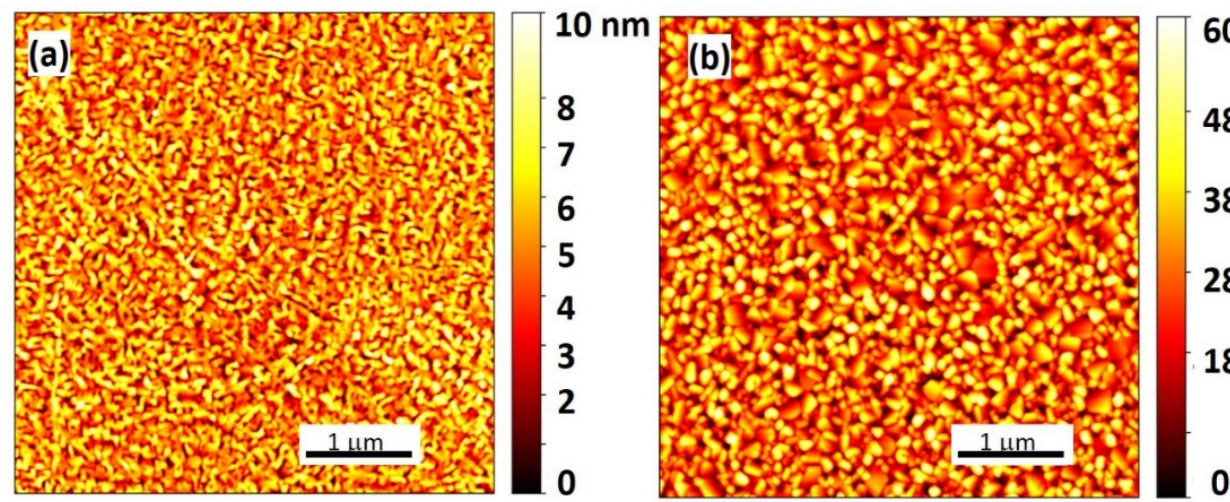

$60 \mathrm{~nm}$

48

38

28

18

Figure A1. AFM micrographs $\mathrm{VO}_{2}$ films on nanosheets. (a) $\mathrm{VO}_{2}$ on $\mathrm{TO}$ nanosheets and (b) $\mathrm{VO}_{2}$ on NWO nanosheets. In each case, the relevant z-scale is shown.

Figure A1 shows the difference in morphology as observed by AFM of $\mathrm{VO}_{2}$ thin films grown on two types of nanosheets. In particular, there is a difference in domain size, where the growth domains have a roughly 2-3 smaller size when $\mathrm{VO}_{2}$ is grown on $\mathrm{TO}$ compared to NWO. The films grown on NWO have a larger peak-to-peak roughness. This difference presumably is a result of the difference in growth kinetics on either type of nanosheet. Note that the individual nanosheets are non-discernable in these images. 


\section{Chapter 3. Tuning the Metal Insulator Transition of Vanadium Dioxide on Oxide Nanosheets}

For practical applications, tuning the metal insulator transition (MIT) behavior of high-quality vanadium dioxide $\left(\mathrm{VO}_{2}\right)$ on arbitrary substrates, such as $\mathrm{Si}$ and glass, is desirable. This chapter demonstrates the ability to tune the MIT temperature $\left(\mathrm{T}_{\mathrm{MIT}}\right)$ of $\mathrm{VO}_{2}$ films by growing them on $\mathrm{NbWO}_{6}$ (NWO) nanosheets on arbitrary substrates and varying the film thickness. The oxidation and crystal structure of $\mathrm{VO}_{2}$ films are determined by X-ray photoelectron spectroscopy and temperature-dependent $\mathrm{X}$-ray diffraction, respectively. It is observed that as the film thickness increases, the $T_{\text {MIT }}$ also increases to the bulk value, $341 \mathrm{~K}$, because of the increase in the rutile caxis of $\mathrm{VO}_{2}$. The strain effect accompanying with the film thickness variation on NWO nanosheets contribute to the shortening of the rutile $C_{R}$ axis in thin films and hence the lowering of $\mathrm{T}_{\mathrm{MIT}}$ of $\mathrm{VO}_{2}$. Furthermore, the arbitrary underlying substrates have negligible influence on the MIT behavior of $\mathrm{VO}_{2}$ on NWO nanosheets. These results open up the possibility to tune the MIT of $\mathrm{VO}_{2}$ films with the free choice of substrates. 


\section{Introduction}

Vanadium dioxide $\left(\mathrm{VO}_{2}\right)$ shows a sharp and reversible metal-insulator transition (MIT) near room temperature, $341 \mathrm{~K}$ in bulk $\mathrm{VO}_{2}$, which is accompanied by a structural transformation from a tetragonal rutile $(R)$ phase $\left(\mathrm{P} 4_{2} / \mathrm{mnm}\right)$ to a monoclinic (M1) phase $\left(\mathrm{P} 2_{1} / \mathrm{C}\right) .^{[1,2]}$ The distinct changes in the electrical and optical properties across the MIT enable many promising applications, such as next-generation transistors ${ }^{[3]}$, memory metamaterials ${ }^{[4]}$, sensors ${ }^{[5]}$, smart windows ${ }^{[6]}$ and optical switching devices ${ }^{[7]}$. However, the ability of tuning the $\mathrm{VO}_{2}$ MIT temperature ( $\left.T_{M I T}\right)$ is necessary for successful application. Indeed, many methods have been utilized to tune the $\mathrm{T}_{\mathrm{MIT}}$ of $\mathrm{VO}_{2}$, such as doping ${ }^{[8,9]}$, oxygen vacancies ${ }^{[10]}$, hydrogenation ${ }^{[11,12]}$ and strain effect $^{[13-21]}$.

The strain effect in $\mathrm{VO}_{2}$ epitaxial films has been an effective approach to tune the $T_{\text {MIT. }}$ It is worth noting that the strain effect results from the elastic strain due to lattice mismatch and the residual thermal strain upon cooling due to the difference in thermal coefficients between the substrate and the film. Many reports on the growth of $\mathrm{VO}_{2}$ films on single crystal substrates showed a strain-dependent $\mathrm{T}_{\text {MIT }}$ accompanying with the film thickness variation. ${ }^{[13-}$ 17,19-21] For example, Muraoka et al. reported that the $\mathrm{T}_{\mathrm{MIT}}$ of $\mathrm{VO}_{2}$ film could be decreased to room temperature on the single crystal rutile $\mathrm{TiO}_{2}(001)_{\mathrm{R}}$ substrate. ${ }^{[13]}$ When the $\mathrm{VO}_{2}$ film thickness increases beyond a critical thickness of $15 \mathrm{~nm}$, the strained $\mathrm{VO}_{2}$ film is partially or fully relaxed, which leads to the increase of its rutile $c$-axis, $C_{R}$, and hence $T_{M I T}{ }^{[14,18]}$ Furthermore, Aetukuri et al. demonstrated that an effective way to vary the strain effect in the fixed thickness film $\mathrm{VO}_{2}$ on $\mathrm{TiO}_{2}(001)_{\mathrm{R}}$ substrates was to vary the thickness of the $\mathrm{RuO}_{2}$ buffer layer, leading to a $\mathrm{T}_{\mathrm{MIT}}$ in the range 285 to 345 K. ${ }^{[16]}$

In Chapter 2, it has been shown that $\mathrm{VO}_{2}$ films with high structural and orientational quality can be epitaxially grown on oxide nanosheets on 
Tuning the Metal Insulator Transition of Vanadium Dioxide on Oxide Nanosheets

arbitrary underlying substrates. Tuning the $\mathrm{VO}_{2} \mathrm{~T}_{\text {MIT }}$ on such substrates is necessary for practical applications. However, it has been unknown whether the strain effect accompanying with the film thickness variation of $\mathrm{VO}_{2}$ films can be induced on NWO nanosheets. Likewise, the influence of underlying substrates on the physical properties of $\mathrm{VO}_{2} / \mathrm{NWO}$ nanosheets has remained unknown. Therefore, in this presented research, the $\mathrm{VO}_{2} / \mathrm{NbWO}_{6}(\mathrm{NWO})$ nanosheet/substrates was comprehensively investigated. A monolayer of NWO nanosheets was deposited on $\mathrm{SiO}_{2} / \mathrm{Si}(111)$ substrates and other substrates such as single crystal $\mathrm{SrTiO}_{3}(001)$, ultralow expansion (ULE) glass and $200 \mathrm{~nm} \mathrm{Si}_{3} \mathrm{~N}_{4} / \mathrm{Si}$. With pulsed laser deposition (PLD), single out-ofplane oriented $\mathrm{VO}_{2}$ films were grown epitaxially on NWO nanosheets with a thickness ranging from 20 to $90 \mathrm{~nm}$ at $520^{\circ} \mathrm{C}$ unless otherwise stated. In situ $\mathrm{X}$-ray photoelectron spectroscopy (XPS) was used to determine the oxidation of the $\mathrm{V}$ atom, whereas the crystal structure of $\mathrm{VO}_{2}$ films was determined by $X$-ray diffraction (XRD). When the film thickness of $\mathrm{VO}_{2}$ increased, the $\mathrm{T}_{\mathrm{MIT}}$ increased toward the bulk value because of the increase of the distance $\mathrm{V}-\mathrm{V}$ atoms in the $C_{R}$ axis direction. The strain effect accompanying with the film thickness variation on NWO nanosheets played a role on the $\mathrm{T}_{\mathrm{MIT}}$ of $\mathrm{VO}_{2}$. Moreover, the underlying substrates had a negligible effect on the characteristics of the MIT in $\mathrm{VO}_{2}$ films on NWO nanosheets.

\section{Results and discussion}

$\mathrm{VO}_{2}$ is one of many phases in the $\mathrm{V}_{\mathrm{x}} \mathrm{O}_{\mathrm{y}}$ family, so XPS is useful to confirm the oxidation state of $\mathrm{V}$ atom in $\mathrm{VO}_{2}$ film on NWO nanosheets. The XPS data was collected in situ at room temperature from $\mathrm{VO}_{2}$ on $\mathrm{NWO}$ nanosheets grown in PLD chamber connected with XPS analyzer. Figure 1a shows a typical two peak structure of V2p, which is due to the spin-orbit splitting. ${ }^{[22]}$ The position of the $\mathrm{V} 2 \mathrm{p}_{3 / 2}$ core-level peak is $515.8 \mathrm{eV}$ with the full width at half maximum (FWHM) of $2.42 \mathrm{eV}$ and that of $\mathrm{V} 2 \mathrm{p}_{1 / 2}$ core-level peak is 523.3 $\mathrm{eV}$. These values are matched to the reported values for $\mathrm{V}^{4+}$ in $\mathrm{VO}_{2 .}{ }^{[22,23]}$ 
Regarding the crystal structure, Figure $1 \mathrm{~b}$ presents the XRD data collected at $303 \mathrm{~K}$ and $403 \mathrm{~K}$ that are below and above the $\mathrm{T}_{\mathrm{MIT}}$ of $90 \mathrm{~nm} \mathrm{VO}$ film grown on a monolayer of NWO nanosheets on a Si(111) substrate. At 303 $\mathrm{K}$, the peak at $64.86^{\circ}$ corresponded to the $(-402)_{\mathrm{M} 1} \mathrm{VO}_{2}$ reflection. Meanwhile at $403 \mathrm{~K}$, the peak shifted to $65.19^{\circ}$ corresponding to $(002)_{\mathrm{R}} \mathrm{VO}_{2}$ reflection. The epitaxial relationship between NWO nanosheets and the $\mathrm{VO}_{2}$ overlayer was discussed in chapter $2 .{ }^{[24]}$
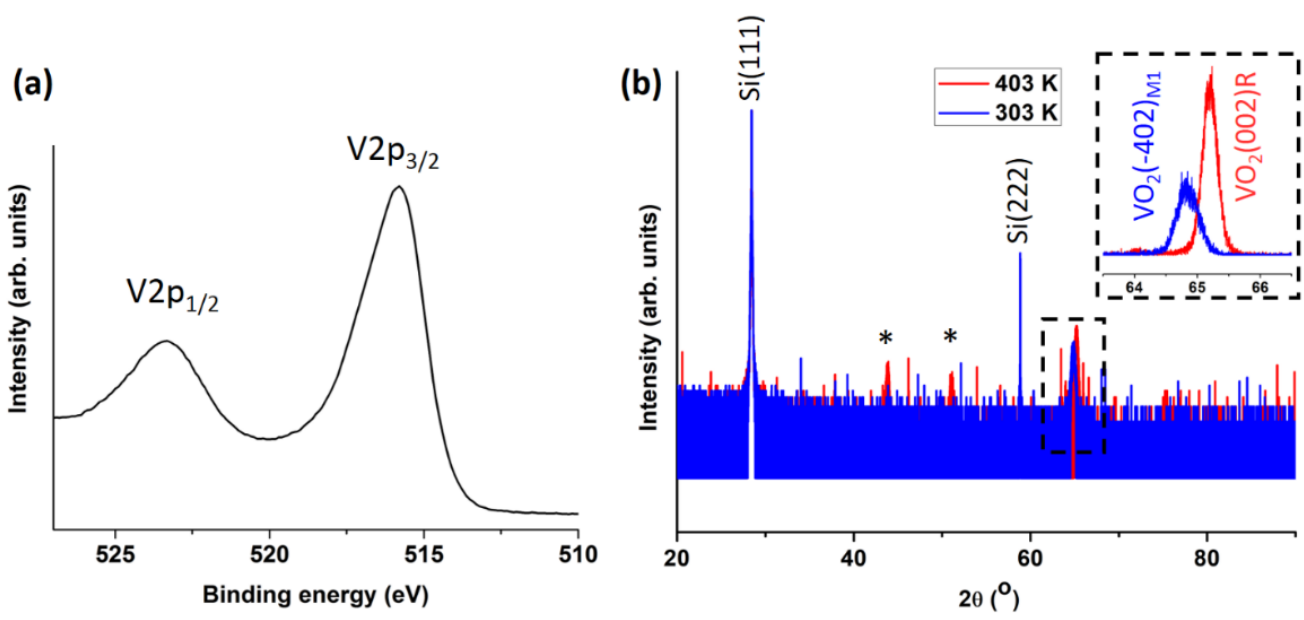

Figure 1. (a) In situ XPS data collected on the $20 \mathrm{~nm} \mathrm{VO}_{2} / \mathrm{NWO} / \mathrm{Si}(111)$ confirmed the oxidation of $\mathrm{V}^{4+}$. (b) Temperature-dependent XRD patterns of the $90 \mathrm{~nm}$ $\mathrm{VO}_{2} / \mathrm{NWO} / \mathrm{Si}(111)$ were measured at $303 \mathrm{~K}$ and $403 \mathrm{~K}$, at which $\mathrm{M} 1$ and $\mathrm{R}$ phases are stable, respectively. The two peaks labelled "*" originate from the silver paste used to glue the sample on the heater stage.

a. $\mathrm{T}_{\mathrm{MIT}}$ tuned by $\mathrm{VO}_{2}$ film thickness on NWO nanosheets

The transport properties of $\mathrm{VO}_{2}$ films were characterized by measuring the resistivity change during the MIT transition. Figure 2 shows the resistivity curve of the $90 \mathrm{~nm} \mathrm{VO}_{2} / \mathrm{NWO} / \mathrm{Si}(111)$ as a function of temperature and $\mathrm{AFM}$ data of the film surface topography. Three characteristic MIT parameters are defined as follows ${ }^{[25]}$ (see Figure $2 \mathrm{~b}$ ) : during heating of a $\mathrm{VO}_{2}$ film, (1) the $\mathrm{T}_{\mathrm{MIT}}$ is the temperature at the minimum of the derivative curve, $d[\log (\rho)] / d \mathrm{~T}$; 
Tuning the Metal Insulator Transition of Vanadium Dioxide on Oxide Nanosheets

(2) the sharpness of the MIT, $\Delta \mathrm{T}$, is characterized by the FWHM of the derivative curve; and (3) the thermal hysteresis, $\Delta \mathrm{H}$, is defined as the difference in temperature at which the derivative curves have the minimum during heating and cooling a $\mathrm{VO}_{2}$ sample. According to the literature, ${ }^{[25-28]} \Delta \mathrm{T}$ is directly proportional to the overall defect density of the $\mathrm{VO}_{2}$ film, including point defects, clusters, impurities, dislocations and grain boundaries, whereas $\Delta \mathrm{H}$ is proportional to the degree of misorientation between grain boundaries. $\mathrm{T}_{\mathrm{MIT}}, \Delta \mathrm{T}$ and $\Delta \mathrm{H}$ values of different $\mathrm{VO}_{2}$ film thicknesses were determined from the resistivity measurements (see Appendix Figure A1).

(a)

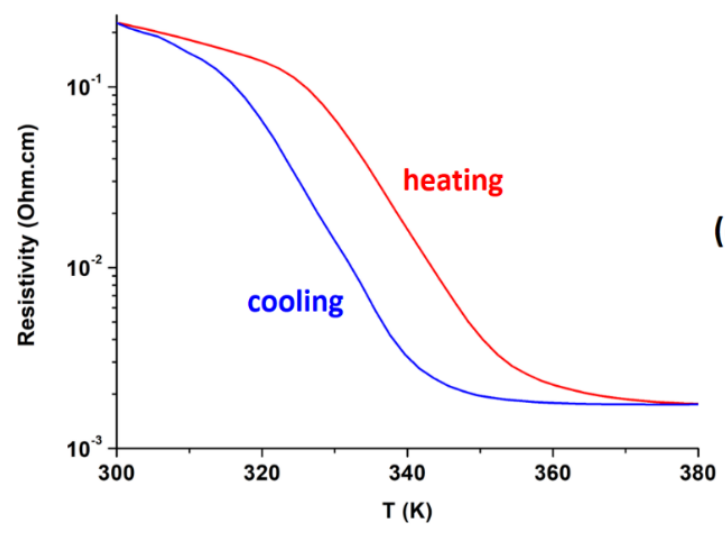

(b)

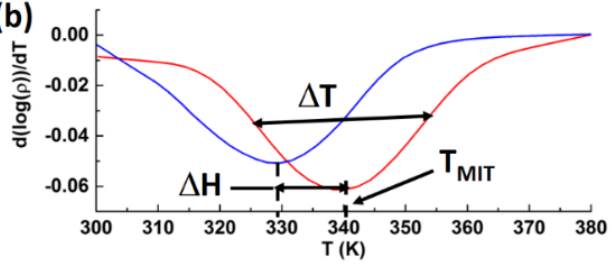

(c)

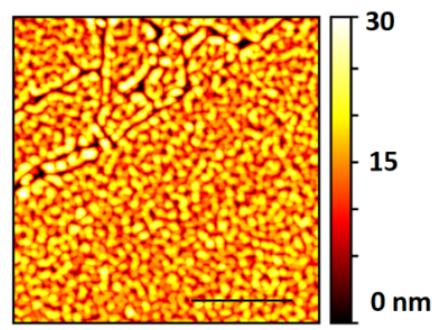

Figure 2. (a) The resistivity curve of $90 \mathrm{~nm} \mathrm{VO} / \mathrm{NWO} / \mathrm{Si}(111)$ as a function of temperature, its quantitative characteristic paramaters of the MIT (b) and its AFM data (c) with scale bar $1 \mu \mathrm{m}$.

As summarized in Table 1, $\Delta \mathrm{T}$ fluctuated around the mean values of 23.7 $( \pm 2.8) \mathrm{K}$ over the whole range of $\mathrm{VO}_{2}$ film thicknesses, hence it was independent on the film thickness of $\mathrm{VO}_{2}$ on NWO nanosheets. Moreover, the AFM data of $\mathrm{VO}_{2}$ films with different thicknesses shows that surface roughness RMS, surface morphology and grain size remained unchanged (see Appendix Figure A2). It indicated that the overall defect density remained unchanged in $\mathrm{VO}_{2}$ films on NWO nanosheets in spite of the film 
thickness. Meanwhile, $\Delta \mathrm{H}$ slightly increased with the increase of the film thickness. Although $\mathrm{VO}_{2}$ films were grown single oriented $(001)_{\mathrm{R}}$ in the outof-plane direction, their in-plane orientation ${ }^{[24]}$ was random, which leaded to a relative large $\Delta \mathrm{H}$. In addition, there were always few gaps between NWO nanosheets, where the bare substrate was exposed during $\mathrm{VO}_{2}$ deposition. As a result, randomly oriented $\mathrm{VO}_{2}$ grains on these gaps may have contributed a small degree of misorientation to the film and hence a slight increase of $\Delta \mathrm{H}$ as the film became thicker.

Table 1. The sharpness of the MIT, $\Delta T$, and the thermal hysteresis, $\Delta \mathrm{H}$, of $\mathrm{VO}_{2} / \mathrm{NWO} / \mathrm{Si}(111)$ with different film thickness. The margin of error due to the instrumental error was $\pm 0.1 \mathrm{~K}$.

\begin{tabular}{c|c|c} 
Film thickness $(\mathrm{nm})$ & $\Delta \mathrm{T}(\mathrm{K})$ & $\Delta \mathrm{H}(\mathrm{K})$ \\
\hline 20 & 25.1 & 7 \\
\hline 30 & 23.3 & 8 \\
\hline 40 & 26.4 & 7 \\
\hline 50 & 20.4 & 8.5 \\
\hline 60 & 24.1 & 8 \\
\hline 70 & 18.8 & 12 \\
\hline 80 & 23.3 & 9 \\
\hline 90 & 28.1 & 10 \\
\hline
\end{tabular}

Figure 3 shows the change of $T_{M I T}$ and the lattice constant of the $C_{R}$ axis as a function of film thickness of $\mathrm{VO}_{2} / \mathrm{NWO} / \mathrm{Si}(111)$. $\mathrm{T}_{\mathrm{MIT}}$ increased linearly with the increase of film thickness below $60 \mathrm{~nm}$, and levels off at the value of bulk $\mathrm{VO}_{2}, 341 \mathrm{~K}$, beyond $70 \mathrm{~nm}$ thickness. According to the literature, the increase 
Tuning the Metal Insulator Transition of Vanadium Dioxide on Oxide Nanosheets

of $\mathrm{T}_{\mathrm{MIT}}$ of $\mathrm{VO}_{2}$ is directly related to the increase of $\mathrm{V}-\mathrm{V}$ ion distance along the rutile $C_{R}$ axis, which influences the orbital overlap and the metallicity in the rutile phase. ${ }^{[14,16-19,21]}$ Indeed, the $\mathrm{C}_{\mathrm{R}}$ of $\mathrm{VO}_{2}$ films on NWO nanosheets followed the same trend as that of $T_{M I T}$ as the film thickness increased.

When an epitaxial film is grown on a bulk single crystal substrate, one can argue that as the film thickness increases beyond a critical limit, the elastic strain induced by a substrate is gradually relaxed in the film. In case of $\mathrm{VO}_{2}$ films on single crystal $\mathrm{TiO}_{2}(001)_{\mathrm{R}}$ substrates, fully strained films were observed below the critical thickness of $15 \mathrm{~nm}-18 \mathrm{~nm}$ with $\mathrm{T}_{\text {MIT }}$ of $290 \mathrm{~K}$, whereas above that thickness, the partially and fully relaxed $\mathrm{VO}_{2}$ films resulted in a gradual increase of $C_{R}$ and hence of $T_{M I T}$ to the bulk values of $\mathrm{VO}_{2}{ }^{[14,17,18,21]}$ In addition to the mentioned strain effect, the finite size effect on thin films is simultaneously present in oxide thin films, varying the lattice constants of the oxide thin films. The $20 \mathrm{~nm} \mathrm{VO}$ film with dominant $(110)_{\mathrm{R}}$ orientation deposited on a Si substrate under the same conditions as $\mathrm{VO}_{2}$ on NWO nanosheets showed a $\mathrm{T}_{\text {MIT }}$ of $357 \mathrm{~K}$ (see Appendix Figure A3), higher than the bulk $\mathrm{VO}_{2}$ value because it had dominant $(110)_{\mathrm{R}}$ orientation, while the finite size effect led to elongation of the $C_{R}$ in-plane. ${ }^{[29]}$ It reasonably assumes that both strain and finite size effects can affect the $\mathrm{C}_{\mathrm{R}}$ value of $\mathrm{VO}_{2}$ films grown on bulk single crystal substrates, and hence the $\mathrm{T}_{\text {MIT }}$ of $\mathrm{VO}_{2}$. 


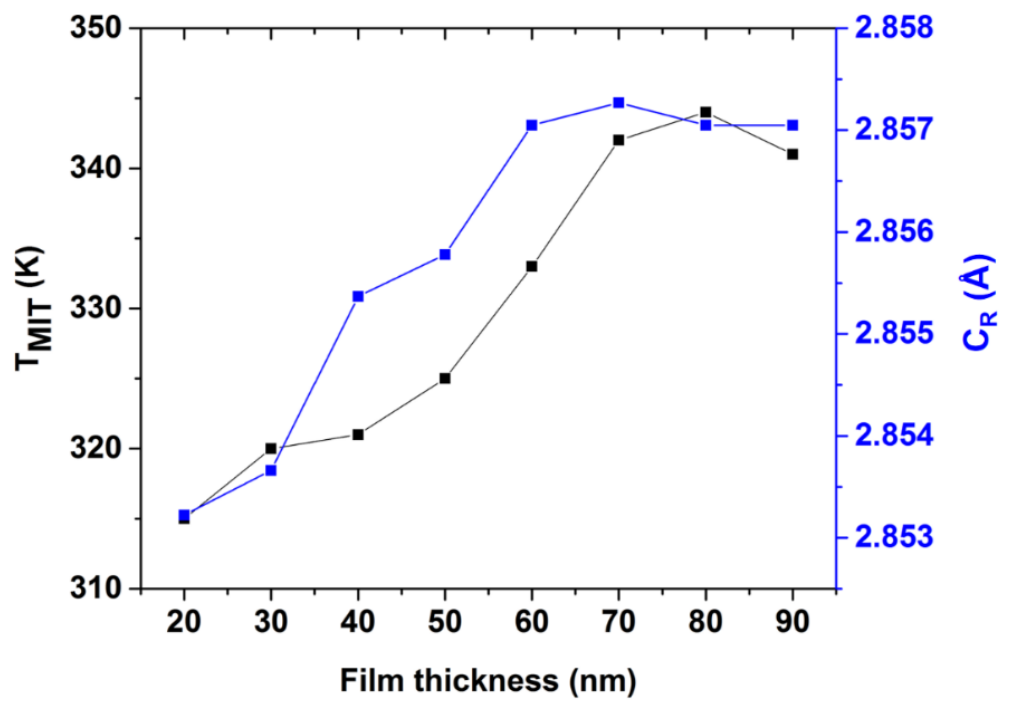

Figure 3. Plots showing the change of $T_{M I T}$ and $C_{R}$ as a function of the film thickness of $\mathrm{VO}_{2} / \mathrm{NWO} / \mathrm{Si}(111)$. $\mathrm{CR}_{\mathrm{R}}$ values were calculated from the peak position of $\mathrm{VO}_{2}(002)_{\mathrm{R}}$ films at $403 \mathrm{~K}$. Both parameters followed the same trend, linearly increasing until reach the constant value.

It must be mentioned that the finite size effect is difficult to disentangle from the effect of epitaxial strain and vice versa. It is reasonable to assume that the finite size effect still plays a role in $\mathrm{VO}_{2}$ films on $\mathrm{NWO}$ nanosheets. However, it is still unclear whether epitaxial strain is present in $\mathrm{VO}_{2}$ thin films on NWO nanosheets (or how much). In order to verify the effect of epitaxial strain, $30 \mathrm{~nm} \mathrm{VO}$ films were grown on single crystal $\mathrm{TiO}_{2}(001)_{\mathrm{R}}, 100 \mathrm{~nm}$ $\mathrm{TiO}_{2}(001)_{\mathrm{R}} / \mathrm{NWO} / \mathrm{Si}(111)$ and $\mathrm{NWO} / \mathrm{Si}(111)$ substrates at $400^{\circ} \mathrm{C}$ instead of $520^{\circ} \mathrm{C}$. The reason to choose the relatively low temperature is because it was reported that the diffusion of $\mathrm{Ti}$ atoms from $\mathrm{TiO}_{2}$ substrates into $\mathrm{VO}_{2}$ films was observed above $400^{\circ} \mathrm{C}$, forming $(\mathrm{Ti}, \mathrm{V}) \mathrm{O}_{2}$ phases. ${ }^{[30]}$ Indeed, it was observed that the appearance of the peak at $63.09^{\circ}$ (see Appendix Figure A4) probably originated from the $\mathrm{Ti}$-rich $(\mathrm{Ti}, \mathrm{V}) \mathrm{O}_{2}$ phase due to the $\mathrm{Ti}$ diffusion. Indeed, this is also our experience as the insertion of one monolayer of NWO nanosheets on single crystal $\mathrm{TiO}_{2}(001)_{\mathrm{R}}$ substrate limited 
Tuning the Metal Insulator Transition of Vanadium Dioxide on Oxide Nanosheets

the Ti diffusion as the peak at $63.09^{\circ}$ was strongly suppressed (see Appendix Figure A4).

In this series, a single out-of-plane oriented $\mathrm{TiO}_{2}(001)_{\mathrm{R}}$ film with a smooth surface was grown at $400^{\circ} \mathrm{C}$ on NWO nanosheets (see Appendix Figure A5). In Figure $4 \mathrm{a}$, it can be seen that the $\mathrm{VO}_{2}(002)$ peaks of three $\mathrm{VO}_{2}$ films grown at $400^{\circ} \mathrm{C}$ on the aforementioned substrates are at the same angle, indicating the same $c_{R}$ lattice constant. It must be noted that the peak-shape seen in Figure 4a for the three films is not the same, suggesting some inhomogeneities across the thickness of the films. In addition, in the reciprocal space map (RSM) around the off-axis $\mathrm{TiO}_{2}(112)_{\mathrm{R}}$ reflection, it was observed that the $\mathrm{VO}_{2}$ films were strained on single crystal $\mathrm{TiO}_{2}(001)_{\mathrm{R}}$ and $100 \mathrm{~nm} \mathrm{TiO}{ }_{2}(001)_{\mathrm{R}} / \mathrm{NWO} / \mathrm{Si}(111)$ substrates, and their $\mathrm{VO}_{2}(112)_{\mathrm{R}}$ reflections were at the same position, indicating the same in-plane $a_{R}$ lattice constant. The $\mathrm{VO}_{2}$ film on NWO nanosheets/Si(111) without intermediate $\mathrm{TiO}_{2}(001)_{\mathrm{R}}$ layer did not give a clear signal in the RSM. As mentioned above, epitaxial strain in oxide thin films has a pure elastic component and a component due to residual thermal strain. Because the lattice constant measured for the 100 $\mathrm{nm} \mathrm{TiO}_{2}(001)_{\mathrm{R}}$ film was the same as the value for bulk single crystal $\mathrm{TiO}_{2}(001)_{\mathrm{R}}$ (Figure 4) and obviously their thermal expansion coefficient was the same, the strain effect in $\mathrm{VO}_{2}$ films in these two samples should be the same. Meanwhile, the lattice mismatch of the bulk $\mathrm{VO}_{2}(001)_{R}\left(a_{R}=4.55 \AA\right)$ with $\mathrm{TiO}_{2}(001)_{R}\left(a_{R}=4.59 \AA\right)$ is $0.85 \%$, and with NWO nanosheets $(a=4.68$ $\AA$ ) it is $2.78 \%, \mathrm{VO}_{2}$ films would experience the in-plane tensile strain on these materials. Due to the Poisson effect in the case of $\mathrm{VO}_{2}(001)_{R}$, an in-plane tensile strain should result in an out-of-plane compressive strain that shortens the $\mathrm{C}_{\mathrm{R}}$ axis. We can safely assume that the finite size effect on $\mathrm{VO}_{2}$ lattice constants of $30 \mathrm{~nm} \mathrm{VO} 2(001)_{R}$ films on the three mentioned substrates would be similar. Then, the strain effect, causing the shortening of $C_{R}$ axis of $\mathrm{VO}_{2}(001)_{\mathrm{R}}$ films, in $\mathrm{VO}_{2}$ film on $\mathrm{NWO} / \mathrm{Si}(111)$ apparently is the same for both 
single crystal $\mathrm{TiO}_{2}(001)_{\mathrm{R}}$ as well as the $100 \mathrm{~nm} \mathrm{TiO} 2(001)_{\mathrm{R}} / \mathrm{NWO} / \mathrm{Si}(111)$ substrates given the same $c_{R}$ lattice constant.

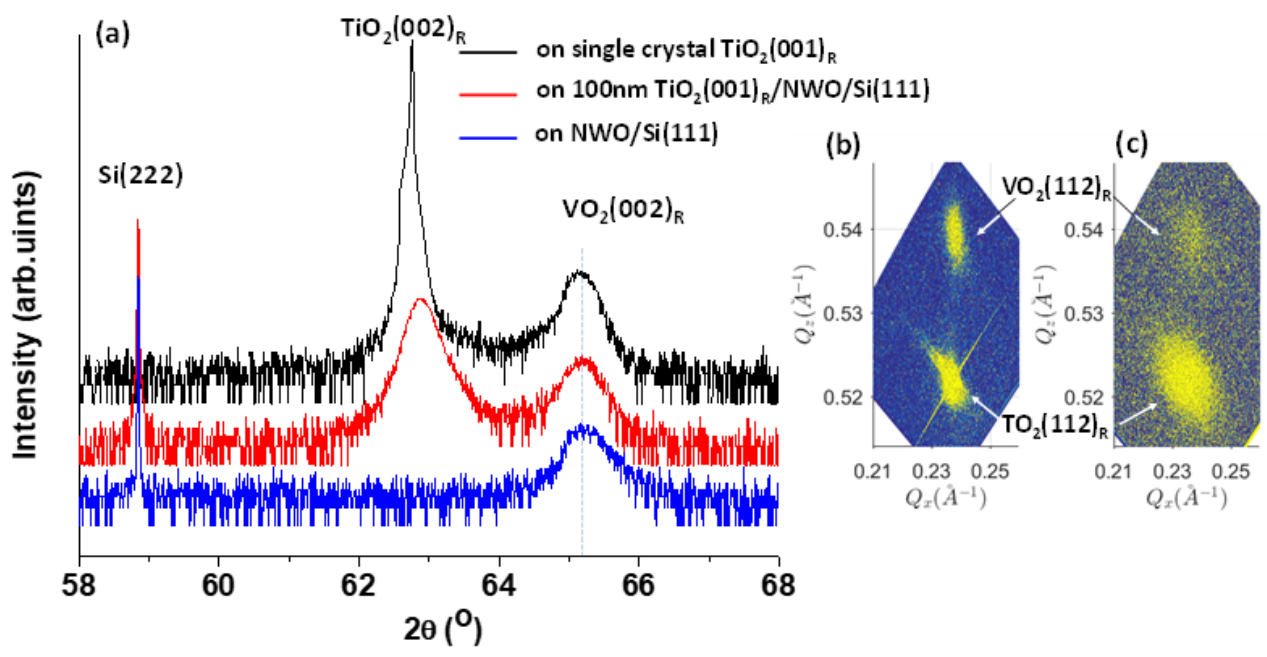

Figure 4. (a) $\mathrm{XRD}$ patterns of $30 \mathrm{~nm} \mathrm{VO}_{2}$ grown at $400^{\circ} \mathrm{C}$ on single crystal $\mathrm{TiO}_{2}(001)_{\mathrm{R}}, 100 \mathrm{~nm} \mathrm{TiO}(001)_{\mathrm{R}} / \mathrm{NWO} / \mathrm{Si}(111)$ and $\mathrm{NWO} / \mathrm{Si}(111)$ substrates. The position of $\mathrm{VO}_{2}$ peaks were the same in all $\mathrm{VO}_{2}$ films. The reciprocal space maps of $30 \mathrm{~nm} \mathrm{VO}$ films on (b) single crystal $\mathrm{TiO}_{2}(001)_{\mathrm{R}}$ and (c) $100 \mathrm{~nm}$ $\mathrm{TiO}_{2}(001)_{\mathrm{R}} / \mathrm{NWO} / \mathrm{Si}(111)$ substrates showing the in-plane reflections of $\mathrm{TiO}_{2}(112)_{\mathrm{R}}$ and $\mathrm{VO}_{2}(112)_{\mathrm{R}}$ in two samples at the similar position.

However, fully disentangling the origins of the strain effect in $\mathrm{VO}_{2}$ film on NWO nanosheets is complicated because of undetermined variables. For example, thermal coefficients of $\mathrm{NbWO}_{6}$ nanosheets and even their parent compounds, $\mathrm{LiNbWO}_{6}$ and $\mathrm{HNbWO}_{6} \cdot \mathrm{xH}_{2} \mathrm{O}$, are unknown. Generally, nanosheets are generally used for flexible devices because of their own flexibility, ${ }^{[11,32]}$ but their Young and shear moduli so far remain unknown. Thus, the relationship between lattice mismatch and elastic strain of NWO nanosheets and $\mathrm{VO}_{2}$ film in particular has been also unclear. For instance, it remains the question whether lattice constants of both NWO nanosheets and $\mathrm{VO}_{2}$ film simultaneously will change to minimize the elastic energy or if there 
Tuning the Metal Insulator Transition of Vanadium Dioxide on Oxide Nanosheets

are other possibilities. Further study is necessary to clarify the strain effect between oxide nanosheets and deposited oxide thin films.

b. Influence of underlying substrates on $\mathrm{VO}_{2} / \mathrm{NWO}$ nanosheets

To the best of our knowledge, after oxide nanosheets were subsequently deposited on substrates at room temperature and then processed at high temperature, i.e. $520^{\circ} \mathrm{C}$, prior to PLD deposition of the $\mathrm{VO}_{2}$ film, the type of interaction or bond between nanosheets and substrates still remains unknown. The difference in thermal expansion coefficients between $\mathrm{VO}_{2}$ /NWO nanosheets and underlying substrates may have caused a residual thermal strain upon cooling down from deposited temperature, probably affecting the $\mathrm{T}_{\text {MIT }}$ of the overlaid $\mathrm{VO}_{2}$ films. Figure 5 shows $\mathrm{T}_{\text {MIT }}$ of $20 \mathrm{~nm} \mathrm{VO} / \mathrm{NWO}$ nanosheets on various substrates as a function of thermal expansion coefficient. The $T_{\text {MIT }}$ remained almost unchanged even though the change of the thermal expansion coefficient varies over three orders of magnitude. Moreover, the surface morphology, $\Delta \mathrm{T}$ and $\Delta \mathrm{H}$ of these $\mathrm{VO}_{2}$ films were similar (see Appendix Figure A2 and Figure A6). Thus, the influence of underlying substrates on the MIT behavior of $\mathrm{VO}_{2}$ on NWO nanosheets was negligible.

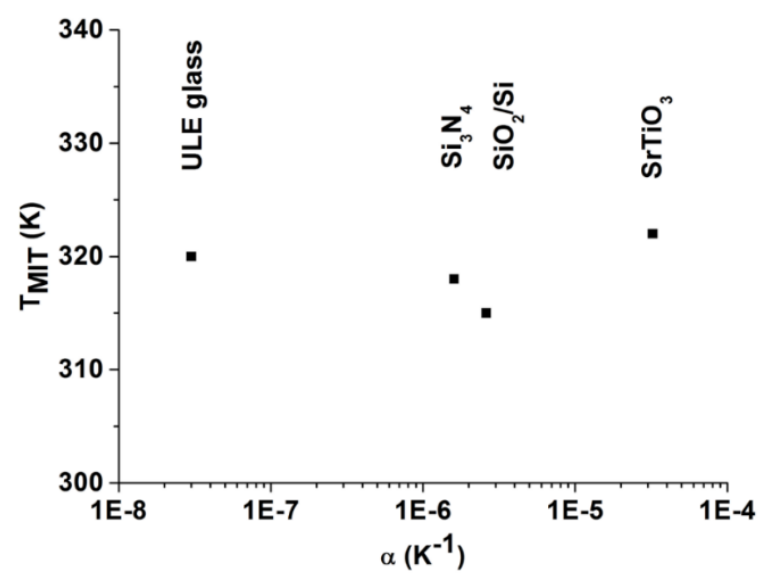

Figure 5. $\mathrm{T}_{\text {MIT }}$ of $20 \mathrm{~nm} \mathrm{VO} / \mathrm{NWO}$ on 4 different substrates is almost constant in the wide range of thermal expansion coefficient. 


\section{Conclusions}

This chapter has shown the ability to tune the MIT behavior of $\mathrm{VO}_{2}$ on NWO nanosheets and the influence of the underlying substrates. The existence of $\mathrm{V}^{4+}$ oxidation state was confirmed as well as the phase transformation between low temperature $\mathrm{M} 1$ monoclinic and high temperature $\mathrm{R}$ rutile phases in $\mathrm{VO}_{2} / \mathrm{NWO}$ nanosheets. It was observed that the sharpness of $\mathrm{VO}_{2}$ MIT, $\Delta \mathrm{T}$, remained constant and the thermal hysteresis, $\Delta \mathrm{H}$, slightly increased as the $\mathrm{VO}_{2}$ film became thicker on NWO nanosheets. Meanwhile, the $\mathrm{T}_{\mathrm{MIT}}$ of $\mathrm{VO}_{2}$ films decreased when the film thickness was reduced because of the shortening of the $c_{R}$ axis. The strain effect accompanying with the thickness variation on NWO nanosheets contributed to the shortening of the $C_{R}$ axis. Lastly, the underlying substrates had negligible influence on the MIT behavior of $\mathrm{VO}_{2} / \mathrm{NWO}$ nanosheets. These results demonstrate that tuning $\mathrm{VO}_{2}$ properties on NWO nanosheets is feasible for practical applications with the free choice of engineering substrates.

\section{Experimental section}

\section{Preparation of NWO nanosheet films}

Lithium carbonate $\mathrm{Li}_{2} \mathrm{CO}_{3}$ (Riedel-de Haen), niobium (V) oxide $\mathrm{Nb}_{2} \mathrm{O}_{5}$ (Alfa Aesar), and tungsten ( $\mathrm{VI}$ ) oxide $\mathrm{WO}_{3}$ (Alfa Aesar) had a purity of $99.0 \%$ or higher and were used as received. Nitric acid $\mathrm{HNO}_{3}(65 \%$, ACROS Organics) and tetra-n-butylammonium hydroxide $\mathrm{TBAOH}\left(40 \%\right.$ wt. $\mathrm{H}_{2} \mathrm{O}$, Alfa Aesar) were used as received. Demineralized water was used throughout the experiments.

$\mathrm{LiNbWO}_{6}$ and $\mathrm{HNbWO}_{6} \cdot \mathrm{xH}_{2} \mathrm{O}$ were synthesized as described in chapter 2. NWO nanosheet solution was obtained by exfoliating $\mathrm{HNbWO}_{6} \cdot \mathrm{xH}_{2} \mathrm{O}$ powder with TBAOH. Full-coverage NWO nanosheet films were deposited on various substrates using the Langmuir-Blodgett method.

Pulsed laser deposition of $\mathrm{VO}_{2}$ thin films 
Tuning the Metal Insulator Transition of Vanadium Dioxide on Oxide Nanosheets

PLD was carried out in a vacuum system equipped with a KrF excimer laser, with a wavelength of $248 \mathrm{~nm}$ (COMPexPro from Coherent Inc.). The central part of the laser beam was selected with a mask and focused on a polycrystalline $\mathrm{V}_{2} \mathrm{O}_{5}$ target. The deposition conditions of the $\mathrm{VO}_{2}$ films were: laser repetition rate $4 \mathrm{~Hz}$, energy density $1.3 \mathrm{~J} \mathrm{~cm}^{-2}$, spot size $1.8 \mathrm{~mm}^{2}$, oxygen pressure $0.01 \mathrm{mbar}$, deposition temperature $520^{\circ} \mathrm{C}$ and $400^{\circ} \mathrm{C}$, and substrate-target distance $50 \mathrm{~mm}$. The growth rate of $\mathrm{VO}_{2}$ was $1 \mathrm{~nm}$ per 300 pulses at $520^{\circ} \mathrm{C}$ and $1 \mathrm{~nm}$ per 200 pulses at $400^{\circ} \mathrm{C}$ (see Appendix Figure A7). The film thickness was controlled by varying the number of pulses in the deposition. The deposition conditions of rutile $\mathrm{TiO}_{2}$ films were: laser repetition rate $2 \mathrm{~Hz}$, energy density $1.0 \mathrm{~J} \mathrm{~cm}^{-2}$, spot size $1.8 \mathrm{~mm}^{2}$, oxygen pressure 0.02 mbar, deposition temperature $400^{\circ} \mathrm{C}$, and substrate-target distance 50 $\mathrm{mm}$. The growth rate of $\mathrm{TiO}_{2}$ was $1 \mathrm{~nm}$ per 151 pulses (see Appendix Figure A7). After deposition, the samples were cooled down to room temperature at a maximum rate of $10^{\circ} \mathrm{C} \mathrm{min}{ }^{-1}$ at the deposition pressure. The single crystal $\mathrm{TiO}_{2}(001)_{\mathrm{R}}$ substrates from CrysTec $\mathrm{GmbH}$ were used.

Analysis and characterization

The morphology of the $\mathrm{VO}_{2}$ films were investigated using atomic force microscopy (AFM, Bruker Dimension ICON) operating in tapping mode and the data were processed using Gwyddion software ${ }^{[33]}$. In situ XPS was performed with an Omicron XM-1000 monochromated Al-K $\alpha$ source. The temperature-dependent crystal structure of $\mathrm{VO}_{2}$ thin films was analyzed using X-ray diffraction (XRD, PANalytical X'Pert Pro MRD) equipped with an Anton Paar DHS 1100 Domed Hot Stage and the Inc. beam Monochr. $4 \times G e 220 \mathrm{Cu}$ asym. LF monochromator was used at the incident X-ray beam

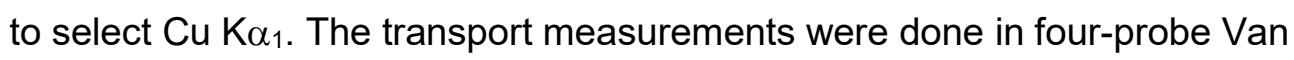
der Pauw configuration using a Quantum Design Physical Properties Measurement System. High resolution scanning electron microscopy (HRSEM) were performed on a Merlin field emission microscope (Zeiss 1550). 


\section{References}

[1] F. J. Morin, Phys. Rev. Lett. 1959, 3, 34.

[2] J. B. Goodenough, J. Solid State Chem. 1971, 3, 490.

[3] M. Nakano, K. Shibuya, D. Okuyama, T. Hatano, S. Ono, M. Kawasaki, Y. Iwasa, Y. Tokura, Nature 2012, 487, 459.

[4] T. Driscoll, H.-T. Kim, B.-G. Chae, B.-J. Kim, Y.-W. Lee, N. M. Jokerst, S. Palit, D. R. Smith, M. D. Ventra, D. N. Basov, Science 2009, 325, 1518.

[5] E. Strelcov, Y. Lilach, A. Kolmakov, Nano Lett. 2009, 9, 2322.

[6] Y. Cui, Y. Ke, C. Liu, Z. Chen, N. Wang, L. Zhang, Y. Zhou, S. Wang, Y. Gao, Y. Long, Joule 2018, 2, 1707.

[7] W. J. M. Kort-Kamp, S. Kramadhati, A. K. Azad, M. T. Reiten, D. A. R. Dalvit, ACS Photonics 2018, 5, 4554.

[8] J. M. Booth, P. S. Casey, Phys. Rev. Lett. 2009, 103.

[9] K. L. Holman, T. M. McQueen, A. J. Williams, T. Klimczuk, P. W. Stephens, H. W. Zandbergen, Q. Xu, F. Ronning, R. J. Cava, Phys. Rev. B 2009, 79, 245114.

[10] J. Jeong, N. Aetukuri, T. Graf, T. D. Schladt, M. G. Samant, S. S. P. Parkin, Science 2013, 339, 1402.

[11] C. Wu, F. Feng, J. Feng, J. Dai, L. Peng, J. Zhao, J. Yang, C. Si, Z. Wu, Y. Xie, J. Am. Chem. Soc. 2011, 133, 13798.

[12] J. Wei, H. Ji, W. Guo, A. H. Nevidomskyy, D. Natelson, Nat. Nanotechnol. 2012, 7, 357.

[13] Y. Muraoka, Z. Hiroi, Appl. Phys. Lett. 2002, 80, 583.

[14] K. Nagashima, T. Yanagida, H. Tanaka, T. Kawai, Phys. Rev. B 2006, 74, 172106.

[15] J. Cao, E. Ertekin, V. Srinivasan, W. Fan, S. Huang, H. Zheng, J. W. L. Yim, D. R. Khanal, D. F. Ogletree, J. C. Grossman, J. Wu, Nat. Nanotechnol. 2009, 4, 732.

[16] N. B. Aetukuri, A. X. Gray, M. Drouard, M. Cossale, L. Gao, A. H. Reid, R. Kukreja, H. Ohldag, C. A. Jenkins, E. Arenholz, K. P. Roche, H. A. Dürr, M. G. Samant, S. S. P. Parkin, Nat. Phys. 2013, $9,661$.

[17] L. L. Fan, S. Chen, Z. L. Luo, Q. H. Liu, Y. F. Wu, L. Song, D. X. Ji, P. Wang, W. S. Chu, C. Gao, C. W. Zou, Z. Y. Wu, Nano Lett. 2014, 14, 4036.

[18] B. Zhi, G. Gao, X. Tan, P. Chen, L. Wang, S. Jin, W. Wu, Mater. Res. Express 2014, 1, 046402.

[19] J. Jian, X. Wang, L. Li, M. Fan, W. Zhang, J. Huang, Z. Qi, H. Wang, ACS Appl. Mater. Interfaces 2017, 9, 5319.

[20] E. Breckenfeld, H. Kim, K. Burgess, N. Charipar, S.-F. Cheng, R. Stroud, A. Piqué, ACS Appl. Mater. Interfaces 2017, 9, 1577.

[21] Y. Yang, X. Mao, Y. Yao, H. Huang, Y. Lu, L. Luo, X. Zhang, G. Yin, T. Yang, X. Gao, J. Appl. Phys. 2018, 125, 082508. 
Tuning the Metal Insulator Transition of Vanadium Dioxide on Oxide Nanosheets

[22] G. Silversmit, D. Depla, H. Poelman, G. B. Marin, R. De Gryse, J. Electron Spectrosc. Relat. Phenom. 2004, 135, 167.

[23] E. Hryha, E. Rutqvist, L. Nyborg, Surf. Interface Anal. 2012, 44, 1022.

[24] P. T. P. Le, K. Hofhuis, A. Rana, M. Huijben, H. Hilgenkamp, G. A. J. H. M. Rijnders, J. E. ten Elshof, G. Koster, N. Gauquelin, G. Lumbeeck, C. Schüßler-Langeheine, H. Popescu, F. Fortuna, S. Smit, X. H. Verbeek, G. Araizi-Kanoutas, S. Mishra, I. Vaskivskyi, H. A. Dürr, M. S. Golden, Adv. Funct. Mater. 2020, 30, 1900028.

[25] J. Narayan, V. M. Bhosle, J. Appl. Phys. 2006, 100, 103524.

[26] D. Brassard, S. Fourmaux, M. Jean-Jacques, J. C. Kieffer, M. A. El Khakani, Appl. Phys. Lett. 2005, 87, 051910.

[27] J. Y. Suh, R. Lopez, L. C. Feldman, R. F. Haglund, J. Appl. Phys. 2004, 96, 1209.

[28] P. Jin, K. Yoshimura, S. Tanemura, J. Vac. Sci. Technol. A 1997, 15, 1113.

[29] J. Jian, A. Chen, W. Zhang, H. Wang, J. Appl. Phys. 2013, 114, 244301.

[30] C. N. Mihailescu, E. Symeou, E. Svoukis, R. F. Negrea, C. Ghica, V. Teodorescu, L. C. Tanase, C. Negrila, J. Giapintzakis, ACS Appl. Mater. Interfaces 2018, 10, 14132.

[31] Z. Lin, Y. Huang, X. Duan, Nat. Electron. 2019, 2, 378.

[32] B. Mendoza-Sánchez, Y. Gogotsi, Adv. Mater. 2016, 28, 6104.

[33] D. Nečas, P. Klapetek, Cent. Eur. J. Phys. 2012, 10, 181. 


\section{Appendix}

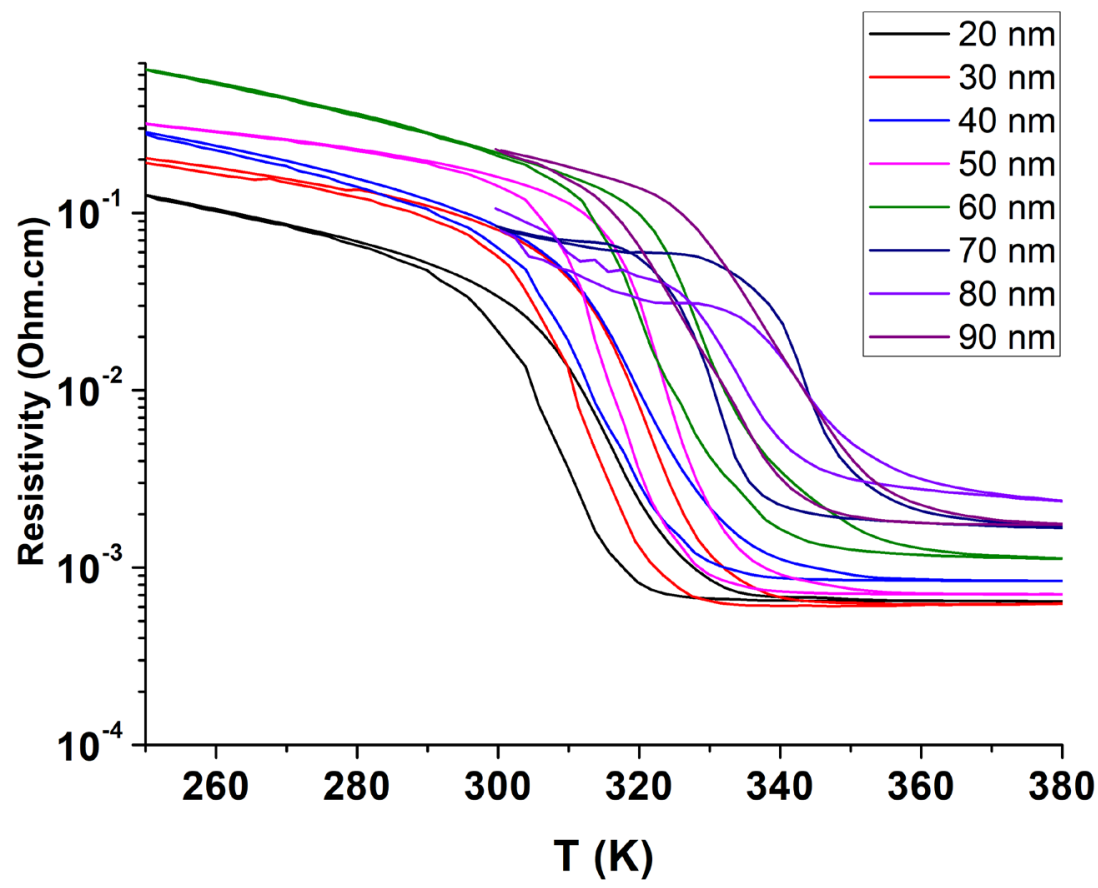

Figure A1. Resistivity curves of different film thicknesses of $\mathrm{VO}_{2} / \mathrm{NWO} / \mathrm{Si}(111)$ grown at $520^{\circ} \mathrm{C}$.

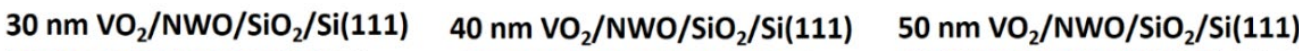
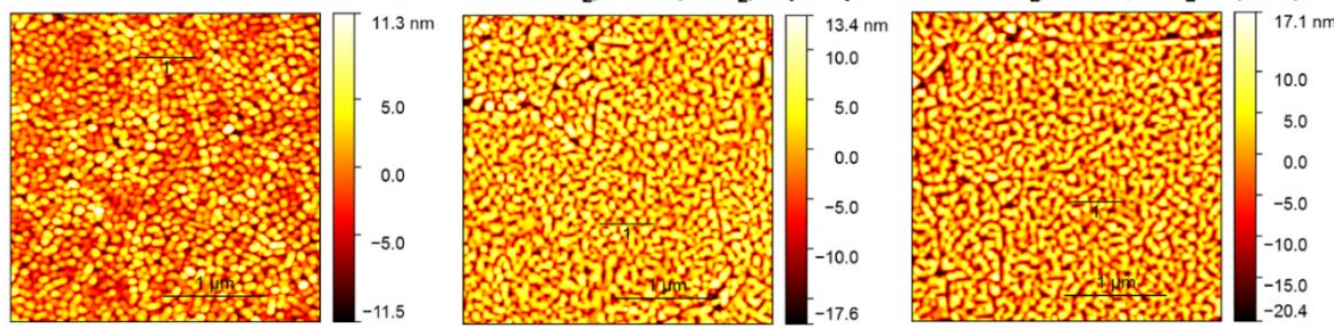

$60 \mathrm{~nm} \mathrm{VO} / / \mathrm{NWO} / \mathrm{SiO}_{2} / \mathrm{Si}(111)$

$70 \mathrm{~nm} \mathrm{VO} / \mathrm{NWO}_{2} / \mathrm{SiO}_{2} / \mathrm{Si}(111)$

$80 \mathrm{~nm} \mathrm{VO} / \mathrm{NWO}_{2} \mathrm{SiO}_{2} / \mathrm{Si}(111)$
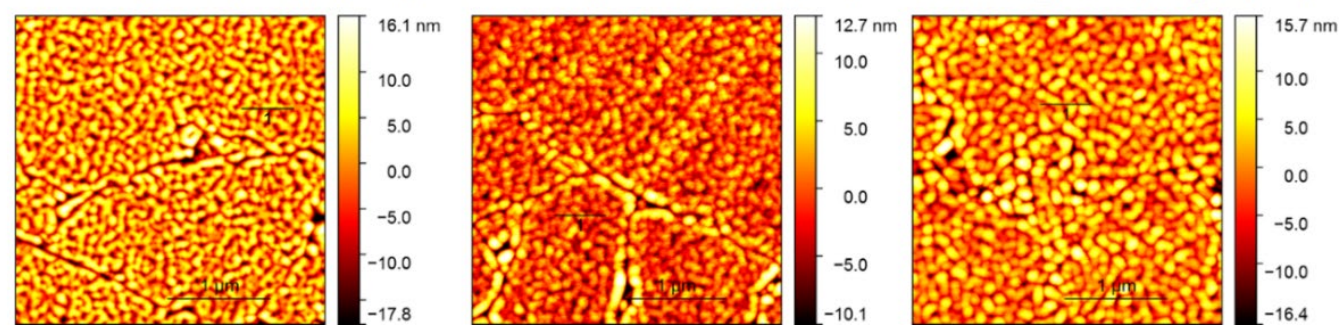
Tuning the Metal Insulator Transition of Vanadium Dioxide on Oxide Nanosheets

$20 \mathrm{~nm} \mathrm{VO} / \mathrm{NWO}_{2} \mathrm{SiO}_{2} / \mathrm{Si}(111) \quad 20 \mathrm{~nm} \mathrm{VO} / \mathrm{NWO} /$ ULE glass

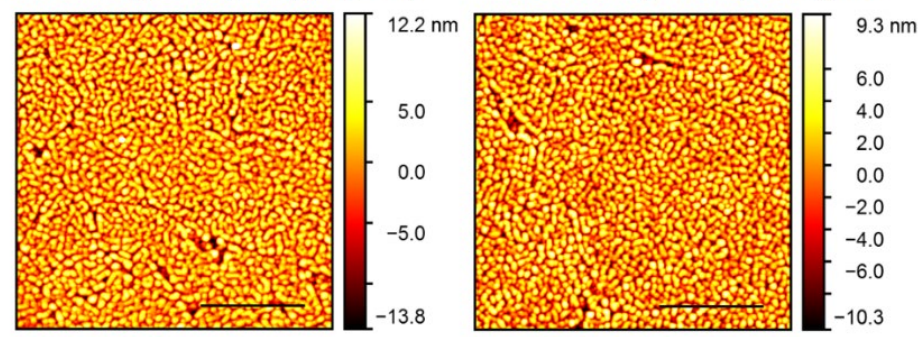

$20 \mathrm{~nm} \mathrm{VO} / \mathrm{NWO} / \mathrm{STO}(001) \quad 20 \mathrm{~nm} \mathrm{VO}_{2} / \mathrm{NWO} / 200 \mathrm{~nm} \mathrm{Si}_{3} \mathrm{~N}_{4} / \mathrm{Si}$

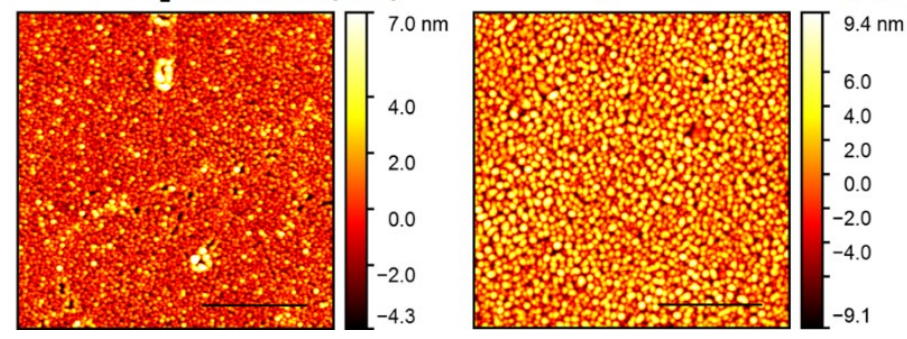

Figure A2. AFM data of PLD VO 2 films with scale bar $1 \mu \mathrm{m}$.

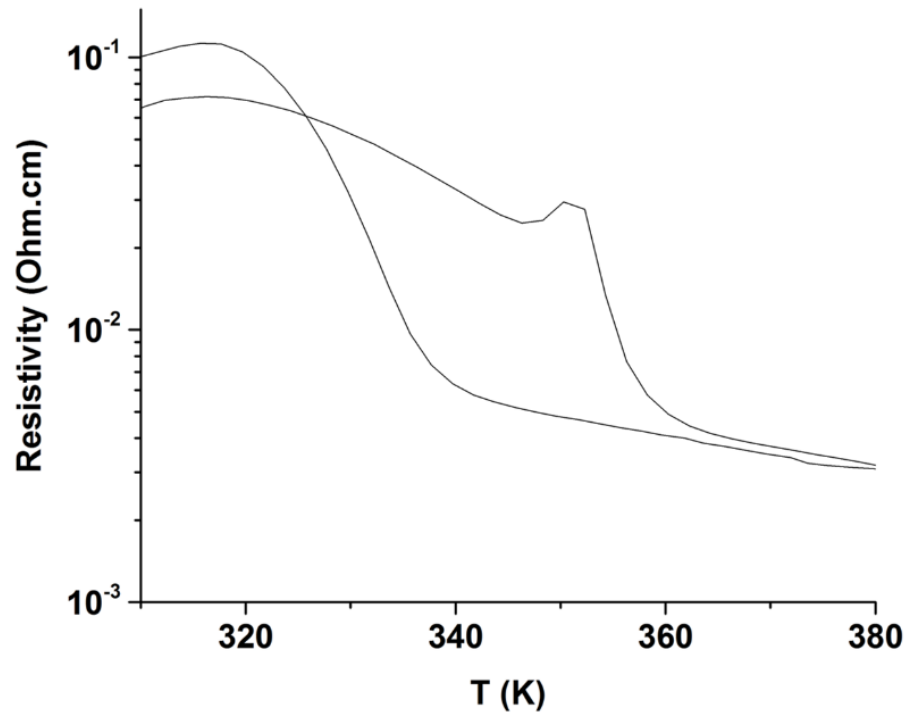

Figure A3. Resistivity curve of $20 \mathrm{~nm} \mathrm{VO} / \mathrm{SiO}_{2} / \mathrm{Si}(111)$. 


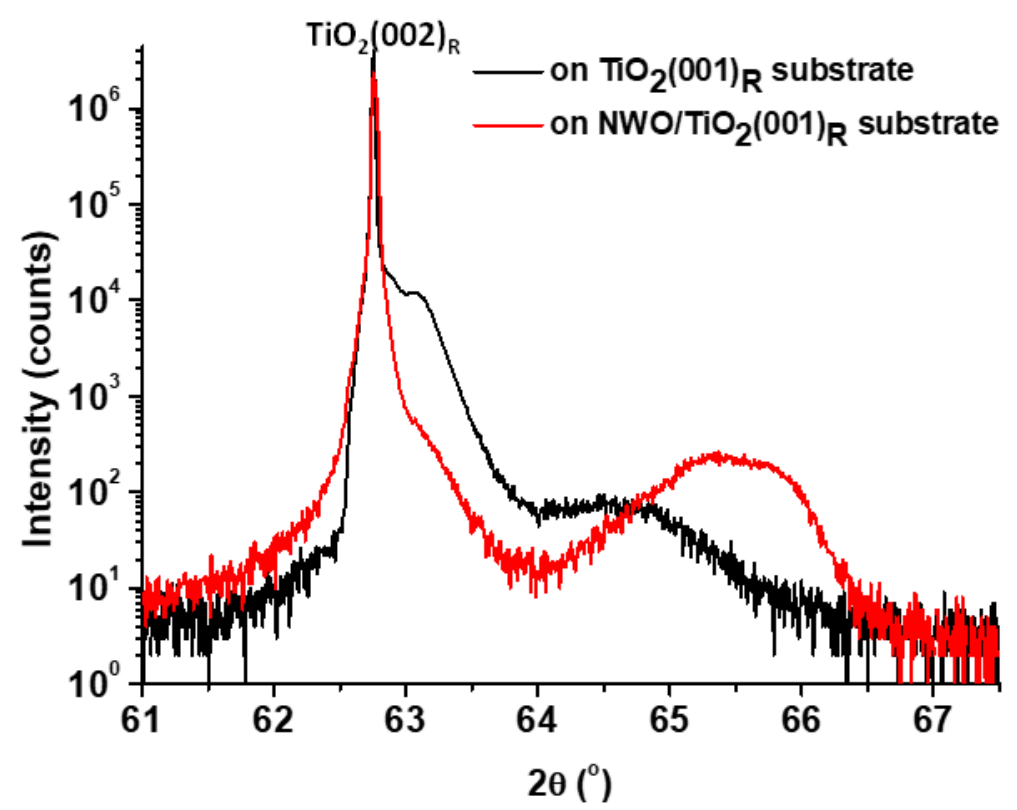

Figure A4. XRD pattern recorded at $403 \mathrm{~K}$ of $20 \mathrm{~nm} \mathrm{VO}{ }_{2}$ grown at $520^{\circ} \mathrm{C}$ on single crystal $\mathrm{TiO}_{2}(001)_{\mathrm{R}}$ substrate and one monolayer of NWO nanosheets on single crystal $\mathrm{TiO}_{2}(001)_{\mathrm{R}}$ substrate. The peak at $63.09^{\circ}$ was originated from the Ti-rich $(\mathrm{Ti}, \mathrm{V}) \mathrm{O}_{2}$ phase. The broadening of the peak at $64.75^{\circ}$ from $\mathrm{VO}_{2}$ film on single crystal $\mathrm{TiO}_{2}(001)$ substrate resulted from the $(\mathrm{Ti}, \mathrm{V}) \mathrm{O}_{2}$ phases. The insertion of one monolayer of NWO nanosheets suppressed the Ti diffusion, resulting in the strongly reduction of the $63.09^{\circ}$ peak intensity. The suppression was not $100 \%$ because the average coverage of one monolayer of NWO nanosheets was only $95-97 \%$. The large broadening of the peak at $65.54^{\circ}$ from $\mathrm{VO}_{2}$ film on $\mathrm{NWO} / \mathrm{TiO}_{2}(001)_{\mathrm{R}}$ resulted from $\mathrm{VO}_{2}$ on NWO nanosheets and $(\mathrm{Ti}, \mathrm{V}) \mathrm{O}_{2}$ phases on bare $\mathrm{TiO}_{2}(001)_{\mathrm{R}}$ substrate, where the Ti diffusion occurred. 
Tuning the Metal Insulator Transition of Vanadium Dioxide on Oxide Nanosheets

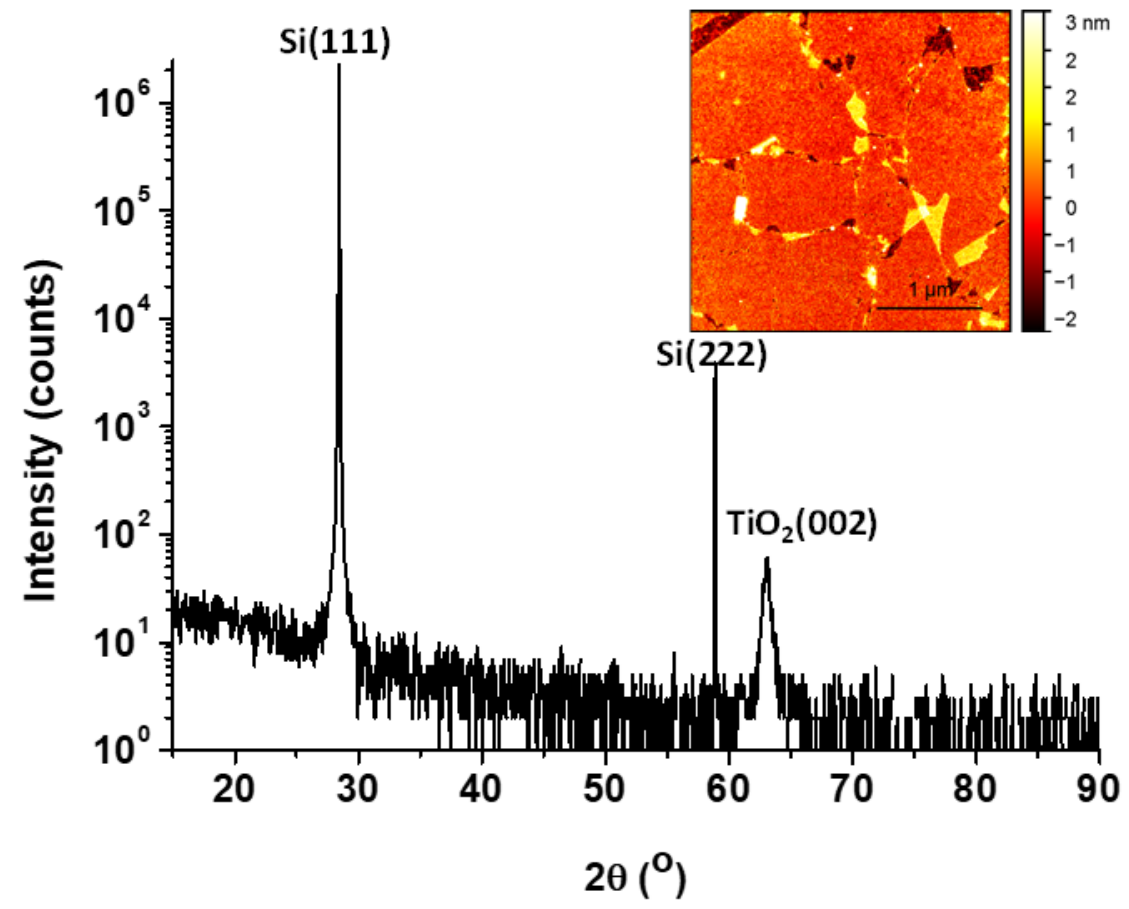

Figure A5. XRD pattern of $\mathrm{TiO}_{2}$ grown at $400^{\circ} \mathrm{C}$ on NWO/Si(111). The growth of the rutile $\mathrm{TiO}_{2}$ film was directed in single out-of-plane $(001)_{\mathrm{R}}$ orientation. The inset shows the surface morphology of $\mathrm{TiO}_{2}(001) \mathrm{R}$ film on $\mathrm{NWO} / \mathrm{Si}(111)$.

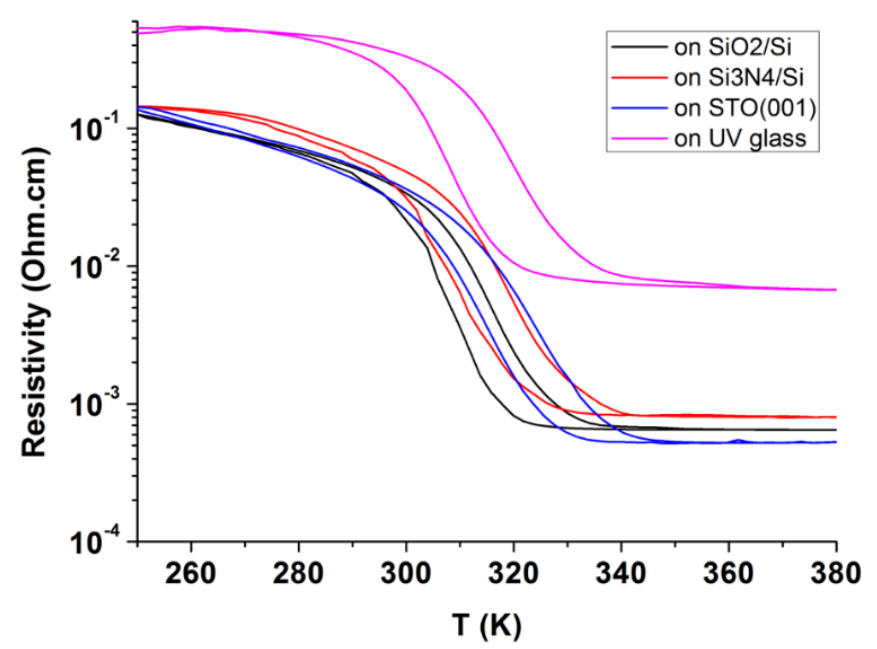

Figure A6. Resistivity curves of $20 \mathrm{~nm} \mathrm{VO}_{2} / \mathrm{NWO}$ on various substrates. 

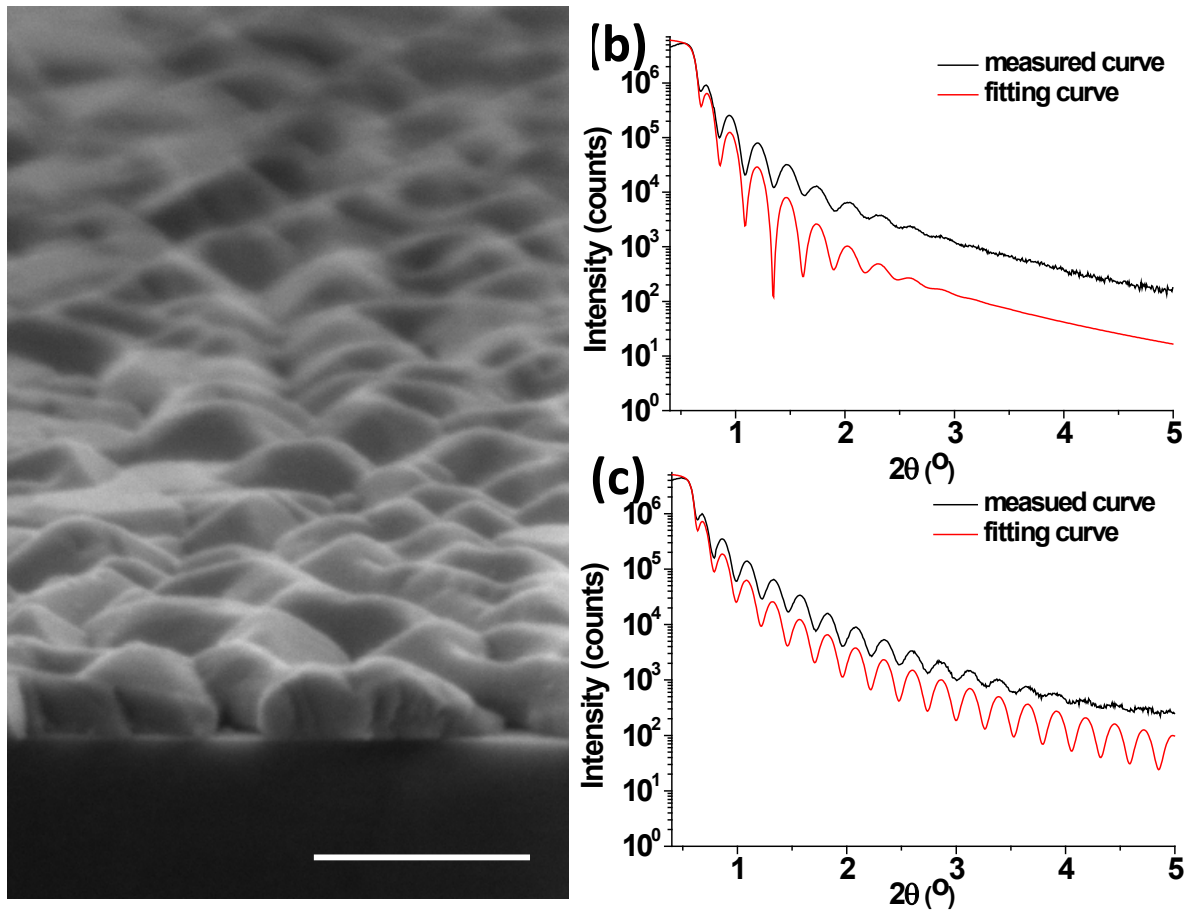

Figure A7. Film thicknesses of $\mathrm{VO}_{2}$ and $\mathrm{TiO}_{2}$ on $\mathrm{NWO} / \mathrm{Si}(111)$. (a) As can be seen in the cross-section HR-SEM image, 15000 pulses of $\mathrm{VO}_{2}$ at $520^{\circ} \mathrm{C}$ resulted in the film thickness of $50 \mathrm{~nm}$. The measured and fitting X-ray reflectivity curves of (b) 6000 pulses $\mathrm{VO}_{2}$ and (c) 5000 pulses $\mathrm{TiO}_{2}$ films, which were grown at $400^{\circ} \mathrm{C}$, showed the thicknesses of $30 \mathrm{~nm}$ and $33 \mathrm{~nm}$, respectively. 


\section{Chapter 4. Shape Control of $\mathrm{Ca}_{2} \mathrm{Nb}_{3} \mathrm{O}_{10}$ Nanosheets to Improve their In-plane Orientation}

Although oxide nanosheets can be used to direct the thin film growth of transition metal oxides in a single out-of-plane orientation, the in-plane orientation of individual nanosheets within a nanosheet-based film is totally random. This chapter shows the ability to improve the in-plane orientation of $\mathrm{Ca}_{2} \mathrm{Nb}_{3} \mathrm{O}_{10}$ nanosheets, and hence of $\mathrm{SrRuO}_{3}$ films grown on them, by controlling their external shape. The parent layered perovskite $\mathrm{KCa}_{2} \mathrm{Nb}_{3} \mathrm{O}_{10}$ particles were formed in square-like platelets thanks to the anisotropic growth in the molten $\mathrm{K}_{2} \mathrm{SO}_{4}$ salt, as opposed to the formation of irregular platelets in a solid state reaction. The exfoliation of $\mathrm{HCa}_{2} \mathrm{Nb}_{3} \mathrm{O}_{10}$, which is the protonated form of $\mathrm{KCa}_{2} \mathrm{Nb}_{3} \mathrm{O}_{10}$, was optimized to retain the square-like shape of $\mathrm{Ca}_{2} \mathrm{Nb}_{3} \mathrm{O}_{10}$ nanosheets. Electron backscattering diffraction confirmed the improved in-plane orientation among square-like $\mathrm{Ca}_{2} \mathrm{Nb}_{3} \mathrm{O}_{10}$ nanosheets with the formation of larger $\mathrm{SrRuO}_{3}$ domains. As a result, $\mathrm{SrRuO}_{3}$ films showed the lower resistivity and higher residual resistivity ratio, $\rho_{300 \kappa} / \rho_{2 \mathrm{~K}}$, on squarelike $\mathrm{Ca}_{2} \mathrm{Nb}_{3} \mathrm{O}_{10}$ nanosheets than on irregularly shaped nanosheets of similar lateral nanosheet size.

*This chapter is based on the published article: "Shape Control of Ca2Nb3O10 Nanosheets: Paving the Way for Monolithic Integration of Functional Oxides with CMOS." ACS Appl. Nano Mater. 2020. 


\section{Introduction}

Single crystal transition metal oxide (TMO) thin films have shown a wide range of physical phenomena, such as multiferroicity, magnetism, metalinsulator transitions and so on. ${ }^{[1,2]}$ The integration of these thin films on $\mathrm{Si}$ could provide new features for practical applications. ${ }^{[3]}$ The introduction of buffer layers, such as yttria-stabilized zirconia, YSZ(001) and strontium titanate, $\mathrm{STO}(001)$, on $\mathrm{Si}(001)$ substrates by physical vapor deposition has stimulated the epitaxial growth of perovskite TMOs. ${ }^{[4,5]}$ Nevertheless, the restriction on lattice constants, crystal symmetry and the native amorphous $\mathrm{SiO}_{2}$ on $\mathrm{Si}$ have limited the number of buffer layers for other TMOs.

Oxide nanosheets have drawn a considerable deal of attention as buffer layers to free the restriction between $\mathrm{Si}$ or amorphous substrates and TMOs. ${ }^{[6]}$ Langmuir-Blodgett (LB) deposition can be employed to easily assemble a monolayer of oxide nanosheets on any desired substrate at room temperature. Oxide nanosheets have lattice constants in a wide large range of sizes, as well as various 2-dimensional (2D) lattice symmetries, ${ }^{[7]}$ that can promote the epitaxial growth of TMOs because individual nanosheets can be considered as micron-sized single crystal substrates. For example, using the layered perovskite $\mathrm{Ca}_{2} \mathrm{Nb}_{3} \mathrm{O}_{10}(\mathrm{CNO})$ nanosheets, it was possible to direct the growth of $\mathrm{LaNiO}_{3}$ and $\mathrm{Pb}(\mathrm{Zr}, \mathrm{Ti}) \mathrm{O}_{3}$ films in one preferred out-of-plane (001) orientation on glass. ${ }^{[8]}$ Rutile $\mathrm{VO}_{2}$ and wurtzite $\mathrm{ZnO}$ thin films were successfully grown on $\mathrm{NbWO}_{6}$ and $\mathrm{MnO}_{2}$ nanosheets, respectively, with a single out-of-plane orientations. ${ }^{[9,10]}$ Particularly, three primary out-of-plane orientations (001), (011) and (111) of STO were realized on $\mathrm{CNO}, \mathrm{Ti}_{0.87} \mathrm{O}_{2}$ and $\mathrm{MoO}_{2}$ nanosheets on glass substrates, respectively, thanks to the lattice matching between the oriented STO films and the oxide nanosheets. ${ }^{[11]}$ The single out-of-plane oriented TMOs on oxide nanosheets showed clear improvements in their physical properties. The $\mathrm{PbZr}_{0.52} \mathrm{Ti}_{0.48} \mathrm{O}_{3}(001)$ film on buffered CNO nanosheets showed the best piezoelectric coefficient of 490 
Shape Control of $\mathrm{Ca}_{2} \mathrm{Nb}_{3} \mathrm{O}_{10}$ Nanosheets to Improve their In-plane Orientation

$\mathrm{pm} / \mathrm{V}$ among piezoelectric films. ${ }^{[12]}$ Moreover, the $\mathrm{SrRuO}_{3}(\mathrm{SRO})(001)_{\mathrm{pc}}$ film on CNO nanosheets achieved an out-of-plane saturated moment of 1.1 $\mu_{\mathrm{B}} / \mathrm{Ru}$, comparable to that of $1.25 \mu_{\mathrm{B}} / \mathrm{Ru}$ on a single crystal STO(001) substrate. ${ }^{[13]}$ Although such TMO films can be grown in a single out-of-plane orientation on oxide nanosheets, their in-plane orientation is totally random because of the in-plane random orientation of oxide nanosheets on arbitrary substrates. This may lead to a degradation of electrical transport properties of TMO thin films due to the scattering of electrons at the grain boundaries with different crystal planes.

To address the latter issue, the shape of layered perovskite-derived CNO nanosheets was controlled to accomplish self-alignment leading to in-plane orientation when deposited on a substrate. The parent compound $\mathrm{KCa}_{2} \mathrm{Nb}_{3} \mathrm{O}_{10}$ (KCNO) particles formed square-like platelets in the molten $\mathrm{K}_{2} \mathrm{SO}_{4}$ salt, whereas they formed irregularly shaped platelets in solid state reaction. The square-like shape of CNO nanosheets, inherent from their parent compound, could be retained during the exfoliation. Monolayers of CNO nanosheets with both square-like and irregular shape were deposited on Si by LB method. Utilizing pulsed laser deposition (PLD), SRO/STO films were deposited to determine the in-plane orientation of CNO nanosheets. Electron backscattering diffraction (EBSD) showed SRO grains with the same in-plane orientation spread over many square-like CNO nanosheets, whereas they were only as large as one irregular nanosheet. The SRO film had lower resistivity and higher residual resistivity ratio, $\rho_{300 K} / \rho_{2 K}$, on the square-like CNO nanosheets than on irregularly shaped ones of similar lateral nanosheet size.

\section{Results and discussion}

The Dion-Jacobson KCNO is a layered perovskite consisting of a triple layer of infinite vertex-shared $\mathrm{NbO}_{6}$ octahedra. It crystalized in the orthorhombic unit cell ( $a=3.8802 \AA, b=7.714 \AA, c=29.508 \AA$ ) with space group $\mathrm{Cmcm} \cdot{ }^{[14]}$ 
Figure 1 shows X-ray diffraction (XRD) patterns of KCNO powders obtained from solid state reaction, denoted as ss-KCNO, and in molten $\mathrm{K}_{2} \mathrm{SO}_{4}$ salt, denoted as ms-KCNO. All peaks of the resulting KCNO powders could be assigned to the reflections of the orthorhombic crystal structure. Here, it is worth noting that ms-KCNO has a high crystal quality and a preferred orientation of KCNO particles in comparison with ss-KCNO because of the high peak intensity and relatively high intensity in the basal plane (00L) reflections. The choice of $\mathrm{K}_{2} \mathrm{SO}_{4}$ salt in the synthesis of ms-KCNO was based on the common $\mathrm{K}$ cation to $\mathrm{KCNO}$, which prevents metal-cation competition in the product compound, and its ease of removal after the synthesis.

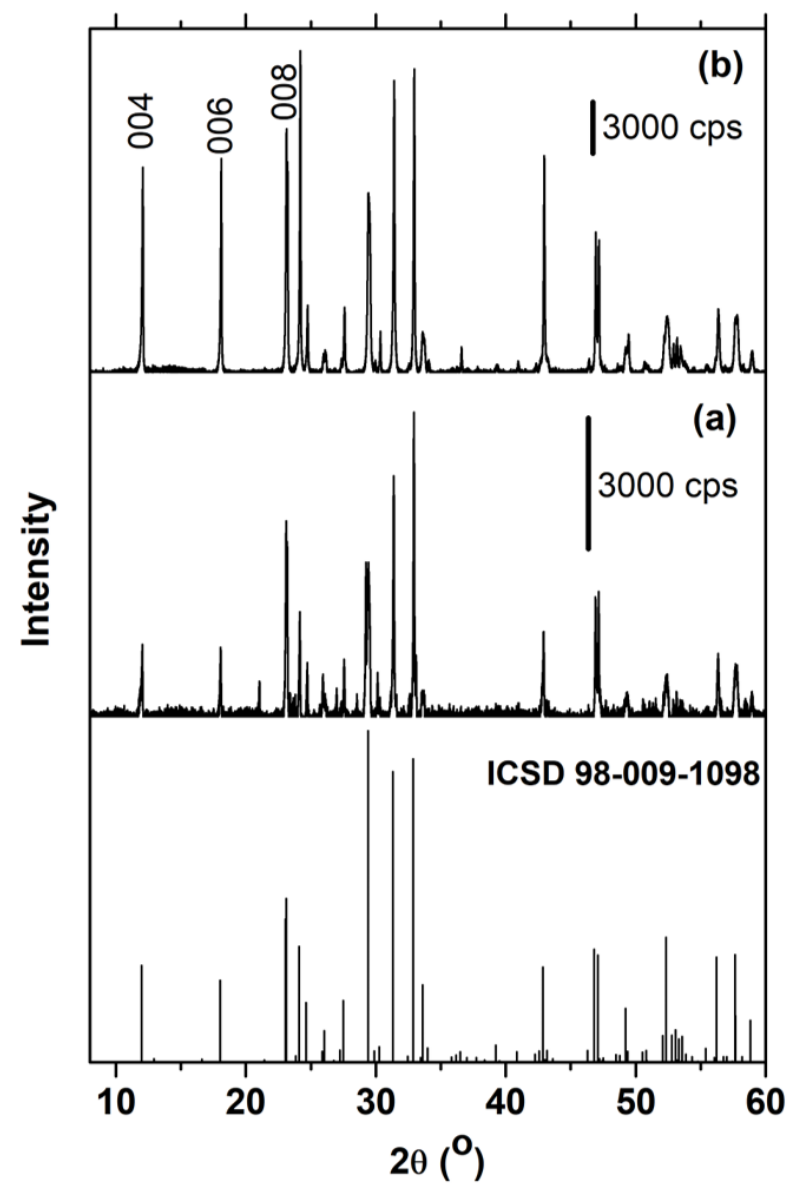

Figure 1. XRD patterns of (a) ss-KCNO and (b) ms-KCNO powders. 
Shape Control of $\mathrm{Ca}_{2} \mathrm{Nb}_{3} \mathrm{O}_{10}$ Nanosheets to Improve their In-plane Orientation

The ss-KCNO and ms-KCNO particles were investigated by scanning electron microscopy (SEM). As shown in Figure 2, ss-KCNO particles formed irregular platelets with lateral dimensions of $1-5 \mu \mathrm{m}$, whereas ms$\mathrm{KCNO}$ crystallized in square-like platelets with lateral dimensions of 1-6 $\mu \mathrm{m}$. According to the literature, ${ }^{[15,16]}$ four main processes happen during the molten salt synthesis: (i) transformation of precursors to principal oxides, (ii) dissolution of principle oxides, (iii) nucleation and (iv) growth of the desired product. In the case of ms- $\mathrm{KCNO}, \mathrm{K}_{2} \mathrm{CO}_{3}$ was transformed to $\mathrm{K}_{2} \mathrm{O}$ during the heating process. Although the solubility of $\mathrm{K}_{2} \mathrm{O}, \mathrm{CaO}$ and $\mathrm{Nb}_{2} \mathrm{O}_{5}$ precursors in the molten $\mathrm{K}_{2} \mathrm{SO}_{4}$ salt has not been reported, it was assumed that all precursor particles were completely dissolved in the molten salt because in the final product, ms-KCNO, there were only square-like platelets, which were not nucleated and grown from irregular-shaped precursor particles. Homogeneous nucleation of KCNO was most likely happened in the molten salt. The growth of $\mathrm{KCNO}$ in the molten $\mathrm{K}_{2} \mathrm{SO}_{4}$ was anisotropic with the preferential growth parallel to the basal plane of KCNO crystal structure. The anisotropic crystal growth in this fashion was also observed in other layered crystal structures. ${ }^{[17-22]}$ Interestingly, the external edges in the basal plane were perfectly straight and parallel/perpendicular to each other thanks to the thermodynamic equilibrium shape of KCNO, so the crystal $a$ and $b$ axes would be coincident with the external straight edges of ms-KCNO platelets. Although there is the slight difference between $a$ and $b / 2$ values of KCNO crystal structure due to the distortion in the crystal symmetry along $a$ and $b$ axes, in the molten $\mathrm{K}_{2} \mathrm{SO}_{4}$ salt the energy required for the growth along $a$ and $b$ axes is probably very similar and therefore resulting in the square-like platelets of ms-KCNO. In other cases, for example, the Dion-Jacobson $\mathrm{RbLaNb}_{2} \mathrm{O}_{7}$ particles, that crystalize in the orthorhombic unit cell $(a=22.329$ $\AA, b=5.6980 \AA, c=5.6950 \AA$ ) with the same space group as $\mathrm{KCNO}$, formed irregular platelets with high aspect ratio between the thickness and the lateral size even though they were grown in molten $\mathrm{RbCl}^{[22]}$ The square-like 
platelets of ms-KCNO will play a key role in the in-plane self-alignment of their exfoliated nanosheet.
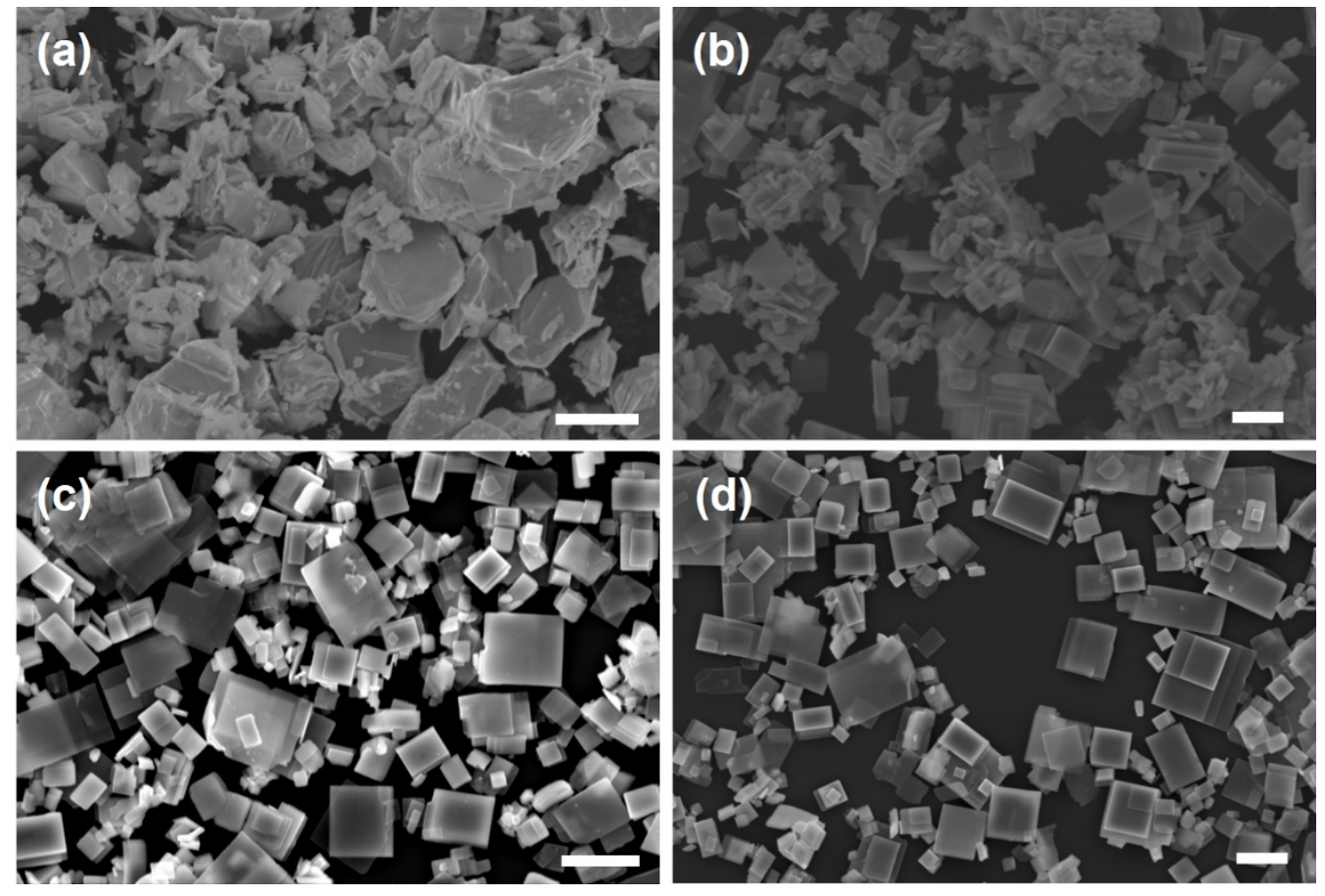

Figure 2. The shape of KCNO and HCNO particles by SEM. (a) ss-KCNO and (b) ms-KCNO powders were dropped on carbon tapes. In order to clearly observe the shape of (c) ms-KCNO and (d) ms-HCNO particles, their powders were deposited on Si substrates using the oil-water interfacial self-assembly, which was described in experimental section. The scale bar is $5 \mu \mathrm{m}$.

The protonation process is necessary for the exfoliation of KCNO into CNO nanosheets. The protonated $\mathrm{HCa}_{2} \mathrm{Nb}_{3} \mathrm{O}_{10}$ ( $\mathrm{HCNO}$ ) form of ms-KCNO, denoted as ms-HCNO, was still maintained in the square-like platelets (see Figure $2 \mathrm{~d}$ ). The protonated form of ss-KCNO is denoted as ss-HCNO. Figure 3 shows atomic force microscopy (AFM) data of CNO nanosheets deposited on Si substrates by the LB method. In Figure 3a, the CNO nanosheets had irregular shape, that are denoted as ir-CNO nanosheets, simply because they were exfoliated from the ss-HCNO powder. Generally, the CNO nanosheet solution was prepared by stirring the mixture of HCNO powder 
Shape Control of $\mathrm{Ca}_{2} \mathrm{Nb}_{3} \mathrm{O}_{10}$ Nanosheets to Improve their In-plane Orientation

and tetra-n-butylammonium hydroxide $(\mathrm{TBAOH})$ solution. Because the thickness of each CNO nanosheet is only $1.2 \mathrm{~nm}$ and fragile, they would sensitive to any mechanical force during the exfoliation process. As can be seen in Figure 3b, only a few square-like CNO nanosheets remained while most CNO nanosheets were broken into irregular shape even though the msHCNO powder was used. In order to retain the square-like shape of CNO nanosheets, the ms-HCNO powder was slowly poured into the TBAOH solution without stirring or shaking. Thanks to the rapidly easy exfoliation driven by acid-base reaction, ${ }^{[23]}$ the exfoliation could happen with minimum mechanical force, therefore the square-like $\mathrm{CNO}$ nanosheets, denoted as sqCNO nanosheets, could be mostly retained (Figure $3 \mathrm{c}$ ). It is worth noting that the lateral size of ir-CNO nanosheets is $4.3 \pm 1.5 \mu \mathrm{m}$, whereas that of sqCNO nanosheets is $4.5 \pm 0.9 \mu \mathrm{m}$. The crystal structure of $\mathrm{HCNO}$ was reported to have a tetragonal structure with the lattice constants of the layered perovskite CNO, $a=b=3.851 \AA^{.24]}$ In addition, the sq-CNO nanosheets would have the crystal $a$ and $b$ axes coincident with their external straight edges, that was inherent from ms-KCNO particles. Therefore, as long as one of the external straight edges of individual sq-CNO nanosheets aligns perpendicularly or parallel to that of other nanosheets, their in-plane crystal $a$ and $b$ axes will be self-aligned. As summarized in Table 1, the sq-CNO nanosheets formed larger domains, in which the nanosheets have the same in-plane orientation with a misalignment of $\pm 4^{\circ}$. 

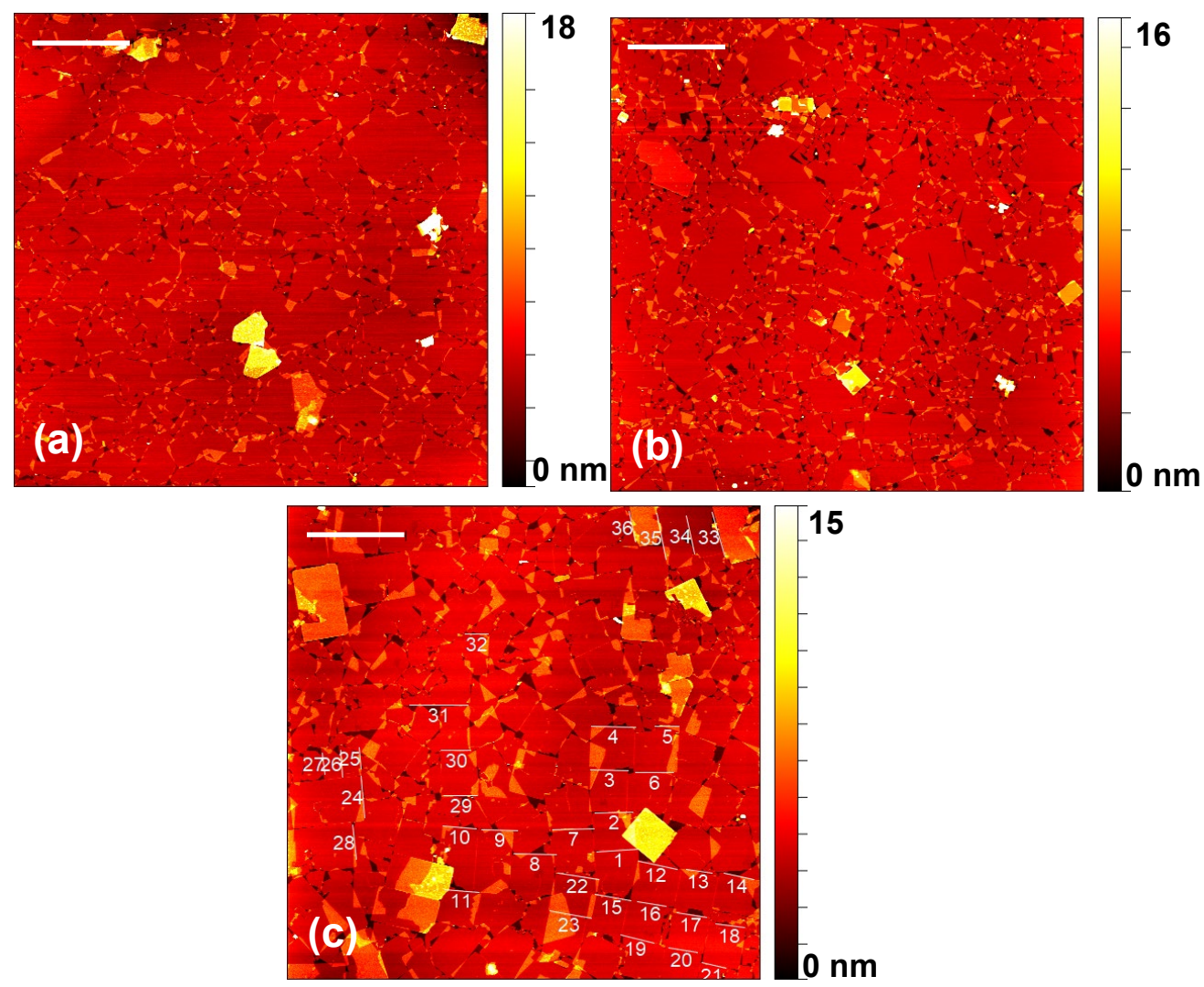

Figure 3. Morphology and shape of CNO nanosheets by AFM. (a) CNO nanosheets had irregular shape from the exfoliation from ss-HCNO. Likewise, (b) most CNO nanosheets had irregular shape, whereas only a few CNO retained square-like shape because the exfoliation of ss-HCNO was carried out while stirring. (c) Most CNO nanosheets retained the square-like shape of ss-HCNO by minimizing the mechanical force during the exfoliation. The scale bar is $10 \mu \mathrm{m}$. 
Shape Control of $\mathrm{Ca}_{2} \mathrm{Nb}_{3} \mathrm{O}_{10}$ Nanosheets to Improve their In-plane Orientation

Table 1. Continuous domains consist of sq-CNO nanosheets, which have similar $\varphi$. $\varphi$ is defined as the angle between one of the straight edges of sq-CNO nanosheets and horizontal axis of AFM image in Figure 3c.

\begin{tabular}{|c|c|c|c|c|c|}
\hline Domain 1 & $\varphi\left(^{\circ}\right)$ & Domain 2 & $\varphi\left({ }^{\circ}\right)$ & Domain 3 & $\varphi\left({ }^{\circ}\right)$ \\
\hline 1 & 3.7 & 12 & -12.1 & 24 & 84.9 \\
\hline 2 & 1.4 & 13 & -8.1 & 25 & 85 \\
\hline 3 & -1.4 & 14 & -12.3 & 26 & 86.1 \\
\hline 4 & -1.2 & 15 & -10.2 & 27 & 82.6 \\
\hline 5 & 0 & 16 & -9.2 & 28 & 83.8 \\
\hline 6 & 0 & 17 & -8.9 & Domain 4 & \\
\hline 7 & 1.3 & 18 & -7.4 & 29 & 0 \\
\hline 8 & -1.2 & 19 & -14 & 30 & 0 \\
\hline 9 & -1.5 & 20 & -9.2 & 31 & 0 \\
\hline 10 & -4.8 & 21 & -13 & 32 & 0 \\
\hline \multirow[t]{5}{*}{11} & -4.6 & 22 & -9 & Domain 5 & \\
\hline & & 23 & -10.1 & 33 & 73.7 \\
\hline & & & & 34 & 77.6 \\
\hline & & & & 35 & 78.7 \\
\hline & & & & 36 & 78 \\
\hline
\end{tabular}


SRO/STO films were deposited on CNO nanosheets in order to verify their in-plane orientation because the nanosheets are too thin for EBSD characterization. The conducting SRO layer was chosen to avoid the charging effect and provide good signal to noise ratio for the characterization. It was shown that although the direct growth of SRO on CNO nanosheets resulted in the film oriented mainly $(001)_{p c}$, where $p_{c c}$ stands for pseudocubic, in the out-of-plane direction, it had minor $(011)_{p c}$ orientation due to the relative large lattice mismatch between $\mathrm{SRO}$ and $\mathrm{CNO}$ nanosheet. ${ }^{[25]} \mathrm{A}$ buffered STO layer on CNO reduced that lattice mismatch to obtain single out-of-plane oriented SRO(001) pc. $^{[13]}$ In Figure 4, XRD patterns of SRO/STO films on ir-CNO and sq-CNO nanosheets show both films were oriented in single out-of-plane direction.

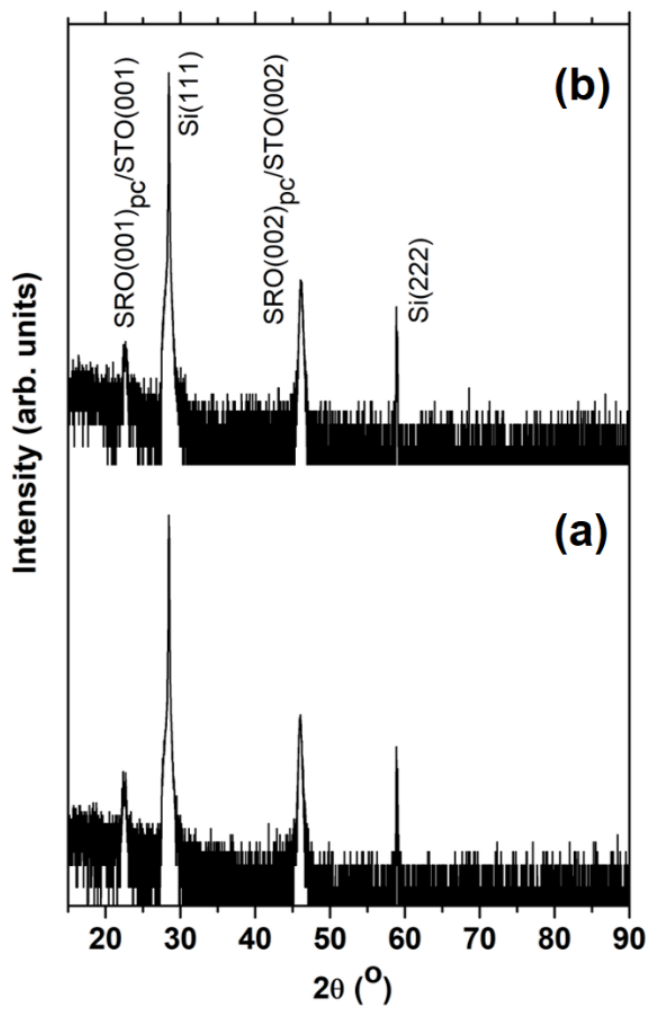

Figure 4. XRD patterns of SRO/STO grown on (a) ir-CNO and (b) sq-CNO nanosheets on $\mathrm{Si}(111)$ substrates. 
Shape Control of $\mathrm{Ca}_{2} \mathrm{Nb}_{3} \mathrm{O}_{10}$ Nanosheets to Improve their In-plane Orientation

Both the out-of-plane and in-plane orientations of SRO films at the micrometer scale were investigated by EBSD (Figure 5). The out-of-plane orientation of SRO films were consistent at both micrometer and millimeter scales, as seen by EBSD (Figure $5 a$ and $5 b$ ) and XRD, respectively. Because SRO and STO films were grown epitaxially on CNO nanosheets, the grain boundaries and the in-plane orientation of films would be the same as those of the underlying CNO nanosheets. As can be seen in Figure $5 \mathrm{c}$ and 5 e, each SRO grain was grown epitaxially on each ir-CNO nanosheet. Moreover, the in-plane orientation of SRO grains was randomly distributed. Owing to the fact that ir-CNO nanosheets have irregular shapes, the crystal $a$ and $b$ axes were not correlated to the external shape, resulting in the totally random in-plane orientation of ir-CNO nanosheets during LB deposition on the Si substrate. Meanwhile, on sq-CNO nanosheets, individual SRO grains, which have one of their straight edges of their grain boundaries pointing in the same direction in Figure $5 \mathrm{~d}$, would have the same in-plane orientation in Figure $5 \mathrm{f}$. As mentioned in the previous paragraph, this was because the external straight edges of sq-CNO nanosheets would be coincident with their crystal $a$ and $b$ axes. Furthermore, SRO grains could form a continuous domain with the same in-plane orientation because their underlying sq-CNO nanosheets had the straight edges aligned with each other continuously. For example, there was a large green area with the in-plane orientation of $\mathrm{SRO}(101)_{\mathrm{pc}}$, that consisted of more than 15 nanosheet grains. The in-plane orientation obtained by EBSD are quite consistent with the analyzed data from in Table 1. Therefore, it was demonstrated that controlling the shape of $\mathrm{CNO}$ nanosheets is able to align the in-plane orientation of CNO nanosheets and the deposited SRO films to a certain extent. The complete self-alignment of $\mathrm{CNO}$ nanosheets could not be achieved because the non-uniform sizes and any left-over broken CNO nanosheets form gaps between nanosheets, and hence the long-range self-alignment was lost. 

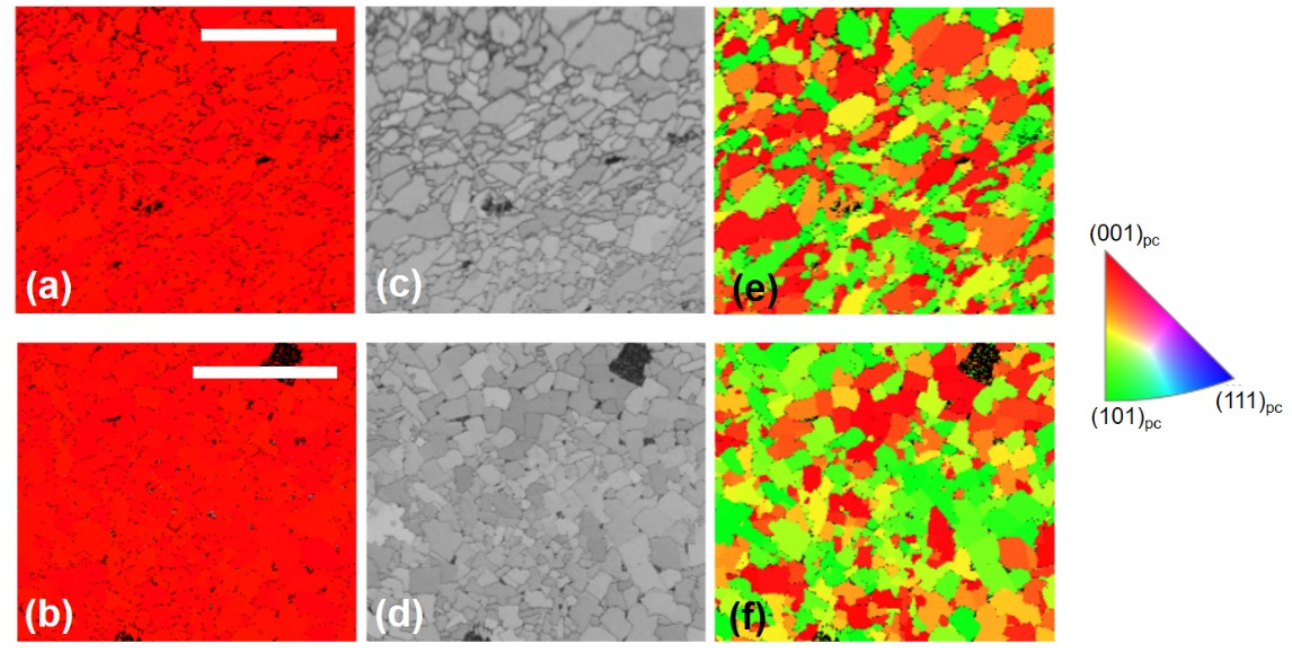

$(101)_{\mathrm{pc}}$

Figure 5. Orientation mapping of SRO grown on two types of CNO nanosheets by EBSD. The out-of-plane orientation of SRO films only directed in (001) pc $_{\text {on }}$ both (a) ir-CNO and (b) sq-CNO nanosheets. The band contrast EBSD (c) and (d) maps displaying the shape of SRO grain boundaries was inherently the shape of ir-CNO and sq-CNO nanosheets, respectively. Each SRO grain was as large as the size of CNO nanosheet (nanosheet grains). (e) shows the in-plane orientation of individual SRO grains on ir-CNO nanosheets distributed randomly, while (f) shows the SRO grains on sq-CNO nanosheets with the same in-plane orientation forming domains larger than the size of individual CNO nanosheet. The scale bar is $25 \mu \mathrm{m}$.

SRO is a good electron conductor that has been used as an electrode in various applications in perovskite heterostructures. ${ }^{[26]}$ Here, the electrical properties were investigated to evaluate the influence of the in-plane orientation of ir-CNO and sq-CNO nanosheets. As can be seen in Figure 6, the Curie temperature $T_{C}$, which is the temperature at the kink of resistivity curve, of both SRO films on two types of nanosheets was $146 \mathrm{~K}$, which is lower than that of bulk SRO, i.e. $160 \mathrm{~K}$. The same phenomenon was also observed in the work of Nijland et al. and explained to be due to strain in the SRO film. ${ }^{[13]}$ The resistivity, $\rho$, of SRO film at $300 \mathrm{~K}$ was slightly lower on sqCNO, $275 \mu \Omega . c m$, than on ir-CNO, $299 \mu \Omega . c m$. Furthermore, the residual resistivity ratio, $\rho_{300 k} / \rho_{2 K}$, of $\mathrm{SRO}$ film on sq-CNO nanosheets was 3.8 , 
Shape Control of $\mathrm{Ca}_{2} \mathrm{Nb}_{3} \mathrm{O}_{10}$ Nanosheets to Improve their In-plane Orientation

somewhat higher than that on ir-CNO nanosheets, 3.5. The improved electrical properties of SRO film on sq-CNO nanosheets compared to ir-CNO nanosheets of similar lateral nanosheet size are probably due to sq-CNO nanosheets having formed clusters of nanosheets with the same in-plane orientation, and the resulting larger SRO domains (Figure 5e) would have less electron scattering.

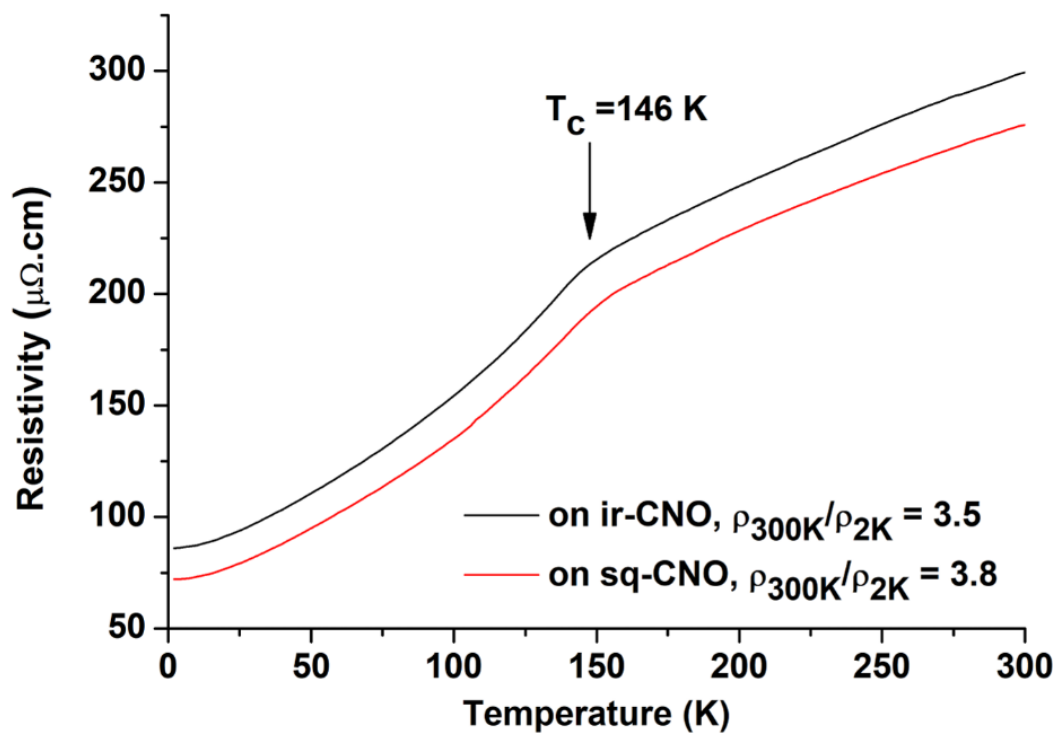

Figure 6. Resistivity of SRO films on ir-CNO and sq-CNO nanosheets as a function of temperature.

\section{Conclusions}

In this chapter, I showed that the in-plane orientation of the monolayer of CNO nanosheets can be self-aligned using their external shape. The parent layered perovskite $\mathrm{KNCO}$ obtained from molten $\mathrm{K}_{2} \mathrm{SO}_{4}$ salt had higher crystal quality than obtained from solid state reaction. The latter phase formed irregularly shaped platelets, whereas the former formed square-like platelet particles thanks to anisotropic growth, which was dependent on the crystal structure of $\mathrm{KCNO}$, in the specific molten $\mathrm{K}_{2} \mathrm{SO}_{4}$ salt. It is obvious that the CNO nanosheets have an irregular shape if they are exfoliated from irregularly shaped platelet particles. However, in order to retain the square- 
like shape of $\mathrm{CNO}$ nanosheets, the mechanical force was minimized during the exfoliation process. During LB deposition, the square-like CNO nanosheets self-aligned along their external straight edges. Because these external edges were coincident with the crystal $a$ and $b$ axes of CNO nanosheets, the resulting in-plane orientation is the same among neighboring square-like CNO nanosheets, as long as one of their straight edges is parallel or perpendicular to the others. It was confirmed by EBSD that epitaxial SRO grains on square-like CNO nanosheets formed larger domains, in which each domain consisted of many nanosheets instead of one nanosheet. The improvement in the in-plane orientation of CNO nanosheets led to an improvement of the electrical properties of the SRO film in terms of resistivity and residual resistivity ratio, $\rho_{300 \mathrm{~K}} / \rho_{2 \mathrm{~K}}$.

\section{Experimental section}

\section{Preparation of CNO nanosheets}

Anhydrous potassium carbonate $\mathrm{K}_{2} \mathrm{CO}_{3}$ (Fluka), potassium sulfate $\mathrm{K}_{2} \mathrm{SO}_{4}$ (Sigma-Aldrich), calcium carbonate $\mathrm{CaCO}_{3}$ (Sigma-Aldrich), niobium(V) oxide $\mathrm{Nb}_{2} \mathrm{O}_{5}$ (Sigma-Aldrich) had purity of $99.0 \%$ or higher and were used as received. Nitric acid $\mathrm{HNO}_{3}(65 \%$, ACROS Organics) and tetra-nbutylammonium hydroxide $\mathrm{TBAOH}\left(40 \%\right.$ wt. $\mathrm{H}_{2} \mathrm{O}$, Alfa Aesar) were used as received. Demineralized water was used throughout the experiments.

A stoichiometric mixture of $\mathrm{K}_{2} \mathrm{CO}_{3}, \mathrm{CaCO}_{3}$ and $\mathrm{Nb}_{2} \mathrm{O}_{5}$ was used in both solid state and molten salt syntheses. The same temperature program was used: heating to $1150^{\circ} \mathrm{C}$ at $3^{\circ} \mathrm{C} /$ minute, holding for 24 hours, and then cooling down to room temperature at $5^{\circ} \mathrm{C} /$ minute. The only difference between solid state and the molten salt syntheses was the addition of $\mathrm{K}_{2} \mathrm{SO}_{4}$ salt into the reactant mixture with the molar ratio of $9\left(\mathrm{~K}_{2} \mathrm{SO}_{4}\right): 1$ (KCNO). The resulting $\mathrm{KCNO}$ powder in $\mathrm{K}_{2} \mathrm{SO}_{4}$ salt was washed in hot water to remove $\mathrm{K}_{2} \mathrm{SO}_{4}$, and then dried at $80^{\circ} \mathrm{C}$. 
Shape Control of $\mathrm{Ca}_{2} \mathrm{Nb}_{3} \mathrm{O}_{10}$ Nanosheets to Improve their In-plane Orientation

Both types of $\mathrm{KCNO}$ powders were protonated in $5 \mathrm{M}$ of $\mathrm{HNO}_{3}$ solution (250 $\mathrm{mL}$ ) while stirring. The acid solution was replaced daily for 3 days. Subsequently, the powders were filtered and washed with $1 \mathrm{~L}$ of water, and then air-dried overnight at room temperature to obtain HCNO powders.

The $\mathrm{KCNO}$ obtained in molten $\mathrm{K}_{2} \mathrm{SO}_{4}$ salt and its protonated $\mathrm{HCNO}$ particles were deposited on Si substrates to observe their morphology and shape using SEM. The particles $(0.2 \mathrm{~g})$ was dispersed in water $(20 \mathrm{~mL})$, and dodecane $(10 \mathrm{~mL})$ was added to form an oil-water interface, then $\mathrm{Si}$ substrates were dipped into the water. The particles were floated at the oilwater interface by slowly adding ethanol $(0.4 \mathrm{~mL})$, and were deposited on $\mathrm{Si}$ substrates by slowly withdrawing the substrates from the solution. The mechanism of the oil-water interfacial self-assembly process can be found elsewhere. ${ }^{[27]}$

The exfoliation of $\mathrm{HCNO}$ powders in $\mathrm{TBAOH}$ with the molar ratio $\mathrm{HCNO} / \mathrm{TBAOH}$ of 1:2 was carried out in 2 different ways. The first one was that both types of $\mathrm{HCNO}$ powders $(0.1 \mathrm{~g})$ were stirred in TBAOH solution (25 $\mathrm{mL}$ ) for 1 hour to obtain $\mathrm{CNO}$ nanosheet solution. The other way was that the HCNO powder $(0.5 \mathrm{~g})$, originated from the molten salt synthesis, was slowly poured into TBAOH solution $(125 \mathrm{~mL})$, and the CNO nanosheet solution was ready after 1 hour. Using the obtained CNO nanosheet solutions, monolayers of CNO nanosheets were deposited on Si substrates using the LB method. ${ }^{[28]}$

\section{Pulsed laser deposition of SRO/STO films on CNO nanosheets}

PLD was performed in a vacuum system equipped with a $\mathrm{KrF}$ excimer laser of $248 \mathrm{~nm}$ (COMPexPro from Coherent Inc.). The PLD conditions for SRO and STO growth can be found elsewhere. ${ }^{[13]}$ The thickness of SRO and STO layers, that was determined by fitting X-ray reflectivity using X'Pert Reflectivity software, were $25 \mathrm{~nm}$ and around $20 \mathrm{~nm}$, respectively (see Figure A1). 
Analysis and characterization

Powder XRD and thin film XRD data were measured using PANalytical $X$ 'Pert Pro with Cu Ka radiation. Monolayers of CNO nanosheets on Si were investigated using AFM, Bruker Dimension ICON, operating in tapping mode. Using edge detection tool in Gwyddion software, ${ }^{[29]}$ the lateral size of CNO nanosheets was determined via the detected area of individual nanosheet with the assumption that nanosheets are square shape. SEM (Jeol JSM6490) was used to acquire the information of synthesized particles. EBSD was carried out on a Merlin field emission microscopy (Zeiss 1550) equipped with an angle-selective backscatter detector. The transport measurements were performed in the four-probe Van der Pauw configuration using a Quantum Design Physical Properties Measurement System. 
Shape Control of $\mathrm{Ca}_{2} \mathrm{Nb}_{3} \mathrm{O}_{10}$ Nanosheets to Improve their In-plane Orientation

\section{References}

[1] W. Eerenstein, N. D. Mathur, J. F. Scott, Nature 2006, 442, 759.

[2] C. N. R. Rao, Annu. Rev. Phys. Chem. 1989, 40, 291.

[3] S. Manipatruni, D. E. Nikonov, I. A. Young, Nat. Phys. 2018, 14, 338.

[4] D. K. Fork, D. B. Fenner, G. A. N. Connell, J. M. Phillips, T. H. Geballe, Appl. Phys. Lett. 1990, 57, 1137.

[5] R. A. McKee, F. J. Walker, M. F. Chisholm, Phys. Rev. Lett. 1998, $81,3014$.

[6] M. A. Timmerman, R. Xia, P. T. P. Le, Y. Wang, J. E. ten Elshof, Chem. - Eur. J. n/a.

[7] M. Osada, T. Sasaki, J. Mater. Chem. 2009, 19, 2503.

[8] K. Kikuta, K. Noda, S. Okumura, T. Yamaguchi, S. Hirano, J. Sol-Gel Sci. Technol. 2006, 42, 381.

[9] P. T. P. Le, K. Hofhuis, A. Rana, M. Huijben, H. Hilgenkamp, G. A. J. H. M. Rijnders, J. E. ten Elshof, G. Koster, N. Gauquelin, G. Lumbeeck, C. Schüßler-Langeheine, H. Popescu, F. Fortuna, S. Smit, X. H. Verbeek, G. Araizi-Kanoutas, S. Mishra, I. Vaskivskyi, H. A. Dürr, M. S. Golden, Adv. Funct. Mater. 2020, 30, 1900028.

[10] T. Shibata, K. Fukuda, Y. Ebina, T. Kogure, T. Sasaki, Adv. Mater. 2008, 20, 231.

[11] T. Shibata, H. Takano, Y. Ebina, D. S. Kim, T. C. Ozawa, K. Akatsuka, T. Ohnishi, K. Takada, T. Kogure, T. Sasaki, J. Mater. Chem. C 2013, 2, 441.

[12] M. D. Nguyen, E. P. Houwman, G. Rijnders, Sci. Rep. 2017, 7, 1.

[13] M. Nijland, S. Thomas, M. A. Smithers, N. Banerjee, D. H. A. Blank, G. Rijnders, J. Xia, G. Koster, J. E. ten Elshof, Adv. Funct. Mater. 2015, 25, 5140.

[14] H. Fukuoka, T. Isami, S. Yamanaka, J. Solid State Chem. 2000, 151, 40.

[15] J. Boltersdorf, N. King, P. A. Maggard, CrystEngComm 2015, 17, 2225.

[16] M.-A. Einarsrud, T. Grande, Chem. Soc. Rev. 2014, 43, 2187.

[17] K. Teshima, K. Horita, T. Suzuki, N. Ishizawa, S. Oishi, Chem. Mater. 2006, 18, 3693.

[18] C. Shivakumara, M. S. Hegde, J. Chem. Sci. 2003, 115, 447.

[19] T. Tanaka, Y. Ebina, K. Takada, K. Kurashima, T. Sasaki, Chem. Mater. 2003, 15, 3564.

[20] D. Arney, L. Fuoco, J. Boltersdorf, P. A. Maggard, J. Am. Ceram. Soc. 2013, 96, 1158.

[21] K. Teshima, S. Lee, A. Yamaguchi, S. Suzuki, K. Yubuta, T. Ishizaki,

T. Shishido, S. Oishi, CrystEngComm 2011, 13, 1190.

[22] D. Arney, P. A. Maggard, ACS Catal. 2012, 2, 1711.

[23] H. Yuan, D. Dubbink, R. Besselink, J. E. ten Elshof, Angew. Chem. Int. Ed. 2015, 54, 9239. 
[24] S. Tahara, Y. Sugahara, Langmuir 2003, 19, 9473.

[25] M. Nijland, S. Kumar, R. Lubbers, D. H. A. Blank, G. Rijnders, G. Koster, J. E. ten Elshof, ACS Appl. Mater. Interfaces 2014, 6, 2777.

[26] G. Koster, L. Klein, W. Siemons, G. Rijnders, J. S. Dodge, C.-B.

Eom, D. H. A. Blank, M. R. Beasley, Rev. Mod. Phys. 2012, 84, 253.

[27] L. Hu, M. Chen, X. Fang, L. Wu, Chem. Soc. Rev. 2012, 41, 1350.

[28] H. Yuan, M. Nguyen, T. Hammer, G. Koster, G. Rijnders, J. E. ten Elshof, ACS Appl. Mater. Interfaces 2015, 7, 27473.

[29] D. Nečas, P. Klapetek, Cent. Eur. J. Phys. 2012, 10, 181. 
Shape Control of $\mathrm{Ca}_{2} \mathrm{Nb}_{3} \mathrm{O}_{10}$ Nanosheets to Improve their In-plane Orientation

\section{Appendix}
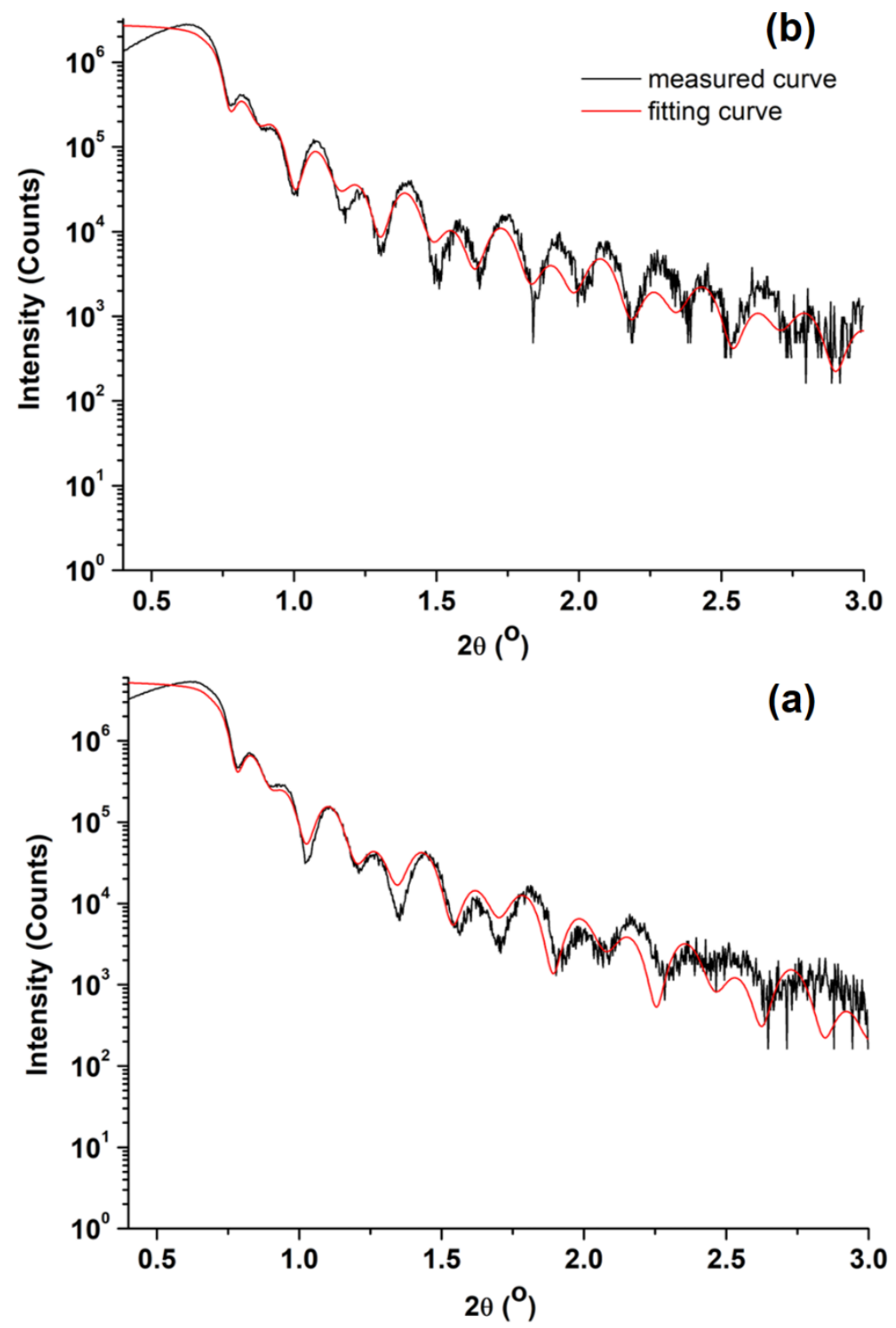

Figure A1. X-ray reflectivity curves and their fitting curves of SRO/STO on (a) ir$\mathrm{CNO}$ and (b) sq-CNO nanosheets on $\mathrm{Si}$. The thickness of SRO on both samples is $25 \mathrm{~nm}$. The thickness of STO thickness is $20 \mathrm{~nm}$ on ir-CNO nanosheets, whereas it is $22 \mathrm{~nm}$ on sq-CNO nanosheets. 



\section{Chapter 5. Epitaxial Lift-off of Freestanding (011) and (111) Oxide Perovskite Thin Films Using Water Sacrificial Layer}

Two-dimensional freestanding thin films of single crystalline oxide perovskites are expected to have great potential in integration of new features to the current Si-based technology. Here, I showed the ability to create freestanding single crystalline (011)- and (111)-oriented oxide perovskite thin films using $\mathrm{Sr}_{3} \mathrm{Al}_{2} \mathrm{O}_{6}$ water-sacrificial layer. The epitaxial $\mathrm{Sr}_{3} \mathrm{Al}_{2} \mathrm{O}_{6}(011)$ and $\mathrm{Sr}_{3} \mathrm{Al}_{2} \mathrm{O}_{6}(111)$ layers were realized on $\mathrm{SrTiO}_{3}(011)$ and $\mathrm{SrTiO}_{3}(111)$, respectively. Subsequently, the archetype $\mathrm{SrRuO}_{3}$ films were epitaxially grown on these sacrificial layers. The freestanding single crystalline $\mathrm{SrRuO}_{3}(011)_{\mathrm{pc}}$ and $\mathrm{SrRuO}_{3}(111)_{\mathrm{pc}}$ films were successfully transferred on Si substrates, demonstrating possibilities to transfer desirable oriented oxide perovskite films on Si and arbitrary substrates. 


\section{Introduction}

The integration of transition metal oxide (TMO) thin films and their heterostructures on $\mathrm{Si}$ are promising to provide new exciting features in applications of electronics, photonics, sensors, solid state lightning, microelectromechanical systems and so on, because of TMOs' rich physical properties. ${ }^{[1-4]}$ The introduction of a buffer layer $\mathrm{SrTiO}_{3}(001)$ (STO) on $\mathrm{Si}(001)$ has triggered the development of epitaxial growth of oxide perovskites on $\mathrm{Si}(001) .{ }^{[5]}$ Furthermore, efforts have been made to epitaxially grow $\left(\mathrm{La}_{\mathrm{x}} \mathrm{Y}_{1-\mathrm{x}}\right)_{2} \mathrm{O}_{3}$ and $\mathrm{Sc}_{2} \mathrm{O}_{3}$ buffer layers on $\mathrm{Si}(111){ }^{[6,7]}$ However, the introduction of buffer layers on $\mathrm{Si}$ suffers from complexities due to the reduction reaction and interdiffusion between oxides and $\mathrm{Si}$ at the interface while retaining the epitaxial relationship. ${ }^{[8-10]}$ Alternatively, oxide nanosheets have been considered as crystalline templates to bridge TMOs and Si. ${ }^{[11,12]}$ Although various TMO thin films have been directed in single out-of-plane orientation using oxide nanosheets, ${ }^{[12-14]}$ true epitaxy has not been achieved over the large scale on Si substrates yet.

Recently, the epitaxial lift-off technique that uses a sacrificial layer has emerged to prepare 2-dimensional (2D) freestanding films of single crystalline TMOs, which can be transferred onto Si substrates. ${ }^{[15-17]}$ The sacrificial layer acts as a crystallographic template to direct the epitaxial growth of TMO thin films, while it should be selectively removable using a chemical etchant without degrading the properties of the TMO thin films. $\mathrm{MgO}, \mathrm{La}_{0.7} \mathrm{Sr}_{0.3} \mathrm{MnO}_{3}$ and $\mathrm{Sr}_{3} \mathrm{Al}_{2} \mathrm{O}_{6}$ (SAO) have primarily served as sacrificial layers to prepare $2 \mathrm{D}$ freestanding TMO thin films thanks to their removability and epitaxial growth on single crystal substrates. ${ }^{[15-17]}$ In addition to the compatible crystal structure of the oxide perovskites, the SAO sacrificial layer can be etched away using water, reducing contaminants and keeping the high-quality of oxide perovskite thin films. ${ }^{[17]}$ 
Epitaxial Lift-off of Freestanding (011) and (111) Oxide Perovskite Thin Films Using Water Sacrificial Layer

Various freestanding oxide perovskites with (001) orientation releasing from SAO sacrificial layers have been fabricated and their properties have been studied. ${ }^{[18-21]}$ The other (011) and (111) orientations also offer the ability to control the physical properties of oxide perovskites. For instance, with a thickness of 3 to $12 \mathrm{~nm}$ on $\mathrm{LaAlO}_{3}$ substrates, $\mathrm{La}_{0.67} \mathrm{Sr}_{0.33} \mathrm{MnO}_{3}(001)$ was insulating while $\mathrm{La}_{0.67} \mathrm{Sr}_{0.33} \mathrm{MnO}_{3}$ (011) was metallic. ${ }^{[22]}$ The magnetic properties of several manganites were more enhanced in (011) than in (001) orientation. ${ }^{[23,24]}$ The crystal structure of oxide perovskites can be regarded as buckled honeycomb-liked lattices in the [111] direction, which is a prerequisite for accessing many quantum phenomena, for example 2D topological insulators and the quantum anomalous Hall state. ${ }^{[25-27]}$ Therefore, 2D freestanding oxide perovskites with (011) and (111) orientations would add new features to $\mathrm{Si}$. In this study, the epitaxial growth of the SAO sacrificial layers on STO(011) and STO(111) orientations were realized using pulsed laser deposition (PLD). Subsequently, metallic itinerant ferromagnetic $\mathrm{SrRuO}_{3}(\mathrm{SRO})$ films were epitaxially grown on SAO/STO heterostructures. It was observed that the epitaxial lift-off time in water was dependent on the crystal orientation of the SAO layers. The 2D freestanding films of single crystalline $\mathrm{SRO}(011)_{\mathrm{pc}}$ and $\mathrm{SRO}(111)_{\mathrm{pc}}$, where $\mathrm{pc}$ stands for pseudocubic, were successfully transferred onto $\mathrm{Si}$ substrates. Before the epitaxial lift-off, large magnetic moments of $3.2 \mu_{\mathrm{B}} / \mathrm{Ru}^{4+}$ and $3.5 \mu_{\mathrm{B}} / \mathrm{Ru}^{4+}$ for $\mathrm{SRO}(011)_{\mathrm{pc}}$ and $\mathrm{SRO}(111)_{\mathrm{pc}}$ films were observed, suggesting $\mathrm{Ru}^{4+}$ in the mixed state of lowand high-spin states and high-spin state, respectively. In contrast, the transferred $\mathrm{SRO}(011)_{\mathrm{pc}} \mathrm{SRO}(111)_{\mathrm{pc}}$ films showed a magnetic moment of 1.0 $\mu_{\mathrm{B}} / \mathrm{Ru}^{4+}$ and $1.7 \mu_{\mathrm{B}} / \mathrm{Ru}^{4+}$, respectively, which resulted from the low-spin state of $\mathrm{Ru}^{4+}$.

\section{Results and discussion}

Figure 1 shows XRD patterns of 100nm SAO films on STO(011) and STO(111) substrates and the corresponding RHEED patterns of the SAO 
films. The peak positions of SAO films at $31.87^{\circ}$ and $39.10^{\circ}$ matched with the bulk values of the SAO(044) and SAO(444) reflections, respectively, and the clear spotty RHEED patterns, which were recorded along the [01-1] direction of STO(011) and STO(111), indicated single crystalline nature of SAO films. The crystal structure of SAO has been described as a superstructure of 64 cubic perovskite units, in which the unit formula $\mathrm{ABO}_{3}$ is $\left(\mathrm{Sr}_{7 / 8} \square_{1 / 8}\right)\left(\mathrm{Sr}_{1 / 4} \mathrm{Al}_{3 / 4}\right)\left(\mathrm{O}_{3 / 4} \square_{1 / 4}\right)_{3}$ with vacancies at $A$ and $O$ positions. ${ }^{[28]}$ Taking domain matching and the $2 \mathrm{D}$ symmetry of the crystal planes between SAO and STO into account, the epitaxial growth of SAO(011) and SAO(111) can be realized on STO(011) and STO(111), respectively, with a lattice mismatch of $1.43 \%$.
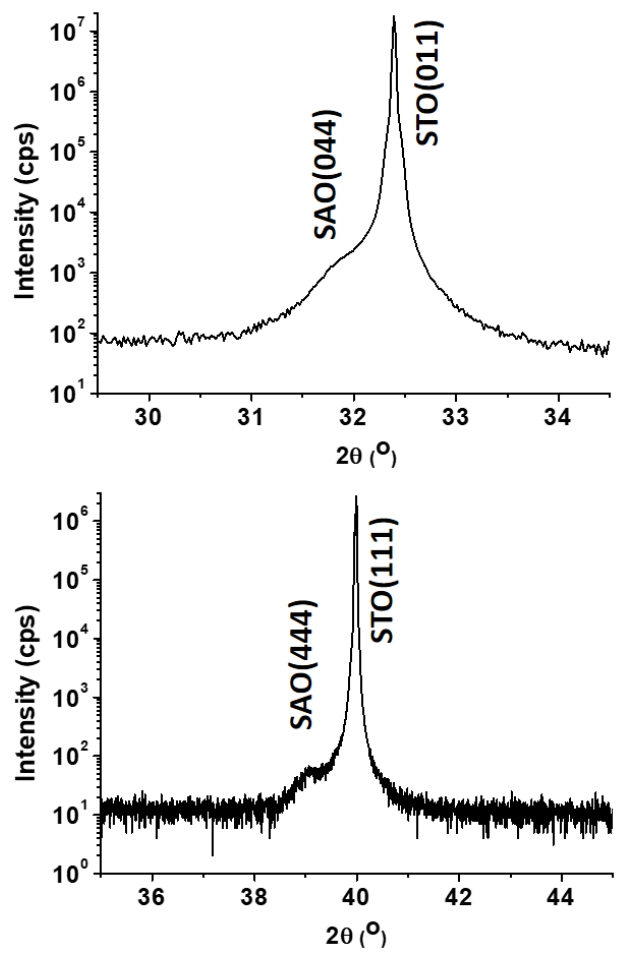

(a)

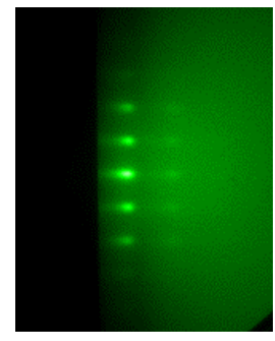

(b)

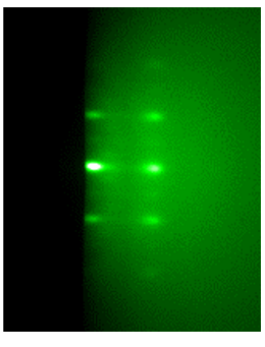

Figure 1. Epitaxial growth of SAO on STO(011) and STO(111) substrates. Panel (a) and (b) show XRD patterns of $100 \mathrm{~nm}$ SAO layers on STO(011) and STO(111) substrates, respectively, with capping STO layers. On the right-hand side, the spotty RHEED patterns of SAO layers were recorded along the [01-1] direction. 
Epitaxial Lift-off of Freestanding (011) and (111) Oxide Perovskite Thin Films Using Water Sacrificial Layer

In Figure $2 a$ and $2 b$, the $2 \theta-\omega$ XRD patterns of SRO grown on $S A O(011)$ and $S A O(111)$, respectively, only showed peaks originating from the STO substrates. $\mathrm{SAO}(044)$ and $\mathrm{SAO}(444)$ peaks were not resolved in these XRD patterns probably because the SAO layers were too thin. However, the spotty and streaky RHEED patterns, which were recorded along the [01-1] direction of SRO grown on SAO(011) and SAO(111), indicated well-crystallized SRO films. With regard to $\mathrm{SRO}(011)_{\mathrm{pc}} / \mathrm{SAO}(011) / \mathrm{STO}(011)$, the reciprocal space map (RSM) around the STO(031) reflection (Figure 2c) showed that $\mathrm{SRO}(011)_{p c}$ was not fully strained to the $\mathrm{STO}(011)$ substrate. The $\mathrm{SRO}(011)_{\mathrm{pc}}$ film had $\mathrm{d}_{(011)}=2.768 \AA$, which was close to $\mathrm{d}_{(011)}=2.762 \AA$ of the STO substrate, and that was why the $\mathrm{SRO}(011)_{\mathrm{pc}}$ peaks were not observed in Figure 2a. Meanwhile, the RSM of SRO(111) pc/SAO(111)/STO(111) (Figure 2d) only showed a STO(231) peak. The SRO(111) $)_{\mathrm{pc}}$ reflections were not resolved probably because its (111) reflections were too close to those of STO(111) due to the insertion of the $\mathrm{SAO}(111)$ layer and its peak intensity was quite low compared to that of STO(111). The temperature-dependent resistivities of SRO(011) $)_{p d} / S A O(011) / S T O(011)$ and SRO(111) $)_{p d} / S A O(111) / S T O(111)$ are shown Figure 2e. Both samples exhibited metallic behavior with a typical kink, which is caused by the ferromagnetic transition of SRO. The transition temperatures $T_{c}$ were $155 \mathrm{~K}$ and $154 \mathrm{~K}$ for SRO(011) $\mathrm{pd} / \mathrm{SAO}(011) / \mathrm{STO}(011)$ and $\operatorname{SRO}(111)_{\mathrm{pc}} / \mathrm{SAO}(111) / \mathrm{STO}(111)$, respectively, which are lower than the $\mathrm{T}_{\mathrm{c}}$ of bulk SRO, $160 \mathrm{~K}$. This indicates that the SRO films were partially strained by the substrates. ${ }^{[29]}$ While the residual resistivity ratio, $\rho_{300 K} / \rho_{2 K}$, of $\mathrm{SRO}(011)_{\mathrm{pc}}$ of 3.6 was better than the ratio 3.0 of $\mathrm{SRO}(111)_{\mathrm{pc}}$, the resistivity of $\mathrm{SRO}(011)_{\mathrm{pc}}$ was much higher than that of $\mathrm{SRO}(111)_{\mathrm{pc}}$. 

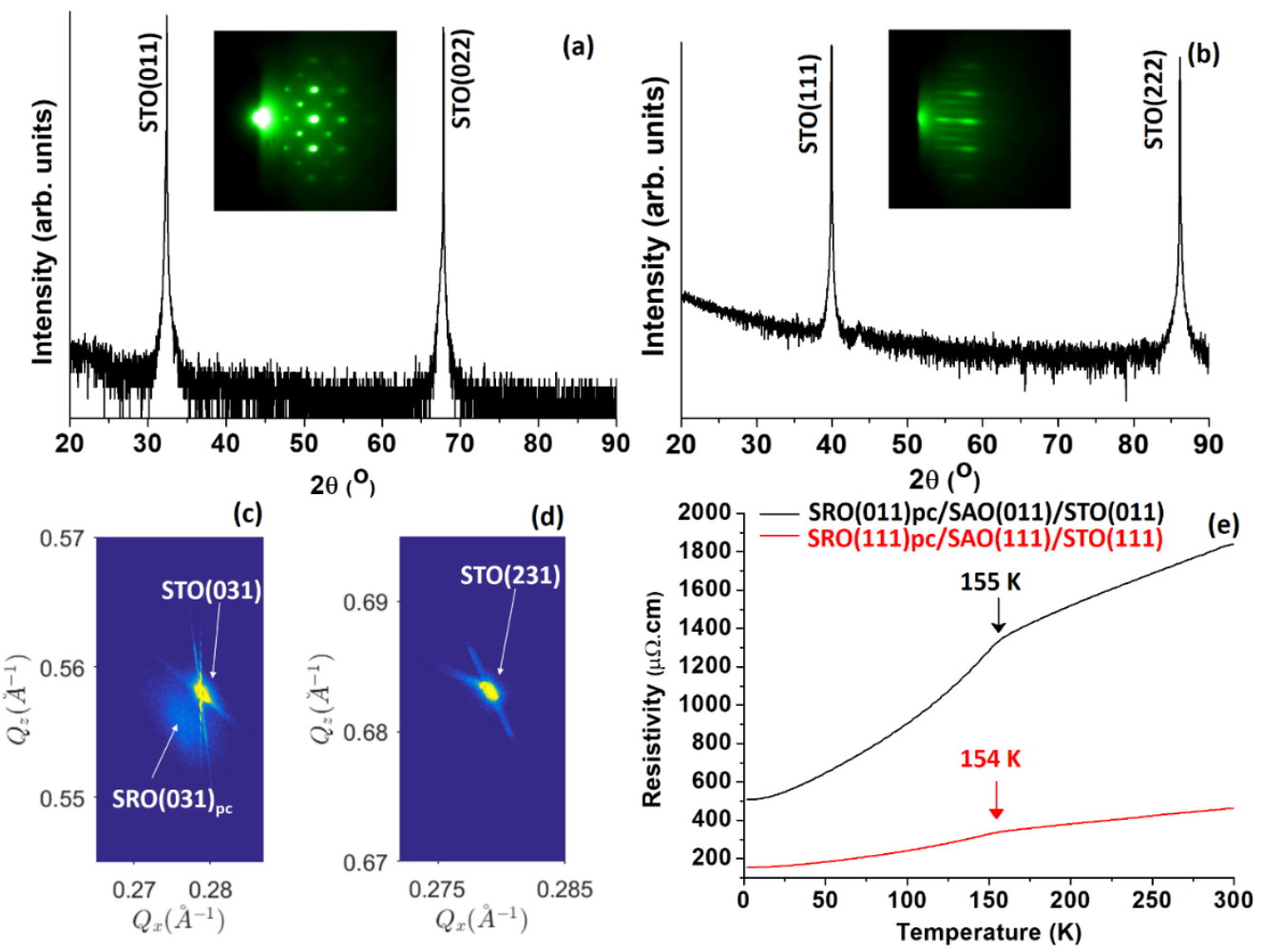

Figure 2. Identification of SRO films on sacrificial SAO layers. Panel (a) and (b) show that the XRD patterns of $\mathrm{SRO}(011)_{\mathrm{pc}} / \mathrm{SAO}(011) / \mathrm{STO}(011)$ and SRO(111)pc/SAO(111)/STO(111), respectively, could not resolve the reflections of SRO and SAO probably because the their reflections were close to those of STO and their intensities were much weaker than that of STO. The insets show clear spotty and streaky RHEED patterns, which were taken along the [01-1] direction of $\mathrm{SRO}(011)_{\mathrm{pc}}$ and $\mathrm{SRO}(111)_{\mathrm{pc}}$ films, respectively, indicating well-crystallized single phase SRO films. RSM around the STO(031) reflection (c) indicated that the SRO(011) pc film was not fully strained by the STO(011) substrate, while RSM around the $\mathrm{STO}(231)$ reflection (d) did not resolve the $\mathrm{SRO}(231)$ reflection of the $\mathrm{SRO}(111)_{\mathrm{pc}}$ film. The transport measurements (e) of $\mathrm{SRO}(011)_{\mathrm{pc}} / \mathrm{SAO}(011) / \mathrm{STO}(011)$ and $\mathrm{SRO}(111)_{\mathrm{pc}} / \mathrm{SAO}(111) / \mathrm{STO}(111)$ exhibited characteristic behavior of SRO films.

It was observed that the epitaxial lift-off time of oxide perovskite films on SAO/STO heterostructures in $\mathrm{H}_{2} \mathrm{O}$ was dependent on the crystallographic 
Epitaxial Lift-off of Freestanding (011) and (111) Oxide Perovskite Thin Films Using Water Sacrificial Layer

orientation of the sacrificial SAO layers. With the same thickness of about 25 $\mathrm{nm} \mathrm{SAO}$, it took about 15 minutes for the lift-off to be complete if the SAO layers were (011)- and (111)-oriented, compared to a few hours if the SAO layers were (001)-oriented. One would expect that $\mathrm{H}_{2} \mathrm{O}$ etches SAO layers at the side planes of the substrates because the top and bottom planes of SAO layers are protected by oxide perovskite films and STO substrates. The observations indicate that the etching rate of SAO films is strongly crystallographically dependent. The $\mathrm{H}_{2} \mathrm{O}$-etching rate and mechanism for different crystallographic orientations of SAO are beyond the scope of this study.

The SRO films were completely lifted off from the STO substrates (Figure 3). However, the transfer process of $\mathrm{SRO}$ films onto $\mathrm{Si}(001)$ substrates resulted in cracks and some areas without SRO films. The film thicknesses were $37 \mathrm{~nm}$ and $24 \mathrm{~nm}$ for the transferred $\mathrm{SRO}(011)_{\mathrm{pc}}$ and $\mathrm{SRO}(111)_{\mathrm{pc}}$ films, respectively. The surface morphology of SRO films remained unchanged after the epitaxial lift-off and transfer processes (see Figure A1).
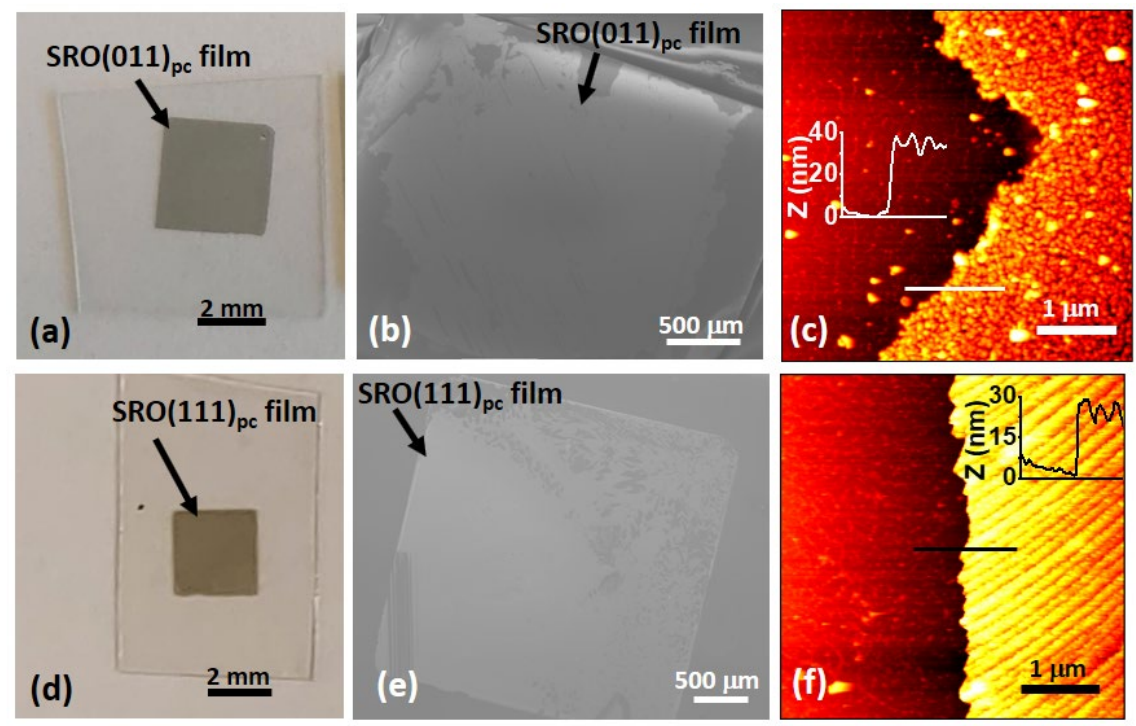

Figure 3. $\mathrm{SRO}(011)_{\mathrm{pc}}$ and $\mathrm{SRO}(111)_{\mathrm{pc}}$ films after the epitaxial lift-off and the transfer to $\mathrm{Si}(001)$ substrates. Millimeter-sized $\mathrm{SRO}(011) \mathrm{pc}(\mathrm{a})$ and $\mathrm{SRO}(111) \mathrm{pc}(\mathrm{d})$ films on 
the supporting polyethylene terephthalate (PET) substrates. Scanning electron microscope (SEM) images of $\mathrm{SRO}(011)_{p c}(b)$ and $\mathrm{SRO}(111)_{p c}(e)$ on $\mathrm{Si}(001)$ substrates. Panel (c) and (f) show atomic force microscopy (AFM) data at the edges of $\mathrm{SRO}(011)_{p c} / \mathrm{Si}(001)$ and $\mathrm{SRO}(111)_{\mathrm{pc}} / \mathrm{Si}(001)$, respectively. The insets show the thickness of transferred SRO films.

The transferred $\mathrm{SRO}(011)_{\mathrm{pc}}$ on $\mathrm{Si}(001)$ substrates clearly showed the reflections of $\mathrm{SRO}(011)_{\mathrm{pc}}$ and $\mathrm{SRO}(022)_{\mathrm{pc}}$ at $32.25^{\circ}$ and $67.49^{\circ}$, respectively,

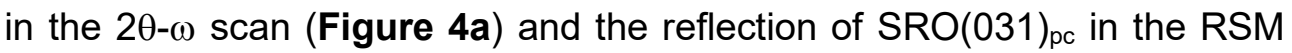
(Figure $4 \mathrm{~b}$ ). Similarly, the $\mathrm{SRO}(222)_{\mathrm{pc}}$ reflection was at $85.67^{\circ}$ in the $2 \theta-\omega$ scan (Figure $4 \mathrm{~d}$ ) and the reflection of $\mathrm{SRO}(231)_{\mathrm{pc}}$, which was not resolved in the RSM of SRO(111) pd SAO(111)/STO(111), was observed in the RSM (Figure $4 \mathrm{e}$ ) for the transferred $\mathrm{SRO}(111)_{\mathrm{pc}}$ on $\mathrm{Si}(001)$ thanks to the separation with the reflections of the $\mathrm{Si}(001)$ substrate. The lattice constants $a_{p c}$ are $3.920 \AA$ and $3.925 \AA$ for transferred $S R O(011)_{p c}$ and $S R O(111)_{p c}$, respectively. Furthermore, Figure $4 \mathrm{c}$ shows that the $\phi$-scan of the in-plane reflection of $\mathrm{SRO}(211)_{\mathrm{pc}}$ of the transferred $\mathrm{SRO}(011)_{\mathrm{pc}}$ on $\mathrm{Si}(001)$ had 2 peaks, which were separated by $180^{\circ}$, consistent with the 2-fold symmetry of the $\mathrm{SRO}(011)_{\mathrm{pc}}$ film. Likewise, the $\phi$-scan of the in-plane reflection of $\mathrm{SRO}(240)_{\mathrm{pc}}$ of the transferred $\mathrm{SRO}(111)_{\mathrm{pc}}$ in Figure $4 \mathrm{f}$ obtained 6 peaks, which were separated by $60^{\circ}$ from each other, as one expected for the 6 -fold symmetry in the $\mathrm{SRO}(111)_{\mathrm{pc}}$ film. The in-plane direction between the transferred SRO films and $\mathrm{Si}(001)$ substrates was not coincident, simply because the transferred SRO films were arbitrarily placed on $\mathrm{Si}(001)$ substrates. Therefore, the SRO films were epitaxially grown on SAO/STO with the orientation of $(011)_{p c}$ and $(111)_{p c}$ and remained single crystalline films after the transfer to $\mathrm{Si}(001)$ substrates. Freestanding single crystalline STO(011) and STO(111) films were also lifted off from SAO/STO heterostructures (see Figure A2). 

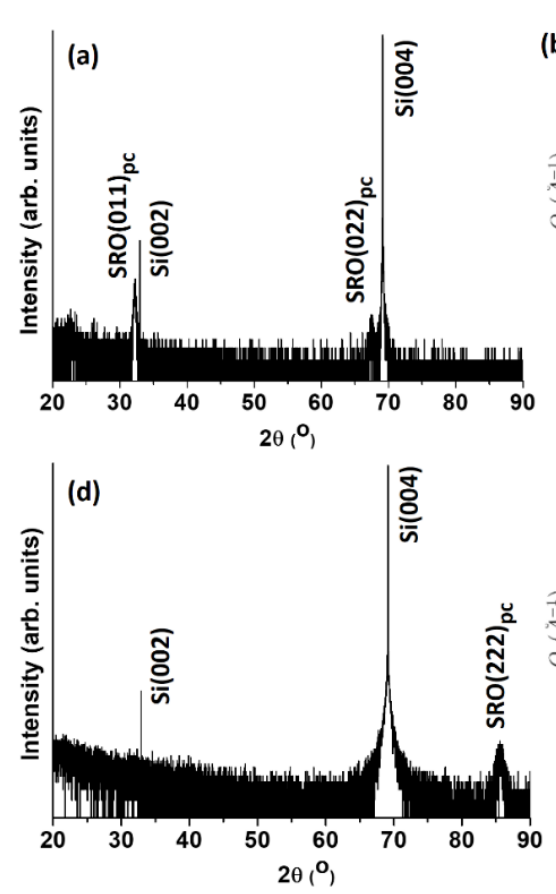
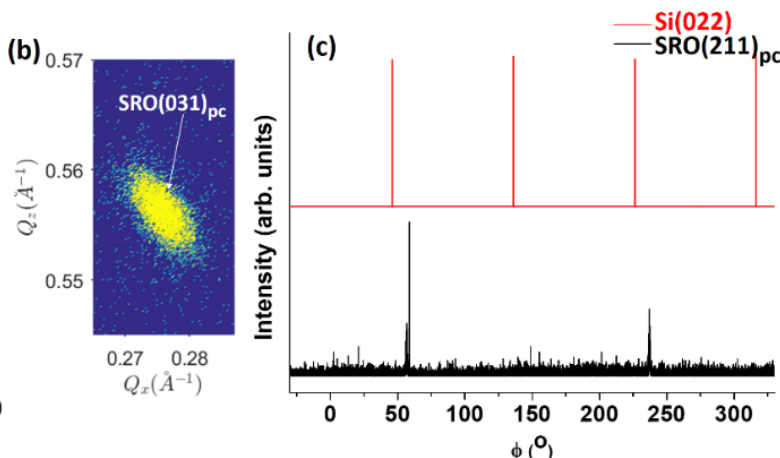

(e)

0.69

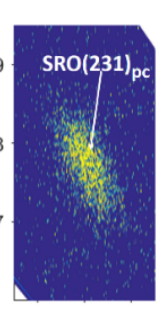

$\begin{array}{lll}0.26 & 0.28 & 0.3\end{array}$ $Q_{x}\left(\hat{A}^{-1}\right)$

Figure 4. Single crystalline $\mathrm{SRO}(011)_{\mathrm{pc}}$ and $\mathrm{SRO}(111)_{\mathrm{pc}}$ films on $\mathrm{Si}(001)$. Clearly resolved reflections in 2 $\theta-\omega$ scans of $\operatorname{SRO}(011)_{p c}(a)$ and $S R O(111)_{p c}(d)$ confirmed single oriented SRO films on $\mathrm{Si}(001)$ substrates. Panel (b) shows clear $\mathrm{SRO}(031) \mathrm{pc}$ reflection of $S R O(011) p c$ film in RMS, while panel (e) displays the $S R O(231)_{p c}$ reflection of $\mathrm{SRO}(111)_{\mathrm{pc}}$ film, which was not resolved when the film was on $\mathrm{STO}(111)$ substrate. The $\phi$-scans reveal 2 peaks, which were separated by $180^{\circ}$, for the inplane reflection $\mathrm{SRO}(211)_{\mathrm{pc}}$ of $\mathrm{SRO}(011)_{\mathrm{pc}}$ in panel (c) and 6 peaks, which were separated $60^{\circ}$, for the in-plane reflection $\mathrm{SRO}(240)_{\mathrm{pc}}$ of $\mathrm{SRO}(111)_{\mathrm{pc}}$ films in panel (f).

Figure 5 shows magnetic hysteresis loops at $2 \mathrm{~K}$ for $\mathrm{SRO}(011)_{\mathrm{pc}}$ and $\mathrm{SRO}(111)_{p c}$ films before the epitaxial lift-off and after the transfer of SRO films on Si substrates. Before the epitaxial lift-off, the saturated magnetic moment was $3.2 \mu_{\mathrm{B}} / \mathrm{Ru}^{4+}$ and $3.5 \mu_{\mathrm{B}} / \mathrm{Ru}^{4+}$ for $\mathrm{SRO}(011)_{\mathrm{pc}}$ and $\mathrm{SRO}(111)_{\mathrm{pc}}$ films, respectively. Taken into account the change of SRO films' volume due to the transfer of SRO films on $\mathrm{Si}$, the saturated magnetic moment was 1.0 $\mu_{\mathrm{B}} / \mathrm{Ru}^{4+}$ and $1.7 \mu_{\mathrm{B}} / \mathrm{Ru}^{4+}$ for $\mathrm{SRO}(011)_{\mathrm{pc}}$ and $\mathrm{SRO}(111)_{\mathrm{pc}}$ films, respectively. 
With regard to $\mathrm{SRO}$, it was suggested that the low-spin $\mathrm{Ru}^{4+}$ state has a magnetic moment of $2 \mu_{\mathrm{B}} / \mathrm{Ru}^{4+}$, while the high-spin one has $4 \mu_{\mathrm{B}} / \mathrm{Ru}^{4+}{ }^{4{ }^{30-35]}}$ The bulk SRO showed $1.1-1.6 \mu_{\mathrm{B}} / \mathrm{Ru}^{4+}$ in the low-spin state. ${ }^{[35]}$ It has been experimentally observed that the high-spin state can be stabilized using epitaxial strain and the symmetry of the lattice distortion via substrates. ${ }^{[30-34]}$ $\mathrm{SRO}(111)_{\mathrm{pc}}$ epitaxially grown on STO(111) adopted the high-spin state with the magnetic moment of $3.5-3.6 \mu_{\mathrm{B}} / \mathrm{Ru}^{4+}$, while $\mathrm{SRO}(011)_{\mathrm{pc}}$ grown on STO(011) had a mixed state of low- and high-spin states with the magnetic moment of $3 \mu_{\mathrm{B}} / \mathrm{Ru}^{4+}{ }^{[30,31]}$ Because the epitaxial lift-off of SRO films happened in pure deionized $\mathrm{H}_{2} \mathrm{O}$ at room temperature, $\mathrm{SRO}$ films are unlikely to have undergone some chemical reaction with $\mathrm{H}_{2} \mathrm{O}$ that would have affected its composition and/or structure. The magnetic moment values of $\mathrm{SRO}(111)_{\mathrm{pc}}$ on $\mathrm{SAO}(111) / \mathrm{STO}(111)$ suggest that the $\mathrm{SRO}(111)_{\mathrm{pc}}$ film has a high-spin state, and the transferred $\mathrm{SRO}(111)_{\mathrm{pc}}$ film on Si substrate adopts the low-spin state like bulk SRO, because it was not under any strain and not distorted by the weak Van der Waals bonds on the Si substrate. Similarly, the $\mathrm{SRO}(011)_{\mathrm{pc}}$ films would have a mixed state of high-spin and low-spin states and the low-spin state before epitaxial lift-off and after the transfer, respectively.
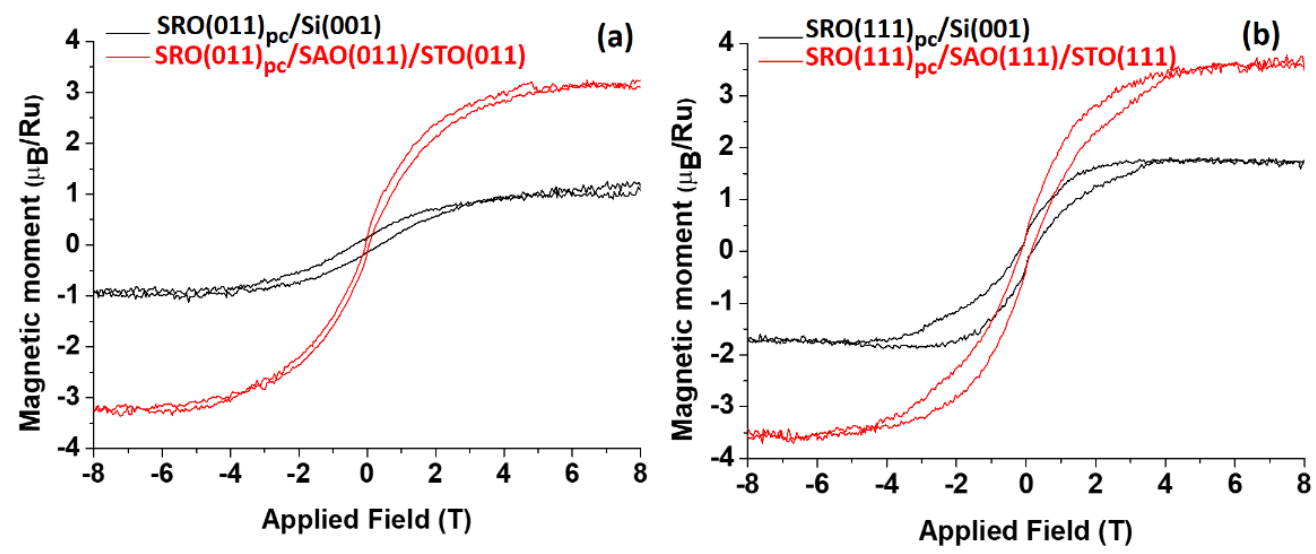

Figure 5. Magnetic hysteresis loops measured with the applied magnetic field perpendicular to the film surface of $\mathrm{SRO}(011)_{\mathrm{pc}}(\mathrm{a})$ and $\mathrm{SRO}(111)_{\mathrm{pc}}(\mathrm{b})$ films at $2 \mathrm{~K}$. 
Epitaxial Lift-off of Freestanding (011) and (111) Oxide Perovskite Thin Films Using Water Sacrificial Layer

The saturated magnetic moment for $\mathrm{Ru}^{4+}$ was $3.2 \mu_{\mathrm{B}} / \mathrm{Ru}^{4+}$ and $3.5 \mu_{\mathrm{B}} / \mathrm{Ru}^{4+}$ for the $\mathrm{SRO}(011)_{p c}$ and $\mathrm{SRO}(111)_{\mathrm{pc}}$ films, respectively, when they were on SAO/STO heterostructures, probably because of the presence of the $\mathrm{Ru}^{4+}$ high-spin state. After the transfer onto Si substrates, $\mathrm{SRO}(011)_{\mathrm{pc}}$ and $\mathrm{SRO}(111)_{\mathrm{pc}}$ films had $1.0 \mu \mathrm{B} / \mathrm{Ru}^{4+}$ and $1.7 \mu \mathrm{B} / \mathrm{Ru}^{4+}$, respectively, as their crystal structure were relaxed to the bulk SRO from epitaxial strain and lattice distortion by SAO/STO heterostructures.

\section{Conclusions}

In this chapter, I have shown 2D freestanding of single crystalline oxide perovskite films with (011) and (111) orientations were successfully synthesized using water-sacrificial SAO layers on single crystal STO substrates. The water-sacrificial SAO layers were epitaxially grown on STO(011) and STO(111) because of lattice mismatch of $1.43 \%$ and similar 2D symmetry of crystal planes. It was observed that the epitaxial lift-off time of oxide perovskite films from SAO layers was dependent on the orientation of SAO. The 2D single crystalline $(011)_{\mathrm{pc}^{-}}$and $(111)_{\mathrm{pc}}$-oriented SRO films were successfully transferred on $\mathrm{Si}$ substrates. SRO films on SAO(011)/STO(011) and SAO(111)/STO(111) heterostructures showed enhanced magnetism of the high-spin state, whereas the transferred SRO films on Si showed bulk-like magnetism of the low-spin state. This study demonstrates the possibility to obtain single crystalline oxide perovskite films with desirable orientation on arbitrary substrates.

\section{Experimental section}

Well-defined atomically flat STO substrates were obtained by treating STO with buffered hydrogen fluoride solution and then thermal annealing as described elsewhere. ${ }^{[36,37]}$ PLD was performed in a vacuum system with a base pressure of $2 \times 10^{-8}$ mbar, equipped with an in-situ RHEED and a $\mathrm{KrF}$ excimer laser of $248 \mathrm{~nm}$ (COMPexPro from Coherent Inc.). The central part of the laser beam was selected with a mask and focused on polycrystalline SAO, SRO, and single crystal STO targets. The substrate temperature 
$700^{\circ} \mathrm{C}$, laser repletion rate $1 \mathrm{~Hz}$, spot size $1.8 \mathrm{~mm}^{2}$ and substrate-target distance $50 \mathrm{~mm}$ were the same for the growth of SAO, SRO and STO layers. Laser energy density and oxygen pressure were $1.25 \mathrm{J.cm}^{-2}$ and $10^{-3} \mathrm{mbar}$ for SAO, $1.3 \mathrm{J.cm}^{-2}$ and $10^{-2} \mathrm{mbar}$ for STO, and $2.1 \mathrm{J.cm}^{-2}$ and $8 \times 10^{-3} \mathrm{mbar}$ for SRO. After deposition, the samples were cooled down to room temperature at a maximum rate of $20^{\circ} \mathrm{C} \cdot \mathrm{min}^{-1}$ at the deposition pressure for STO/SAO/STO heterostructures and at 100 mbar oxygen pressure for SRO/SAO/STO heterostructures. The growth rate was $1.88 \mathrm{~nm}$ per 100 pulses for SAO(011) and SAO(111) (see Figure A3). The transfer of epitaxial films from SAO water-sacrificial layers on supporting substrates was done as described elsewhere. ${ }^{[17,38]}$

The crystal structure of samples was analyzed using PANalytical X'Pert Pro with the Inc. beam Monochr. 4xGe220 Cu asym. LF monochromator to select $\mathrm{Cu} \mathrm{Ka}{ }_{1}$ radiation. SEM (Jeol JSM-6490) was used to acquire the images of the transferred SRO films on $\mathrm{Si}$ substrates in order to calculate the transferred film area based on the contrast between SRO and Si. Surface morphologies of samples were investigated using AFM, Bruker Dimension ICON, operating in tapping mode and analyzed by Gwyddion software ${ }^{[39]}$. The transport measurements were performed in the four-probe Van der Pauw configuration and the magnetic properties were measured with the magnetic field perpendicular to the film surface using vibrating sample magnetometry in a Quantum Design Physical Properties Measurement System. 
Epitaxial Lift-off of Freestanding (011) and (111) Oxide Perovskite Thin Films Using Water Sacrificial Layer

\section{References}

[1] W. Eerenstein, N. D. Mathur, J. F. Scott, Nature 2006, 442, 759.

[2] C. N. R. Rao, Annu. Rev. Phys. Chem. 1989, 40, 291.

[3] A. A. Demkov, A. B. Posadas, Integration of Functional Oxides with Semiconductors; Springer New York: New York, NY, 2014.

[4] S. Manipatruni, D. E. Nikonov, I. A. Young, Nat. Phys. 2018, 14, 338.

[5] R. A. McKee, F. J. Walker, M. F. Chisholm, Phys. Rev. Lett. 1998, $81,3014$.

[6] S. Guha, N. A. Bojarczuk, V. Narayanan, Appl. Phys. Lett. 2002, 80, 766.

[7] D. O. Klenov, L. F. Edge, D. G. Schlom, S. Stemmer, Appl. Phys. Lett. 2005, 86, 051901.

[8] V. Shutthanandan, S. Thevuthasan, Y. Liang, E. M. Adams, Z. Yu, R. Droopad, Appl. Phys. Lett. 2002, 80, 1803.

[9] X. Gu, D. Lubyshev, J. Batzel, J. M. Fastenau, W. K. Liu, R. Pelzel, J. F. Magana, Q. Ma, L. P. Wang, P. Zhang, V. R. Rao, J. Vac. Sci. Technol. B Microelectron. Nanometer Struct. Process. Meas. Phenom. 2009, 27, 1195.

[10] J. W. Reiner, A. M. Kolpak, Y. Segal, K. F. Garrity, S. Ismail-Beigi, C. H. Ahn, F. J. Walker, Adv. Mater. 2010, 22, 2919.

[11] M. A. Timmerman, R. Xia, P. T. P. Le, Y. Wang, J. E. ten Elshof, Chem. - Eur. J. 2020, n/a.

[12] T. Shibata, H. Takano, Y. Ebina, D. S. Kim, T. C. Ozawa, K. Akatsuka, T. Ohnishi, K. Takada, T. Kogure, T. Sasaki, J. Mater. Chem. C 2013, 2, 441.

[13] P. T. P. Le, K. Hofhuis, A. Rana, M. Huijben, H. Hilgenkamp, G. A. J. H. M. Rijnders, J. E. ten Elshof, G. Koster, N. Gauquelin, G. Lumbeeck, C. Schüßler-Langeheine, H. Popescu, F. Fortuna, S. Smit, X. H. Verbeek, G. Araizi-Kanoutas, S. Mishra, I. Vaskivskyi, H. A. Dürr, M. S. Golden, Adv. Funct. Mater. 2020, 30, 1900028.

[14] M. Nijland, S. Thomas, M. A. Smithers, N. Banerjee, D. H. A. Blank, G. Rijnders, J. Xia, G. Koster, J. E. ten Elshof, Adv. Funct. Mater. 2015, 25, 5140.

[15] D. M. Paskiewicz, R. Sichel-Tissot, E. Karapetrova, L. Stan, D. D. Fong, Nano Lett. 2016, 16, 534.

[16] S. R. Bakaul, C. R. Serrao, M. Lee, C. W. Yeung, A. Sarker, S.-L. Hsu, A. K. Yadav, L. Dedon, L. You, A. I. Khan, J. D. Clarkson, C. $\mathrm{Hu}$, R. Ramesh, S. Salahuddin, Nat. Commun. 2016, 7, 1.

[17] D. Lu, D. J. Baek, S. S. Hong, L. F. Kourkoutis, Y. Hikita, H. Y. Hwang, Nat. Mater. 2016, 15, 1255.

[18] S. S. Hong, M. Gu, M. Verma, V. Harbola, B. Y. Wang, D. Lu, A. Vailionis, Y. Hikita, R. Pentcheva, J. M. Rondinelli, H. Y. Hwang, Science 2020, 368, 71. 
[19] L. Han, Y. Fang, Y. Zhao, Y. Zang, Z. Gu, Y. Nie, X. Pan, Adv. Mater. Interfaces 2020, 7, 1901604.

[20] D. Ji, S. Cai, T. R. Paudel, H. Sun, C. Zhang, L. Han, Y. Wei, Y. Zang, M. Gu, Y. Zhang, W. Gao, H. Huyan, W. Guo, D. Wu, Z. Gu, E. Y. Tsymbal, P. Wang, Y. Nie, X. Pan, Nature 2019, 570, 87.

[21] P. Singh, A. Swartz, D. Lu, S. S. Hong, K. Lee, A. F. Marshall, K. Nishio, Y. Hikita, H. Y. Hwang, ACS Appl. Electron. Mater. 2019, 1, 1269.

[22] A. Tebano, A. Orsini, D. Di Castro, P. G. Medaglia, G. Balestrino, Appl. Phys. Lett. 2010, 96, 092505.

[23] I. C. Infante, F. Sánchez, J. Fontcuberta, M. Wojcik, E. Jedryka, S. Estradé, F. Peiró, J. Arbiol, V. Laukhin, J. P. Espinós, Phys. Rev. B 2007, 76, 224415.

[24] M. Minohara, Y. Furukawa, R. Yasuhara, H. Kumigashira, M. Oshima, Appl. Phys. Lett. 2009, 94, 242106.

[25] S. Okamoto, D. Xiao, J. Phys. Soc. Jpn. 2018, 87, 041006.

[26] L. Si, O. Janson, G. Li, Z. Zhong, Z. Liao, G. Koster, K. Held, Phys. Rev. Lett. 2017, 119, 026402.

[27] Y. Wang, Z. Wang, Z. Fang, X. Dai, Phys. Rev. B 2015, 91, 125139.

[28] J. A. Alonso, I. Rasines, J. L. Soubeyroux, Inorg. Chem. 1990, 29, 4768.

[29] G. Koster, L. Klein, W. Siemons, G. Rijnders, J. S. Dodge, C.-B. Eom, D. H. A. Blank, M. R. Beasley, Rev. Mod. Phys. 2012, 84, 253.

[30] X. K. Ning, Z. J. Wang, Z. D. Zhang, J. Appl. Phys. 2015, 117, 093907.

[31] A. Grutter, F. Wong, E. Arenholz, M. Liberati, A. Vailionis, Y. Suzuki, Appl. Phys. Lett. 2010, 96, 082509.

[32] A. J. Grutter, F. J. Wong, E. Arenholz, A. Vailionis, Y. Suzuki, Phys. Rev. B 2012, 85, 134429.

[33] X. W. Wang, Y. Q. Zhang, H. Meng, Z. J. Wang, D. Li, Z. D. Zhang, J. Appl. Phys. 2011, 109, $07 D 707$.

[34] J. Liu, Y. Feng, R. Tang, R. Zhao, J. Gao, D. Shi, H. Yang, Adv. Electron. Mater. 2018, 4, 1700522.

[35] P. B. Allen, H. Berger, O. Chauvet, L. Forro, T. Jarlborg, A. Junod, B. Revaz, G. Santi, Phys. Rev. B 1996, 53, 4393.

[36] G. Koster, B. L. Kropman, G. J. H. M. Rijnders, D. H. A. Blank, H. Rogalla, Appl. Phys. Lett. 1998, 73, 2920.

[37] A. Biswas, P. B. Rossen, C.-H. Yang, W. Siemons, M.-H. Jung, I. K. Yang, R. Ramesh, Y. H. Jeong, Appl. Phys. Lett. 2011, 98, 051904.

[38] X.-D. Chen, Z.-B. Liu, C.-Y. Zheng, F. Xing, X.-Q. Yan, Y. Chen, J.G. Tian, Carbon 2013, 56, 271.

[39] D. Nečas, P. Klapetek, Cent. Eur. J. Phys. 2012, 10, 181. 
Epitaxial Lift-off of Freestanding (011) and (111) Oxide Perovskite Thin Films Using Water Sacrificial Layer

\section{Appendix}
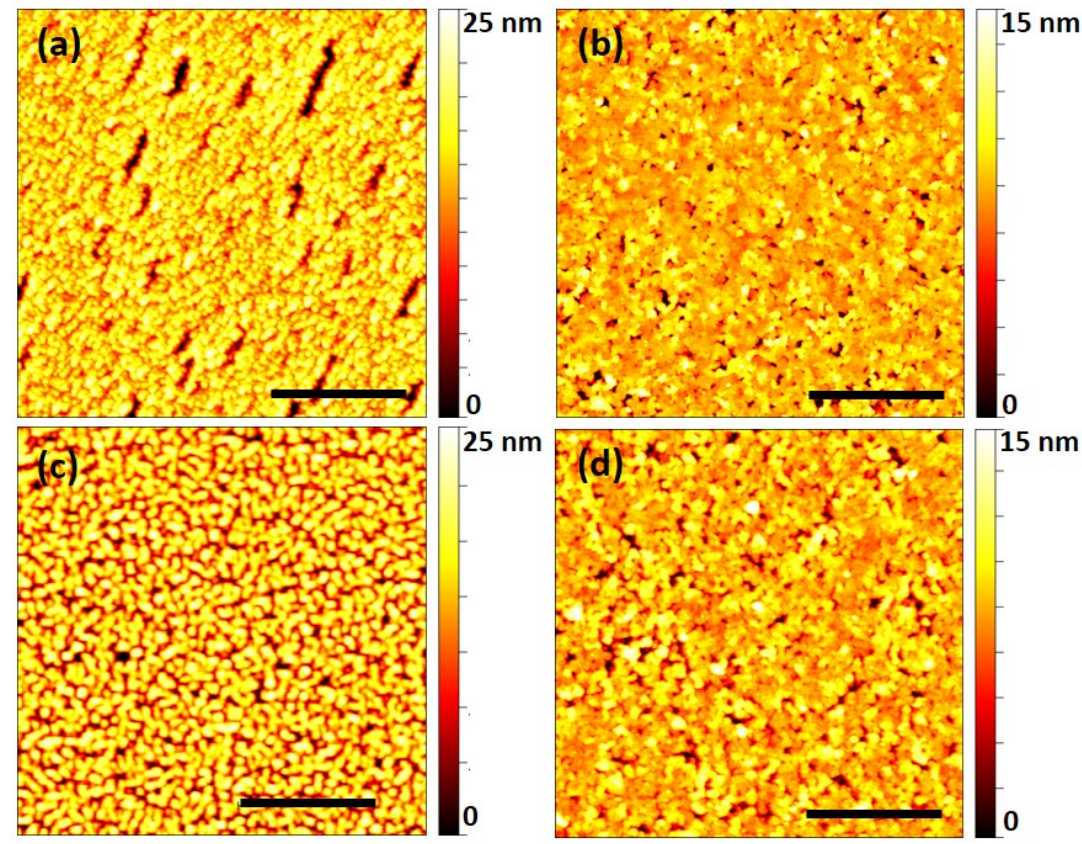

Figure A1. AFM data of $\mathrm{SRO}(011)_{\mathrm{pc}}$ and $\mathrm{SRO}(111)_{\mathrm{pc}}$ films before the epitaxial liftoff and after the transfer on $\mathrm{Si}(001)$ substrates. Panel (a) and (b) show the surface morphology of SRO films in $\mathrm{SRO}(011)_{\mathrm{pc}} / \mathrm{SAO}(011) / \mathrm{STO}(011)$ and SRO(111)pc/SAO(111)/STO(111), respectively. Panel (c) and (d) display the surface morphology of $\mathrm{SRO}(011)_{\mathrm{pc}}$ and $\mathrm{SRO}(111)_{\mathrm{pc}}$ on $\mathrm{Si}(001)$ substrates, respectively. The scale bar is $1 \mu \mathrm{m}$. 

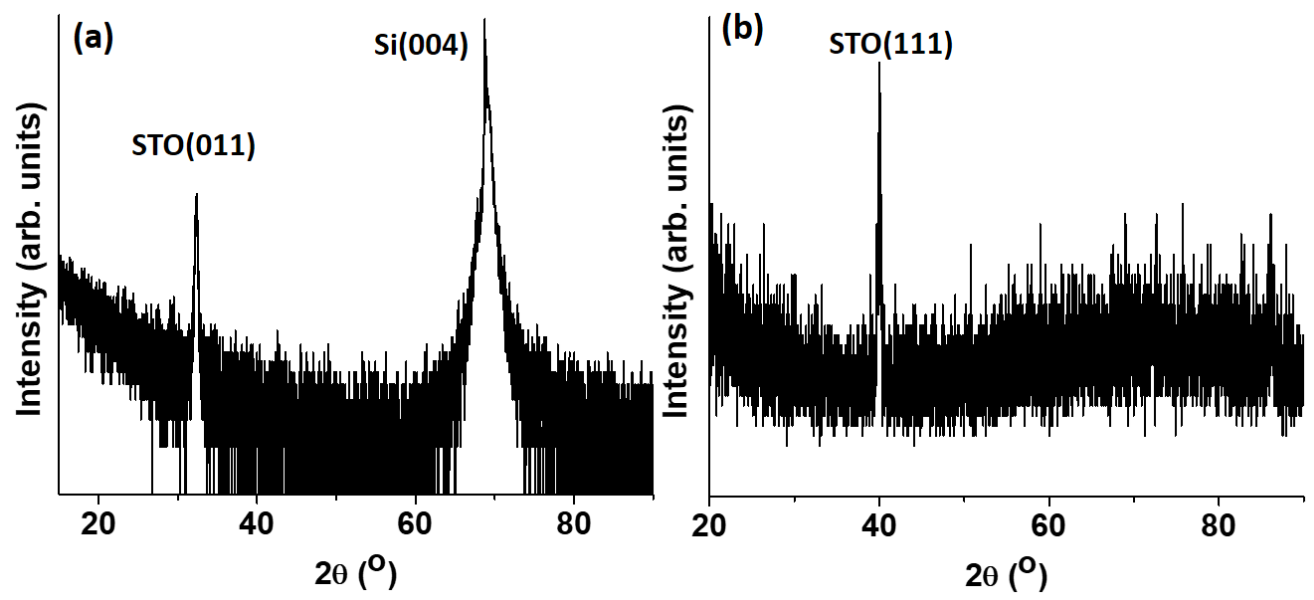

Figure A2. XRD patterns of STO films lifted off from SAO/STO heterostructures, STO(011) on Si(001) (a) and STO(111) on polydimethylsiloxane (PDMS).
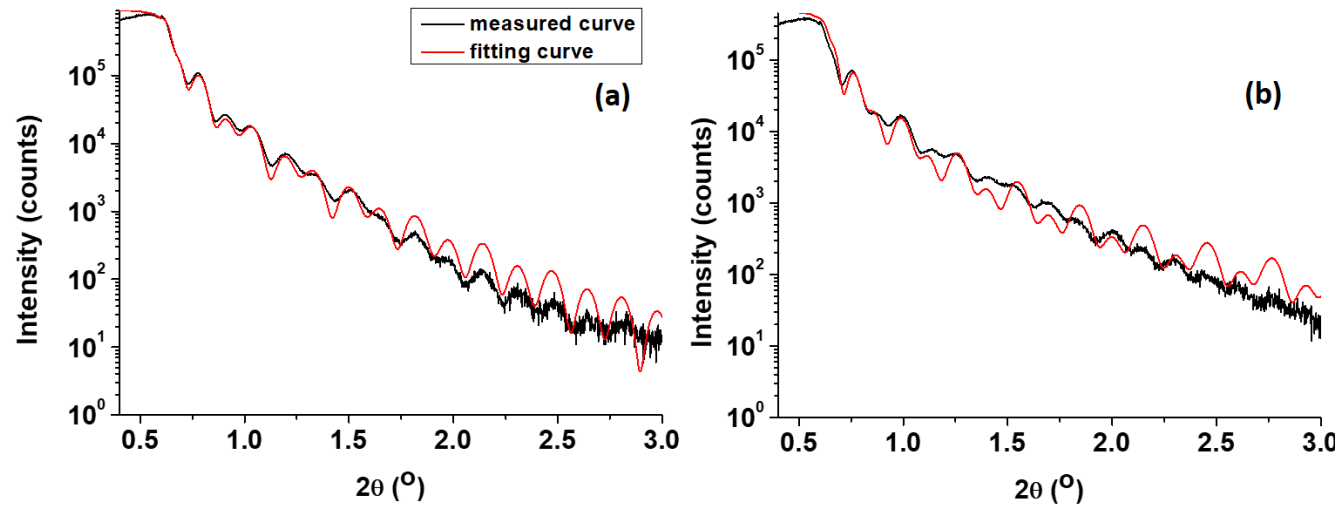

Figure A3. X-ray reflectivity curves and their fitting curve, which were obtained by X'Pert Reflectivity software, of STO(011)/SAO(011)/STO(011) (a) and STO(111)/SAO(111)/STO(111) (b) heterostructures. The thickness was $23.5 \mathrm{~nm}$ for 1250 pulses of SAO(011) and $27.4 \mathrm{~nm}$ for 1450 pulses of SAO(111). The STO thickness was $28 \mathrm{~nm}$ for both samples. 


\section{Chapter 6. Challenges and Opportunities}

While the current research in tailoring oxide thin films on arbitrary substrates has offered opportunities for the advancement of technology, there are still remaining challenges that need to be solved to bring the research's results toward the industrial applications. At the same time, these challenges serve as opportunities for further work in oxide nanosheets and sacrificial layer materials. 
Here, I present experimental ideas for possible future work. In particular, a better understanding of the influence of oxide nanosheets on epitaxial oxide thin films is necessary to improve and engineer their functional properties. To overcome the current limitations regarding to the use of oxide nanosheets and sacrificial layers in the growth of functional oxide thin films, several suggestions are made.

In the current research, three different kinds of oxide nanosheets have been investigated to control the orientation of oxide thin films. They have offered the electron and X-ray based characterizations in transmission mode, local manipulation of orientations, and tunable properties of oxide thin films. It is well-known that strain engineering oxide thin films by bulk single crystal substrates offers the ability to tune existing or obtain new functional properties. ${ }^{[1,2]}$ Meanwhile, individual oxide nanosheets can be regarded as micron-sized single crystal substrates with thicknesses of a few nanometers. Chapter 3 showed that the strain state of $\mathrm{VO}_{2}$ film on $\mathrm{NbWO}_{6}$ nanosheets was similar to that on $\mathrm{T} \mathrm{TiO}_{2}(001)_{\mathrm{R}}$ single crystal substrate. However, there is still an open-ended question whether the epitaxial strain can be induced in $\mathrm{VO}_{2}$ films in particular or any oxide thin film in general by oxide nanosheets or vice-versa. The study of oxide thin films' properties on a single oxide nanosheet and its high-resolution transmission electron microscope (TEM) of the cross-sectioned oxide thin film/oxide nanosheet can shed the light on this topic. The challenge lies in aligning such a single domain with the incoming electron beam.

Although the in-plane orientation among oxide nanosheets was locally enhanced by shape control in chapter 4 , the overall orientation at the millimeter-scale was randomly distributed. Here, I suggest that lithography can make a photoresist mask on a substrate with well-defined sizes and shapes, and the photoresist mask would help to align oxide nanosheets on the substrate. A combination between the shape control of oxide nanosheets 
and the substrate surface treatment possibly facilitates the in-plane alignment among oxide nanosheets at a larger scale toward industrial applications.

Furthermore, the area of the freestanding perovskite oxide thin films released from sacrificial layers on single crystal substrates is often limited below 1 $\mathrm{mm}^{2}$ due to the crack formation during lift-off and transfer processes. Several transfer processes, which were used to obtain large wafer-scale 2D van der Waal materials, ${ }^{[3-5]}$ seem not applicable in the transfer of oxide thin films. A better understanding of lift-off mechanism would promote an effective transfer process preventing the crack formation in freestanding oxide thin films. 


\section{References}

[1] P. Zubko, S. Gariglio, M. Gabay, P. Ghosez, J.-M. Triscone, Annu. Rev. Condens. Matter Phys. 2011, 2, 141.

[2] Z. Huang, Ariando, X. R. Wang, A. Rusydi, J. Chen, H. Yang, T. Venkatesan, Adv. Mater. 2018, 30, 1802439.

[3] X. Li, Y. Zhu, W. Cai, M. Borysiak, B. Han, D. Chen, R. D. Piner, L. Colombo, R. S. Ruoff, Nano Lett. 2009, 9, 4359.

[4] Y. Lee, S. Bae, H. Jang, S. Jang, S.-E. Zhu, S. H. Sim, Y. I. Song, B. H. Hong, J.-H. Ahn, Nano Lett. 2010, 10, 490.

[5] X.-D. Chen, Z.-B. Liu, C.-Y. Zheng, F. Xing, X.-Q. Yan, Y. Chen, J.G. Tian, Carbon 2013, 56, 271. 


\section{Summary}

Realizing high-quality epitaxial transition metal oxide thin films on $\mathrm{Si}$, glass or arbitrary substrates is promising to offer novel features and high performance for devices in electronics, optoelectronics, sensors and so on. In this thesis, the manipulation of transition metal oxide thin film orientations, both out-of-plane and in-plane directions, on arbitrary substrates is studied by two methods: oxide nanosheets and single crystal substrates with a sacrificial layer. Regarding the first approach using oxide nanosheets, they can serve as templates for the thin film growth of transition metal oxides in one preferred out-of-plane orientation, enabling the free choice of substrates for both fundamental studies and practical applications. The reasons are that atomic-flat oxide nanosheets have a wide range of lattice constants and various 2D lattice symmetries, and they are easily deposited on any substrate surfaces through solution-based Langmuir-Blodgett technique. Concerning the second approach using single crystal substrates, the epitaxial lift-off of single crystalline oxide perovskite thin films with different orientations is realized using sacrificial layers deposited on single crystal substrates.

As an example of the first approach, $\mathrm{VO}_{2}$ epitaxy on oxide nanosheets that are deposited on either amorphous $\mathrm{SiO}_{2}$ of $\mathrm{Si}$ substrates or X-ray transparent $\mathrm{Si}_{3} \mathrm{~N}_{4}$ membranes was studied in chapter 2 . Considering lattice symmetry and lattice/domain mismatch, the epitaxial growth of $\mathrm{VO}_{2}$ films was realized in two distinct $(011)_{\mathrm{M} 1} /(110)_{\mathrm{R}}$ and $(-402)_{\mathrm{M} 1} /(002)_{\mathrm{R}}$ orientations on $\mathrm{Ti}_{0.87} \mathrm{O}_{2}$ (TO) and $\mathrm{NbWO}_{6}(\mathrm{NWO})$ nanosheets, respectively. The transport and soft X-ray absorption in transmission mode results showed the high-quality of epitaxial $\mathrm{VO}_{2}$ films on oxide nanosheets, equal to those on bulk single crystal substrates. Furthermore, the micro-level and deterministic control over two 
$\mathrm{VO}_{2}$ film orientations on a single substrate was achieved using $\mathrm{TO}$ and NWO nanosheets in combination with lithography. This study demonstrates the ability to obtain high-quality transition metal oxide films with desirable orientations for specific device applications and fundamental research by oxide nanosheets and free choice of substrates.

Based on the work in chapter 2, the effects of $\mathrm{VO}_{2}$ film thickness and the underlying substrates on the properties of epitaxial $\mathrm{VO}_{2}$ film on $\mathrm{NWO}$ nanosheets were further investigated in chapter 3. Regarding the characteristic parameters of $\mathrm{VO}_{2}$ metal-insulator transition (MIT), the transport measurements showed that the sharpness of MIT, $\Delta \mathrm{T}$, was unchanged and the thermal hysteresis, $\Delta \mathrm{H}$, slightly increased as the film became thicker on NWO nanosheets. Simultaneously, the MIT temperature, $\mathrm{T}_{\mathrm{MIT}}$, of $\mathrm{VO}_{2}$ films decreased as the film thickness was reduced because of the shortening of the $c_{R}$ axis, which was determined by $X$-ray diffraction. The strain effect accompanying the film thickness variation on NWO nanosheets contributed to the shortening of the $c_{R}$ axis. Moreover, the underlying substrates with different thermal expansion coefficients had negligible influence on the MIT behavior of the $\mathrm{VO}_{2}$ film on NWO nanosheets. The study shows that tuning $\mathrm{T}_{\mathrm{MIT}}$ of $\mathrm{VO}_{2}$ on NWO nanosheets is practical for applications regardless of the choice of substrates.

Even though oxide nanosheets can promote the epitaxial growth of the transition metal oxide films in a single out-of-plane orientation, the in-plane orientation of the epitaxial films is totally random. Effort was made to align the in-plane orientation of oxide nanosheets (chapter 4). The synthesis of the parent layered perovskite $\mathrm{KCa}_{2} \mathrm{Nb}_{3} \mathrm{O}_{10}(\mathrm{KCNO})$ in molten $\mathrm{K}_{2} \mathrm{SO}_{4}$ salt resulted in high-quality crystals with square-like platelet shape. The protonation process did not affect the shape of KCNO. Under optimal exfoliation conditions, square-like $\mathrm{Ca}_{2} \mathrm{Nb}_{3} \mathrm{O}_{10}$ (CNO) nanosheets were obtained. The external shape of the square-like $\mathrm{CNO}$ nanosheets enabled the self- 
alignment of the in-plane orientation among nanosheets during LangmuirBlodgett deposition on substrates because their external edges were coincident with the crystal $a$ and $b$ axes. The epitaxial $\mathrm{SrRuO}_{3}(\mathrm{SRO})$ grains on individual square-like CNO nanosheets formed larger domains, in which each domain consisted of many nanosheets instead of one nanosheet. Although full in-plane alignment was not achieved, the improvement of inplane orientation of square-like CNO nanosheets over longer distances led to an enhancement of the electrical properties of SRO film in terms of resistivity and residual resistivity ratio $\rho_{300 k} / \rho_{2 k}$. The study exhibits the ability to improve the in-plane orientation of oxide nanosheets, and hence of transition metal oxide films grown on them by controlling their external shape.

The second approach to obtain high-quality transition metal oxide films is to use sacrificial layers that are epitaxially grown on single crystal substrates. In chapter 5, the ability to obtain freestanding single crystalline oxide perovskite films with (011) and (111) orientations was investigated. Watersoluble epitaxial $\mathrm{Sr}_{3} \mathrm{Al}_{2} \mathrm{O}_{6}$ (SAO) layers were successfully grown on single crystal $\mathrm{SrTiO}_{3}$ (STO) substrates with (011) and (111) orientations. The epitaxial lift-off time of oxide perovskite films from SAO layers in water was dependent on the orientation of SAO. The freestanding single crystalline

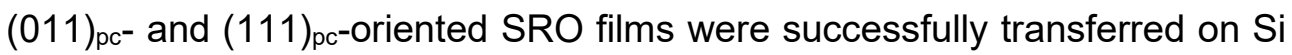
substrates. Single crystalline SRO films before the epitaxial lift-off showed the enhanced magnetism, while the transferred ones on Si exhibited bulklike magnetism because of the difference in the strain state of SRO films. This study opens the opportunities to obtain single crystalline oxide perovskite films with desirable orientation on arbitrary substrates. 



\section{Samenvatting}

De realisatie van hoogwaardige dunne films van epitaxiaal gegroeide overgangsmetaaloxides op silicium, glas of willekeurige andere substraten schept vele mogelijkheden voor nieuwe functies en verbeterde prestaties in elektronica, opto-elektronica, sensoren, e.d. In dit proefschrift worden twee methoden beschreven om controle te kunnen uitoefenen over de kristaloriëntatie van dunne films van overgangsmetaaloxides, zowel in het vlak als loodrecht daarop, op willekeurige substraten. De ene methode maakt gebruik van zgn. oxide 'nanosheets', de andere methode van éénkristallijne substraten in combinatie met een 'sacrificial layer'.

Oxidische nanosheets kunnen worden gebruikt als een sjabloon waarmee de groeirichting van dunne films van overgangsmetaaloxiden in de richting loodrecht op het vlak van het substraat kan worden gecontroleerd. Dit maakt de keuze van het type substraat voor zowel fundamentele studies als voor praktische toepassingen arbitrair. De atomair vlakke oxide nanosheets bezitten een breed scala aan roosterconstanten en 2D-roostersymmetrieën, en kunnen gemakkelijk op elk gewenst substraatoppervlak worden afgezet met behulp van de zgn. Langmuir-Blodgett-techniek.

De tweede benadering, waarin éénkristallijne substraten worden gebruikt, realiseert epitaxiale filmgroei met diverse oriëntaties foor gebruik te maken van sacrificial layers ('opofferingslagen'), die van tevoren op deze éénkristalsubstraten zijn afgezet.

Als voorbeeld van de eerste methode, wordt de groei van epitaxiale $\mathrm{VO}_{2}$ films op nanosheets, die op hun beurt zijn afgezet op amorf $\mathrm{SiO}_{2}$ van $\mathrm{Si}$-substraten en op röntgentransparante $\mathrm{Si}_{3} \mathrm{~N}_{4}$-membranen, beschreven in hoofdstuk 2 . Rekening houdend met de roostersymmetrie en het niet volledig overeenkomende rooster/domein, kan epitaxiale groei van $\mathrm{VO}_{2}$-films in 2 
oriëntaties worden gerealiseerd, $\mathrm{nl}$. de $(011)_{\mathrm{M} 1} /(110)_{\mathrm{R}}$ oriëntatie op $\mathrm{Ti}_{0.87} \mathrm{O}_{2}$ (TO) nanosheets, en de $(-402)_{\mathrm{M} 1} /(002)_{\mathrm{R}}$ oriëntatie op $\mathrm{NbWO}_{6}$ (NWO) nanosheets. Elektrische transportmetingen en de zachte röntgenabsorptie in transmissiemodus hebben aangetoond dat de kwaliteit van deze $\mathrm{VO}_{2}$-films gelijk is aan die op bulk-monokristalsubstraten. Ook is aangetoond dat de $\mathrm{VO}_{2}$ filmoriëntatie lokaal, d.w.z. op microniveau, kan worden gecontroleerd door gebruik te maken van TO en NWO nanosheets in combinatie met lithografie. Deze studie toont aan dat georiënteerde overgangsmetaaloxidefilms van hoge kwaliteit op een willekeurig type substraat kunnen worden gerealiseerd.

Op basis van de resultaten in hoofdstuk 2 is de invloed van $\mathrm{VO}_{2}$ filmdikte en onderliggend substraat op de eigenschappen van epitaxiale $\mathrm{VO}_{2}$ films op NWO nanosheets verder onderzocht in hoofdstuk 3. Naarmate de film op NWO nanosheets dikker werd, bleef de scherpte van de $\mathrm{VO}_{2}$-metaalisolatorovergang (MIT), $\Delta \mathrm{T}$, onveranderd, terwijl de thermische hysterese, $\Delta \mathrm{H}$, licht toenam. Tevens nam de MIT-temperatuur, $\mathrm{T}_{\mathrm{MIT}}$, van $\mathrm{VO}_{2}$ films af naarmate de film dunner werd. Dit is een gevolg van de verkorting van de $C_{R^{-}}$ as, zoals aangetoond met röntgendiffractie. De laterale rek, die afhankelijk is van de filmdikte op NWO nanosheets, draagt ook bij aan verkorting van de $C_{R}$-as. Tevens is vastgesteld dat de onderliggende substraten met zeer verschillende thermische uitzettingscoëfficiënten een verwaarloosbare invloed hebben op het MIT-gedrag van $\mathrm{VO}_{2}$ films op NWO nanosheets. Deze studie toont dus aan dat het afstemmen van $\mathrm{T}_{\mathrm{MIT}}$ van $\mathrm{VO}_{2}$ op $\mathrm{NWO}$ nanosheets in de praktijk mogelijk is, en niet afhangt van de keuze van het onderliggende substraat.

Hoewel oxidische nanosheets de epitaxiale groei van dunne films in één enkele oriëntatie loodrecht op het groeivlak kunnen bevorderen, is de oriëntatie van sheets in het vlak van de epitaxiale films in principe totaal willekeurig. $\mathrm{Er}$ is getracht om een methode te ontwikkelen om oxide 
nanosheets in het vlak ten opzichte van elkaar te oriënteren (hoofdstuk 4). De bouwstenen hiervoor zijn gevormd middels synthese van de gelaagde perovskiet $\mathrm{KCa}_{2} \mathrm{Nb}_{3} \mathrm{O}_{10}$ ( $\mathrm{KCNO}$ ) in gesmolten $\mathrm{K}_{2} \mathrm{SO}_{4}$. Dit resulteerde in hoogwaardige kristallen met een rechthoekige plaatjesvorm. Protonering van deze KCNO kristallen had geen invloed op hun externe vorm. Onder optimale exfoliatie-omstandigheden werden vervolgens vierkante $\mathrm{Ca}_{2} \mathrm{Nb}_{3} \mathrm{O}_{10}$ (CNO) nanosheets gevormd. De uitwendige vorm van deze rechthoekige CNO nanosheets en het feit dat hun buitenranden samenvielen met de kristallografische $a$ en $b$ assen maakte de onderlinge uitlijning van hun oriëntatie tijdens Langmuir-Blodgett-depositie mogelijk. De epitaxiaal gegroeide $\mathrm{SrRuO}_{3}(\mathrm{SRO})$ domeinen op deze geordende CNO-nanosheet films waren groter dan de individuele onderliggende CNO sheets. Hoewel volledige uitlijning in het vlak niet werd bereikt, leidde de verbeterde oriëntatie op een grotere lengteschaal tot een verbetering van de elektrische eigenschappen van de SRO-films in termen van soortelijke weerstand en de weerstandsverhouding $\rho_{300 k} / \rho_{2 k}$. Deze studie toont aldus de mogelijkheid aan om de onderlinge oriëntatie van oxide nanosheets in het vlak van een film te verbeteren door hun externe vorm te controleren.

Een tweede methode om hoogwaardige overgangsmetaaloxidefilms te verkrijgen is door gebruik te maken van sacrificial layers die epitaxiaal op enkelkristalsubstraten waren gegroeid. In hoofdstuk 5 is de mogelijkheid onderzocht om vrijstaande enkelkristallijne oxide perovskietfilms met (011) en (111) oriëntaties te verkrijgen door de sacrificial layers selectief te verwijderen. 



\section{List of publications}

1. Le, P. T. P.; Hofhuis, K.; Rana, A.; Huijben, M.; Hilgenkamp, H.; Rijnders, G. A. J. H. M.; Elshof, J. E. ten; Koster, G.; Gauquelin, N.; Lumbeeck, G.; Schüßler-Langeheine, C.; Popescu, H.; Fortuna, F.; Smit, S.; Verbeek, X. H.; Araizi-Kanoutas, G.; Mishra, S.; Vaskivskyi, I.; Dürr, H. A.; Golden, M. S. Tailoring Vanadium Dioxide Film Orientation Using Nanosheets: A Combined Microscopy, Diffraction, Transport, and Soft X-Ray in Transmission Study. Adv. Funct. Mater. 2020, 30 (1), 1900028. https://doi.org/10.1002/adfm.201900028.

P.T.P.L. and K.H. contributed equally to the work. P.T.P.L. made and deposited oxide nanosheets on substrates under supervision of J.E. tE.. P.T.P.L., K.H. and A.R. synthesized the $\mathrm{VO}_{2}$ samples under supervision of G.K., G.A.J.H.M.R. and H.H.. P.T.P.L. and K.H. performed AFM, XRD and data analysis. N.G. and G.L. performed ACOM-TEM and data analysis. K.H., A.R. and M.H. conducted transport measurements. P.T.P.L. and N.G. analyzed SEM and EBSD data. K.H., C.S-L., H.P., F.F., S.S., X.H.V., G.A-K., S.M., I.V., H.A.D. and M.S.G. performed XAS and data analysis. P.T.P.L., G.K., N.G. and M.S.G. wrote the manuscript and all authors contributed to the discussion and revision of the manuscript.

2 Schlotter, W. F.; Beye, M.; Zohar, S.; Coslovich, G.; Dakovski, G. L.; Lin, M.-F.; Liu, Y.; Reid, A.; Stubbs, S.; Walter, P.; Nakahara, K.; Hart, P.; Miedema, P. S.; LeGuyader, L.; Hofhuis, K.; Le, P. T. P.; Elshof, J. E. ten; Hilgenkamp, H.; Koster, G.; Verbeek, X. H.; Smit, S.; Golden, M. S.; Durr, H. A.; Sakdinawat, A. Balanced Detection in Femtosecond XRay Absorption Spectroscopy to Reach the Ultimate Sensitivity Limit. ArXiv200613968 Phys. 2020. 
3. Timmerman, M. A.; Xia, R.; Le, P. T. P.; Wang, Y.; ten Elshof, J. E. Metal Oxide Nanosheets as 2D Building Blocks for the Design of Novel Materials. Chem. - Eur. J. 2020, 26 (42), 9084-9098. https://doi.org/10.1002/chem.201905735.

4. Le, P. T. P.; ten Elshof, J. E.; Koster, G. Shape Control of Ca2Nb3O10 Nanosheets: Paving the Way for Monolithic Integration of Functional Oxides with CMOS. ACS Appl. Nano Mater. 2020. https://doi.org/10.1021/acsanm.0c02137.

5. Chen, B.; Jovanovic, Z.; Abel, S.; Le, P. T. P.; Halisdemir, U.; Smithers, M.; Diaz-Fernandez, D.; Spreitzer, M.; Fompeyrine, J.; Rijnders, G.; Koster, G. Integration of Single-Oriented Oxide Superlattices on Silicon Using Various Template Techniques. ACS Appl. Mater. Interfaces 2020. https://doi.org/10.1021/acsami.0c10579. 


\section{Acknowledgements}

In the last part of my thesis, I would like to thank all people who encouraged, helped and supported me in the last four years. This thesis would not be done without those people.

First of all, I am most grateful to my supervisors, Gertjan and André, for their guidance. Gertjan and André gave me the opportunity to freely explore my ideas in the lab and guided me back on the right track. Your patience, encouragement and suggestions helped me to address scientific questions throughout my PhD.

Many thanks go to all the members (former and present) of Inorganic materials Science (IMS) group for the help in my research and life. I would like to thank Huiyu, Ben, Thanh, Daniel, Jaap, Dominic, Karin, Mark, Ron, Binbin for the first trainings of tools I used in the lab and helped me whenever I had the technical problems with the tools. I would also like to thank Bernald, Guus, Evert and Mark for giving me advices to perform my experiments. I gratefully acknowledge the technical support of Dominic, Karin, Harry and Laura for their wonderful job. In addition, I am thankful to my officemates (former and present), Jun, Philip, Laura, Shu, Yura and Moritz for nice discussion and chat. I would also like to express my gratitude to all former and present IMSers, Monica, Rebecca, Minh, Pierre, Deepak, Ufuk, Petra, David, Tom, Tjeerd, Wiria, Yorick, Kevin, Sizhao (Fox), Sina, Kit, Shweta, Marijn, Tatiana, Melvin, Yang, Rui, Jie, Nathan, Akarsh, Alan, Noureen, Luc. I especially thank Yorick and Fox (my paranymphs) for organizing many things for my PhD ceremony. I would also like to thank Marion and Jose for all your help with the paper work. In addition, I am thankful to Mark Smithers $(\mathrm{MESA}+)$, Kai (PIN) for measuring my samples and Frank (ICE) for technical support. 
I would also like to express my gratitude to my committee members, Prof. dr. ir. J.W.M. Hilgenkamp, Prof. dr. J.G.E. Gardeniers, Prof. dr. ir. L. Lefferts, Prof. dr. B. Noheda and Prof. dr. A. Hardy for spending time to evaluate this work.

I would like to take this opportunity to thank my master supervisor, Beatriz, for her support, advices and help during my master research.

I am thankful to my collaborators, Dr. Nicolas Gauquelin and his group (Electron Microscopy for Materials Science, EMAT) for taking TEM images, Prof. Mark S. Golden and his group (Quantum Materials Amsterdam group), Christian Schüßler-Langeheine (Helmholtz-Zentrum Berlin für Materialien und Energie), Horia Popescu (Synchrotron SOLEIL), Franck Fortuna (CSNSM), Igor Vaskivskyi (Department of Physics and Astronomy, Uppsala University) for XAS measurements and data analysis. Special thanks go to Kevin Hofhuis, Abhimanyu Rana and Prof. Hans Hilgenkamp (ICE) for sample preparation.

I would also like to thank Jan and Truus Olde Monnikhof, Emmy and Sophia and my neighbor, Hanzel, for their kind supports and help in Oldenzaal,

At the end I would like to thank my family for their endless and unconditional love and my Vietnamese friends and teachers for their supports in my home language.

Đầu tiên, con cảm ơn mẹ đã cho con tất cả, bố và chú Tâm. Cảm ơn vợ, lúc nào cũng ở bên chồng, cũng đã 11 năm rồi. Cảm ơn con trai của ba, Miến, mặc dù chưa biết gì nhiều ngoài làm ba vui và lâu lâu la ó um sùm, và một đứa còn nhỏ xíu $(17 \mathrm{~mm}$ ) chưa ra đời nữa còn trong bụng mẹ trong mùa covid (chưa biết Bún hay Phở nha). Cảm ơn gia đình chị Linh anh Sáu, Vân, Tí và mấy đứa cháu, Trúc chị, Trúc em, Hải, Phúc nữa. Cảm ơn cái bìa sách Trúc em vẽ nha. Cảm ơn ông bà ngoại Miến,dì ba của Miến, anh Hưng, gia 
đình anh Vinh chị Thắm, gia đình anh Hiển chị Oanh, và gia đình anh Long chị Trâm.

Ngoài ra, cảm ơn anh Minh, bị em nhờ cắt $\mathrm{Si}$, glass hoài. Cảm ơn Thành vì nói tám đủ mọi thứ chuyện, và anh Hiển, anh Hải, chị Hòa, chị Lan Anh, anh Đức, anh Nhân.

Hơn nữa, cảm ơn mọi người em/mình đã gặp nhau ở Groningen và đã ăn trực ở đâu đó cùng nhau: gia đình anh Tiến chị Gia, anh Thịnh, anh Thiện, anh Lâm, gia đình anh Bảy chị Mai, gia đình anh Anh Phạm chị Hoa, gia đình anh Tuấn Anh chị Tính, gia đình chị Phương, Tuấn Rô, Hoa, Lân, Mai, Trang, Hằng, Nhật Minh, Hữu Minh, Phương Anh, Yến, chị Nguyệt, chị Thảo. Cảm ơn gia đình chị Hiền anh Jo cùng nhau đi từ Gro đến Twente để có những buổi $B B Q$ và ăn và ăn. Cảm ơn chị Lan, chị Thoa và chị Lam cùng ăn uống trong những chuyến về Việt Nam.

Nhân dịp này, em cũng muốn gửi lời cảm ơn những người cô thầy ở khoa Hóa, trường Đại Học Bách Khoa thành phố Hồ Chí Minh. Đặc biệt,em muốn cảm ơn cô Nguyễn Ngọc Hạnh đã truyền lửa cho em theo đuổi con đường dài của khoa học và giúp đỡ em trong quá trình học tập. Em cảm ơn anh Dũng và anh Trung đã trò chuyện và tiếp lửa cho em, và cảm ơn anh Trung động viên trong khi hai anh em đang ở trời Âu mỗi ngườ ở một nước. Và em cảm ơn thầy Long, cô Tuyết Mai giúp đỡ trong quá trình làm luận án cử nhân. Cuối cùng, cảm ơn những người bạn K08 khoa Hóa, lớp a5 Bùi Thị Xuân.

Phu T. P. Le / Lê Trần Phong Phú September, 2020 Oldenzaal, The Netherlands. 